Caracterização de carga de trabalho para testes de modelos de servidores web

\author{
Luis Henrique Castilho da Silva
}





\title{
Caracterização de carga de trabalho para testes de modelos de servidores web
}

\author{
Luis Henrique Castilho da Silva
}

Profa. Dra. Regina Helena Carlucci Santana

(Orientadora)

Dissertação apresentada ao Instituto de Ciências Matemáticas e de Computação, como parte dos requisitos para a obtenção do título de Mestre em Ciências de Computação e Matemática Computacional.

USP - São Carlos

Setembro de 2006 

Dedico este trabalho aos meus pais, Cida e Marcino, que muito me ensinaram nesta vida, e ao meu melhor amigo, meu irmão Ricardo. 



\section{Agradecimentos}

Agradeço, primeiramente, a Deus, pelas oportunidades na minha vida.

Aos meus pais, Marciano e Maria Aparecida, pela educação, por estarem presentes em todos os momentos difíceis e felizes da minha vida, pela confiança que depositam sempre em mim, pela preocupação, pelo apoio financeiro, enfim, por tudo.

Ao meu irmão Ricardo, pelas conversas, incentivos, suas piadas engraçadas, brigas, críticas e pelos momentos que proporcionaram muitas felicidades.

À professora Regina Santana, pela orientação nesses últimos anos e pelos conhecimentos transmitidos durante o mestrado.

Ao professor Marcos Santana, pelas críticas e opiniões seguras. Também ao Mário Teixeira, cuja proposta deu origem a este trabalho de mestrado.

Ao professor Rodrigo Mello, pelas sugestões, dicas e senhas dos clusters para a execução das simulações. Também aos demais professores do grupo.

Ao Jorge Senger e Marco Aurélio, por disponibilizarem os logs de servidores Web para o estudo.

Às demais pessoas da minha família, principalmente, ao meu primo Rodrigo Elísio.

Ao Júlio Estrella, pela sua simplicidade, suas brincadeiras que agradam o ambiente de trabalho, competência, e pela amizade que adquirimos nesses dois anos de mestrado em São Carlos. Também a Alessandra Barbato, pela sua paciência, pelas conversas que me permitiram compreender o seu trabalho e sua ajuda nas execuções das simulações.

Aos amigos do LaSDPC, Hima, Juliano, Renato (Japa), Caio, Michel, Gustavo, Luciano, Edmilson, Geraldo, Lucas, Fábio, Valter, Augusto, Marcelo e Ottone, pela ajuda e por proporcionarem um ambiente de trabalho alegre.

Ao Maikon Bueno, pelo seu companheirismo, preocupação com o bem estar dos amigos, sua simplicidade e, principalmente, pela amizade que construímos nesses dois últimos anos. Também aos outros grandes amigos do ICMC-USP, Augusto, Guilherme, Jean, Bruno, entre outros.

Aos guardas do ICMC-USP, Robertão, Dornelas e Arli, pelas piadas, conversas, e, principalmente, pela disposição em atender os alunos.

Aos meus amigos de infância, Renato, Fernando, Tiago, e Álvaro, pelos momentos de descontração e pela amizade que conservo até hoje.

A todos, que mesmo indiretamente, contribuíram para a conclusão deste mestrado.

Ao CNPq, pelo apoio financeiro dado a este trabalho. 



\section{Resumo}

A World Wide Web é um meio de comunicação em constante crescimento, agregando diversos componentes e serviços em um ritmo acelerado. Os novos tipos de sites, tais como, o comércio eletrônico (e-commerce), notícia/informação (Web-publishing), vídeo sob demanda exigem ainda mais recursos do servidor. Nesse contexto, visando adequar a avaliação de desempenho aos novos ambientes da Web, o presente trabalho apresenta um estudo caracterizando diversos traces de servidores Web Apache, permitindo coletar dados importantes que definem a forma como os usuários e servidores interagem. Com esses dados, quatro tipos de categorias de sites foram analisados: Padrão (composto da média de todos os traces analisados), Acadêmico, Notícia/Informação e Tradicional. Nessa análise avaliam-se quatro aspectos: o intervalo de chegada, o código de resposta, o tipo objeto e o tamanho do objeto e ao final, modelos matemáticos são propostos para representar essas características. Além disso, este trabalho também desenvolveu um gerador de cargas de trabalho sintéticas, o W4Gen(World Wide Web Workload Generator). Com uma interface gráfica amigável, ele permite aos seus usuários gerar novas cargas com base nos modelos matemáticos. Além disso, ele também permite modificar as características essenciais para simular novos tipos de cargas. Para validar os resultados deste trabalho, utilizou-se o modelo de servidor Web com diferenciação de serviços (SWDS), verificando o desempenho em situações de sobrecarga. 



\section{Abstract}

World Wide Web is a media in constant growth, joining several components and services in an accelerated evolution. The new kinds of sites, such as, E-commerce, Web-publishing and demand video still uses more servers resources. In this context, adapting the new Web environment to performance evaluation, the present work accomplished a characterization study of several Apache Web servers traces, allowing collect important data that define the form as users and servers interact. With these data, four types of sites categories were analyzed: Default (composed of all trace), Academic, Web-publishing and Traditional. In this analysis, it was evaluated four aspects: the arrival time, the status code, the object class and the object size and at the end, mathematical models are proposed to represent those characteristics. Furthermore, a synthetic workload generator was also developed. With a graphical interface, the W4Gen (World Wide Web Workload Generator), as called, allows the users to generate new workloads based on mathematical models. Besides, it also allows to modify the four essential aspects preseted above to simulate new types of workloads. Finally, to validate the results, the Web server model with differentiated services was used, verifying the performance in overload situations. 



\section{Sumário}

Lista de Figuras

Lista de Tabelas

Lista de Abreviaturas e Siglas

$x x i$

1 Introdução 1

1.1 Contextualização . . . . . . . . . . . . . . . . . . . . 1

1.2 Motivação . . . . . . . . . . . . . . . . . . . . 2

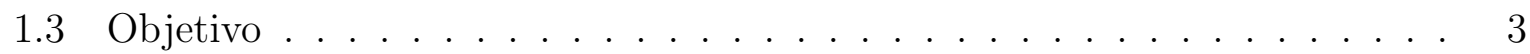

1.4 Estrutura da Dissertação . . . . . . . . . . . . . . . . . . . . . 3

2 Infra-estrutura da Web 5

2.1 Considerações Iniciais . . . . . . . . . . . . . . . . . . . . . 5

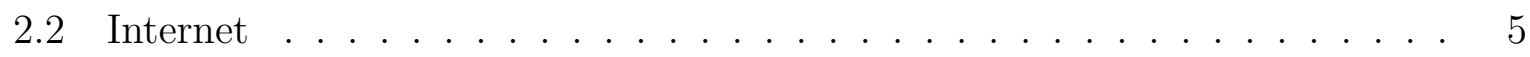

2.2.1 Protocolo TCP/IP . . . . . . . . . . . . . 6

2.2 .2 Arquitetura TCP/IP . . . . . . . . . . . . . . 8

2.3 Protocolo HTTP . . . . . . . . . . . . . . . . . . . . . . . . . . . . . . 12

2.3.1 O Protocolo de Requisição-Resposta . . . . . . . . . . . . . . . . 12

2.3.2 Evolução do HTTP . . . . . . . . . . . . . . . . . . . . . . . . . 14

2.4 Arquitetura de Servidores $W e b \ldots \ldots \ldots \ldots \ldots$

2.4.1 Organização dos Servidores . . . . . . . . . . . . . . . . 16

2.5 Considerações Finais . . . . . . . . . . . . . . . . . . . . 17 
3 Qualidade de Serviço na Internet $\quad 19$

3.1 Considerações Iniciais . . . . . . . . . . . . . . . . . . . . . . . . . . . . . 19

3.2 Qualidade de Serviço . . . . . . . . . . . . . . . . 20

3.2.1 Serviços Integrados . . . . . . . . . . . . . . . . . . . . . 20

3.2.2 Serviços Diferenciados . . . . . . . . . . . . . . . . . 21

3.2.3 Serviços Diferenciados em Nível de Aplicação . . . . . . . . . . . . 21

3.3 Servidor Web com Diferenciação de Serviços . . . . . . . . . . . . . . . 22

3.3.1 Classificação das Requisições . . . . . . . . . . . . . . . . . . . . . 24

3.3.2 Controle de Admissão . . . . . . . . . . . . . . . . . . . . . . 25

3.3.3 Mecanismos de Diferenciação de Serviços . . . . . . . . . . . . . . 26

3.4 Considerações Finais . . . . . . . . . . . . . . . . . . . . 26

4 Caracterização da Carga de Trabalho da Web 29

4.1 Considerações Iniciais . . . . . . . . . . . . . . . . . . . . . . . . . . . . 29

4.2 Trabalhos Relacionados . . . . . . . . . . . . . . . . . . . 30

$4.2 .1 \quad$ A Busca de Invariantes . . . . . . . . . . . . . . . . . 30

4.2.2 Log da Copa do Mundo de $1998 \ldots \ldots$. . . . . . . . . . . . . . . . 32

4.2 .3 Outros Trabalhos . . . . . . . . . . . . . . . . . . . 34

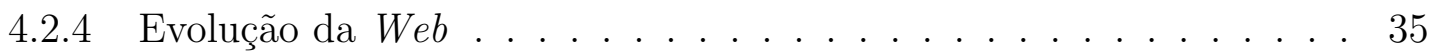

4.3 Coleção de Dados . . . . . . . . . . . . . . . . . . . . . . . . . . . 37

4.3 .1 Formato do $\log$ Apache . . . . . . . . . . . . . . . . . . . . . . . . 37

4.3.2 Informações Gerais dos Logs . . . . . . . . . . . . . . . . . . . . . . 39

4.3 .3 Redução dos Dados . . . . . . . . . . . . . . . . . . . . . . 40

4.4 Caracterização da Carga de Trabalho . . . . . . . . . . . . . . . . . . . . 41

4.4 .1 Características Gerais . . . . . . . . . . . . . . . . . 42

4.4 .2 Código de Resposta . . . . . . . . . . . . . . . . . . . . . . . 44

4.4 .3 Classe de Objeto . . . . . . . . . . . . . . . . . . . 45 
4.4 .4 Intervalo de Chegada . . . . . . . . . . . . . . . . . . . 48

4.4 .5 Tamanho do Objeto . . . . . . . . . . . . . . 53

4.5 Caracterização por Categoria . . . . . . . . . . . . . . 57

4.5.1 Categoria Acadêmico . . . . . . . . . . . . . . . 58

4.5.2 Categoria Notícia/Informativo . . . . . . . . . . . . . . 69

4.5 .3 Categoria Tradicional . . . . . . . . . . . . . . . . . . 79

4.5.4 Comparativo entre as Categorias . . . . . . . . . . . . . 90

4.6 Considerações Finais . . . . . . . . . . . . . . . . . . . . . . . . . 92

5 W4Gen $\quad 95$

5.1 Considerações Iniciais . . . . . . . . . . . . . . . . . . . . . 95

5.2 Trabalhos Relacionados . . . . . . . . . . . . . . . . . . 95

5.3 Sobre o W4Gen . . . . . . . . . . . . . . . . . . . . . . . . . . . . 98

5.3.1 Biblioteca de Modelos Matemáticos . . . . . . . . . . . . . . . . . 98

5.3.2 Características Gerais . . . . . . . . . . . . . . . 99

5.3.3 Modelo de Carga de Trabalho . . . . . . . . . . . . . . . . . . 100

5.4 Modelagem do W4Gen . . . . . . . . . . . . . . . . . 101

5.4 .1 Diagrama de Classe . . . . . . . . . . . . . . . . 102

5.5 Interface Gráfica . . . . . . . . . . . . . . . . . . . . 104

5.5.1 Código de Resposta . . . . . . . . . . . . . . . . . . . 104

5.5.2 Classe de Objeto . . . . . . . . . . . . . . . . 105

5.5 .3 Intervalo de Chegada . . . . . . . . . . . . . . . . 106

5.5.4 Tamanho do Objeto . . . . . . . . . . . 107

5.6 Considerações Finais . . . . . . . . . . . . . . . . . . 107

6 Simulações com a Carga de Trabalho do W4Gen 109

6.1 Considerações Iniciais . . . . . . . . . . . . . . . . . . . . . . 109 
6.2 Características Gerais da Simulação . . . . . . . . . . . . . . . . . . 109

6.2 .1 Simpack . . . . . . . . . . . . . . . . . . 109

6.2.2 Parametrização . . . . . . . . . . . . . . . . . . . . . . . 110

6.3 Avaliação de Desempenho do SWDS . . . . . . . . . . . . . . . . . . 111

6.3.1 Simulação com as Características da Copa de 1998 . . . . . . . . . 111

6.3.2 Simulação com uma Carga Padrão . . . . . . . . . . . . . . . . 113

6.4 Considerações Finais . . . . . . . . . . . . . . . . . . . . 115

$\begin{array}{lll}7 & \text { Conclusão } & 117\end{array}$

7.1 Considerações Finais . . . . . . . . . . . . . . . . . . . . . . . . 117

7.2 Trabalhos Relacionados . . . . . . . . . . . . . . . . . . . . 118

7.3 Contribuições . . . . . . . . . . . . . . . . . . . . . . . . . . 119

7.4 Sugestões para Trabalhos Futuros . . . . . . . . . . . . . . . . 120

Referências

123

Apêndice A - Funções de Distribuição de Probabilidade 


\section{Lista de Figuras}

2.1 Modelo de referência OSI e TCP/IP. . . . . . . . . . . . . 8

2.2 Comunicação lógica da camada de Transporte. . . . . . . . . . . . . . . . . 10

2.3 Funcionamento do protocolo HTTP/1.0. . . . . . . . . . . . . . . . 15

3.1 Modelo de servidor Web com diferenciação de serviços (SWDS). . . . . . . 23

3.2 Modelo do controle de admissão (TEIXEIRA, 2004). . . . . . . . . . . 26

4.1 Modelo matemático para o tamanho dos objetos da Copa do mundo de 1998. 34

4.2 Evolução da carga de trabalho dos servidores $W e b . \quad \ldots . . . . .36$

4.3 Comparação das versões do protocolo HTTP nos últimos anos. . . . . . . . 43

4.4 Modelo de distribuição Geométrico para os códigos de resposta. . . . . . . 45

4.5 Análise das classes de objetos dos traces de servidores Web. . . . . . . . 47

4.6 Intervalo de chegada médio dos objetos Imagem, HTML e Dinâmico. . . 50

4.7 Intervalo de chegada médio dos objetos Texto, Documento e Script Cliente. 51

4.8 Intervalo de chegada médio dos objetos Áudio, Binário e Vídeo. . . . . . . . 52

4.9 Tamanho médio dos objetos Imagem, HTML e Dinâmico. . . . . . . . . . . 54

4.10 Tamanho médio dos objetos Texto, Documento e Script cliente. . . . . . . 55

4.11 Tamanho médio dos objetos Áudio, Binário e Vídeo. . . . . . . . . . . . . . 56

4.12 Análise dos códigos de respostas da categoria Acadêmico. . . . . . . . . . . 59

4.13 Análise das classes de objetos da categoria Acadêmico. . . . . . . . . . . . 60

4.14 Intervalo de chegada dos objetos Imagem, HTML e Dinâmico da categoria Acadêmico. . . . . . . . . . . . . . . . . . . . 62

4.15 Intervalo de chegada dos objetos Texto, Documento e Script Cliente da categoria Acadêmico. . . . . . . . . . . . . . . . . . 63 
4.16 Intervalo de chegada dos objetos Áudio, Binário e Vídeo da categoria Acadêmico. . . . . . . . . . . . . . . . . . . . . 64

4.17 Tamanho dos objetos Imagem, Linguagem de marcação e Dinâmico da categoria Acadêmico. . . . . . . . . . . . . . . . . . . . . . . . . 66

4.18 Tamanho dos objetos Texto, Documento e Script Cliente da categoria Acadêmico.

4.19 Tamanho dos objetos Áudio, Binário e Vídeo da categoria Acadêmico. . . . 68

4.20 Análise dos códigos de respostas da categoria Notícia/Informativo. . . . . . 70

4.21 Análise das classes de objetos da categoria Notícia/Informativo. . . . . . . 71

4.22 Intervalo de chegada dos objetos Imagem, Linguagem de marcação e Dinâmico da categoria Notícia/Informativo. . . . . . . . . . . . . . . . . . . . 72

4.23 Intervalo de chegada dos objetos Texto, Documento e Script cliente da categoria Notícia/Informativo. . . . . . . . . . . . . . . . . 73

4.24 Intervalo de chegada dos objetos Áudio, Binário e Vídeo da categoria Notícia/Informativo. . . . . . . . . . . . . . . . . . . . . 74

4.25 Tamanho dos objetos Imagem, Linguagem de marcação e Dinâmico da categoria Notícia/Informativo. . . . . . . . . . . . . . . . . . . 76

4.26 Tamanho dos objetos Texto, Documento e Script cliente da categoria Notícia/Informativo. . . . . . . . . . . . . . . . . . . . . . . 77

4.27 Tamanho dos objetos Áudio, Binário e Vídeo da categoria Notícia/Informativo. . . . . . . . . . . . . . . . . . . . . 78

4.28 Análise dos códigos de respostas da categoria Tradicional. . . . . . . . . . . 80

4.29 Análise das classes de objetos da categoria Tradicional. . . . . . . . . . . . 81

4.30 Intervalo de chegada dos objetos Imagem, Linguagem de marcação e Dinâmico da categoria Tradicional. . . . . . . . . . . . . . . . . . . . . 83

4.31 Intervalo de chegada dos objetos Texto, Documento e Script cliente da categoria Tradicional. . . . . . . . . . . . . . . . . . . . . . . . . 84

4.32 Intervalo de chegada dos objetos Áudio, Binário e Vídeo da categoria Tradicional. . . . . . . . . . . . . . . . . . . . . 85 
4.33 Tamanho dos objetos Imagem, Linguagem de marcação e Dinâmico da categoria Tradicional. . . . . . . . . . . . . . . . . . . . . . 87

4.34 Tamanho dos objetos Texto, Documento e Script cliente da categoria Tradicional. . . . . . . . . . . . . . . . . . . . 88

4.35 Tamanho dos objetos Áudio, Binário e Vídeo da categoria Tradicional. 89

4.36 Evolução da carga de trabalho com base nos resultados atuais. . . . . . . . 94

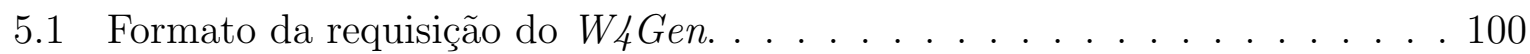

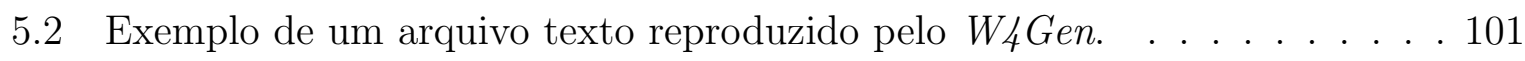

5.3 Diagrama de classe do pacote componente. . . . . . . . . . . . . . . 103

5.4 Diagrama de classe do pacote layoutsistema. . . . . . . . . . . . . 103

5.5 Diagrama de classe do pacote distribuicoes. . . . . . . . . . . . . . . . 104

5.6 Interface do W4Gen para manipular o código de resposta. . . . . . . . . . 105

5.7 Interface do W4Gen para manipular o objetos. . . . . . . . . . 106

5.8 Interface do W4Gen para manipular o intervalo de chegada. . . . . . . . 106

5.9 Interface do W4Gen para manipular o tamanho dos objetos. . . . . . . . . 107 


\section{Lista de Tabelas}

2.1 Métodos implementados no protocolo HTTP/1.1. . . . . . . . . . . . . 13

2.2 Classe de código de resposta do protocolo HTTP. . . . . . . . . . . . . . . 14

4.1 Invariantes da carga de trabalho da Web (ARLITT; WILLIAMSON, 1996). . . 31

4.2 Resumo dos códigos de respostas da Copa de 1998 (ARLITT; JIN, 1999). . . 33

4.3 Resumo dos objetos da Copa de 1998 (ARLITT; JIN, 1999). . . . . . . . . . 33

4.4 Resumo dos objetos do trace de e-commerce (WANG et al., 2003). . . . . . . 35

4.5 Resumo das informações dos logs antes do pré-processamento. . . . . . . . 39

4.6 Resumo da classificação dos traces. . . . . . . . . . . . . . . . . . . . 40

4.7 Resumo das informações dos logs após o pré-processamento. . . . . . . . . 41

4.8 Resumo das versões do protocolo HTTP. . . . . . . . . . . . . . . . . . . . 42

4.9 Resumo dos métodos mais utilizado pelo protocolo HTTP. . . . . . . . . . 44

4.10 Resumo dos códigos de respostas do protocolo HTTP. . . . . . . . . . . . . 44

4.11 Classificação das extensões de arquivos. . . . . . . . . . . . . . . . . . 46

4.12 Modelos matemáticos para simular os intervalos de chegada. . . . . . . . . 53

4.13 Modelos Matemáticos para simular o tamanho dos objetos. . . . . . . . . 58

4.14 Modelos matemáticos para o intervalo de chegada da categoria Acadêmico. 65

4.15 Modelos matemáticos para o tamanho dos objetos da categoria Acadêmico. 69

4.16 Modelos matemáticos para o intervalo de chegada da categoria Notícia/Informativo. . . . . . . . . . . . . . . . . . . . 75

4.17 Modelos matemáticos para o tamanho dos objetos da categoria Notícia/Informativo. . . . . . . . . . . . . . . . . . 79

4.18 Modelos matemáticos para o intervalo de chegada da categoria Tradicional. 86 
4.19 Modelos matemáticos para o tamanho dos objetos da categoria Tradicional. 90

4.20 As invariantes das categorias de Web sites. . . . . . . . . . . . . . . 92

5.1 O domínio de valores para os campos da requisição. . . . . . . . . . . . . . 101

6.1 Parâmetros do modelo SWDS (TEIXEIRA, 2004) . . . . . . . . . . . . 110

6.2 Configurações gerais do modelo SWDS. . . . . . . . . . . . . . . . 111

6.3 Informações sobre a carga de trabalho representativa do log da Copa. . . . 112

6.4 Estatísticas da simulação usando a carga do W4Gen. . . . . . . . . . . . 113

6.5 Estatísticas da simulação usando o log da Copa de 1998. . . . . . . . . . . 113

6.6 Informações gerais sobre a carga de trabalho Padrão 01. . . . . . . . . . . . . 114

6.7 Informações gerais sobre a carga de trabalho Padrão 02 . . . . . . . . . . . . 114

6.8 Estatísticas da simulação usando uma carga Padrão 1. . . . . . . . . . . . . 114

6.9 Estatísticas da simulação usando a carga Padrão 2 . . . . . . . . . . . . 115

A.1 Definições das funções de distribuição de probabilidade. . . . . . . . . . . . 129

A.2 Definições das funções densidade de probabilidade. . . . . . . . . . . . . . 130 


\title{
Lista de Abreviaturas e Siglas
}

\author{
API Application Programming Interface \\ ASP Active Server Pages \\ ARP Address Resolution Protocol \\ CDN Content Delivery Network \\ CISC Centro de informática de São Carlos \\ CPU Central Processing Unit \\ DoD Department of Defense \\ DNS Domain Name Service \\ DSCP Differentiated Services Codepoint \\ FTP File Transfer Protocol \\ FCFS First-come first-served \\ HTML HyperText Markput Language \\ HTTP HyperText Transfer Protocol \\ IETF Internet Engineering Task Force \\ ICMP Internet Control Message Protocol \\ IIS Internet Information Service \\ IP Internet Protocol \\ JSP Java Server Pages \\ LAN Local Area Network \\ LaSDPC Laboratório de Sistemas Distribuídos e Programação Concorrente \\ MAC Media Access Control \\ OSI Open Systems Interconnection \\ PDU Protocol Data Unit \\ PRIAdap Mecanismo de Prioridade Adaptativo \\ PSOL Probability/Statistics Object Library \\ PHP HiperText Proprocessor \\ QoS Quality of Service \\ RARP Reverse Address Resolution Protocol \\ RFC Request for Comments
}


RR Round Robin

RSV Mecanismo de Reserva de Recursos

RSVAdap Mecanismo de Reserva Adaptativa de Recursos

RSVP Resource Reservation Protocol

SMTP Simple Mail Transfer Protocol

SQF Shortest Queue First

SURGE Scalable URL Reference Generator

SWDS Servidor Web com Diferenciação de Serviços

TCP Transmission Control Protocol

TCP/IP Trasmission Control Protocol/Internet Protocol

UDP User Datagram Protocol

UML Unified Modeling Language

URL Universal Resource Locator

W3C World Wide Web Consortium

W4Gen World Wide Web Workload Generator

WAN Wide Area Network

WWW World Wide Web 


\section{Introdução}

\subsection{Contextualização}

A informática, no último século, evoluiu em proporções muito superiores a outros setores da indústria. Nesse domínio destaca-se a Internet, cujo crescimento superou até mesmo as expectativas dos seus próprios idealizadores. Projetada para conectar os principais sistemas de computadores de algumas universidades e organizações de pesquisas (TANENBAUM, 2002), a Internet era usada, basicamente, por professores e estudantes universitários. Com a criação da World Wide Web, os usuários puderam criar, localizar e visualizar documentos em hipertexto sobre uma diversidade de assuntos. Toda essa facilidade popularizou a Internet e, na década de 90, a $W e b$ tornou-se o serviço mais utilizado em toda a rede mundial de computadores.

Atualmente, a quantidade de informações da Internet supera sua disponibilidade de transferência, degradando o tempo de resposta para o usuário final. Adicionar mais recursos na rede que possibilite aumentar a troca de dados é uma solução parcial. Entretanto, ela não oferece uma garantia para o problema, já que o número de usuários e o volume de dados crescem rapidamente com o tempo, provocando aumento do tráfego (KUROSE; ROSS, 2006). Com isso é necessário introduzir novas idéias capazes de solucionar as exigências dos novos tipos de aplicações.

A fim de resolver tais dificuldades, tendo em vista que nem todo o tipo de tráfego possui a mesma prioridade (DOVROLIS; RAMANATHAN, 1999), o conceito de qualidade de serviço (QoS - Quality of Service) foi proposto. Aquele tratamento rudimentar, que se baseia no primeiro a chegar e, assim, no primeiro a ser atendido, foi substituído pelo modelo de diferenciações de serviços, com diferentes níveis de qualidade (CHEN; MOHAPATRA, 2002), destaque para os serviços integrados e diferenciados.

A qualidade de serviço prestado na Internet, entretanto, está longe do ideal. O que existe atualmente é $Q o S$ na camada de rede, segundo o modelo OSI (Open Systems 
Interconnection), na qual as informações são diferenciadas em classes até o instante em que ela chega ao servidor Web. A partir desse ponto, todos os pedidos são tratados de maneira igualitária, segundo a política de atendimento FCFS (First-come first-served).

A Web é um sistema em expansão, que incorpora novos componentes e serviços em um ritmo acelerado. Aplicações mais recentes, tais como, o comércio eletrônico e vídeos sob demanda aumentam ainda mais a rede. Esse crescimento tem proporcionado um número cada vez maior de solicitações, elevando o tempo de resposta para uma requisição. Assim, é importante que esse tempo esteja em um nível aceitável, caso contrário, os usuários não utilizarão mais o serviço. Dessa forma, alguns trabalhos da literatura, tais como, (CHEN; MOHAPATRA, 2002; ANDREOLINI et al., 2004; TEIXEIRA, 2004) acrescentam, de alguma forma, diferenciação de serviço à camada de aplicação, obtendo qualidade de serviço em todas as etapas, desde a origem no cliente, até seu tratamento no servidor.

\subsection{Motivação}

Empresas privadas, agências de governo, instituições de pesquisa, enfim, milhões de pessoas dependem cada vez mais da Web. À medida que a demanda por serviços aumenta, a infra-estrutura dos servidores deve ser capaz de suportar essa mudança. Como conseqüência, determinar as características da carga de trabalho é um passo importante para diversos trabalhos, tais como, o projeto de novos modelos de servidores Web e de mecanismos de diferenciação, já que a carga de trabalho está relacionada diretamente ao desempenho do sistema.

Baseado nessa complexidade de caracterizar a carga de trabalho da Web, Teixeira (2004) validou seus experimentos por meio de simulações, utilizando como entrada, traces de servidores Web da copa do mundo de 1998 (ARLITT; JIN, 2000). Cargas de trabalho mais recentes com diferentes aspectos, como o tamanho dos objetos do tipo imagem, além de outros ambientes comuns da Web, tais como, servidores de Web-publishing ${ }^{1}$, com elevada quantidade de requisições dinâmicas, e Acadêmicos, com transferência frequente de documentos, não pôde ser avaliada, tornando-se um estudo paralelo a ser verificado no futuro. O desenvolvimento de abordagens que permitam superar a dificuldade de mensurar o desempenho de modelos de servidores $W e b$, principalmente, no que diz respeito a obtenção de cargas de trabalho adequadas para testar servidores Web sob diferentes aspectos, é a principal motivação para esse trabalho.

\footnotetext{
${ }^{1}$ Também conhecidos como servidores de notícia.
} 


\subsection{Objetivo}

Os objetivos do presente trabalho é caracterizar e desenvolver um gerador de cargas de trabalho sintéticas, que possa ser utilizado como entrada para diversos outros trabalhos para avaliação de desempenho. Com o gerador será possível reproduzir cargas de diferentes ambientes, tais como, sites de Web-publishing com elevado número de requisições dinâmicas ou, modificar as características essenciais, como o intervalo de chegada das requisições e o tamanho dos objetos, a fim de reproduzir um novo tipo de carga de trabalho. Para alcançar essas expectativas, o presente trabalho propõe abordar os seguintes pontos:

- Caracterização da carga de trabalho de diversos servidores Web por meio da análise de logs de servidores reais.

- Desenvolvimento de um protótipo capaz de gerar cargas de trabalho sintéticas para modelos de servidores $W e b$, com base nos dados coletados a partir da caracterização da carga de trabalho. Esse protótipo permite o usuário modificar suas características, modelando os diversos tipos de ambientes.

- Validação do gerador por meio de avaliações de desempenho utilizando o modelo de servidor SWDS (Servidor Web com Diferenciação de Serviços), proposto em Teixeira (2004), e de mecanismos de diferenciação, propostos em Barbato et al. (2005) para o atendimento de requisições, comparando os resultados obtidos com as avaliações usando traces reais, como da copa do mundo de 1998.

\subsection{Estrutura da Dissertação}

Essa dissertação está dividida em 7 capítulos. Nesse capítulo foi introduzido o tema do trabalho desenvolvido, discutindo a motivação e os principais objetivos alcançados durante o mestrado.

No capítulo 2 será abordada a estrutura da Internet, destacando a pilha de protocolo TCP/IP (Transmission Control Protocol/Internet Protocol) e a forma como os servidores Web são estruturados.

No capítulo 3 será apresentado o conceito de qualidade de serviço e suas ramificações, com destaque para o modelo SWDS, proposto por Teixeira (2004). Além disso, discutemse os mecanismos de diferenciação de serviços implementados no modelo de SWDS. 
No capítulo 4 será apresentado, inicialmente, uma revisão bibliográfica sobre diversos estudos relacionados a cargas de trabalhos de servidores Web. Além disso, neste capítulo será discutido os resultados da caracterização da carga de trabalho de nove traces de servidores $W e b$, coletado por meio de logs de servidores Apache. Quatro características são avaliadas: código de resposta, classe de objeto, intervalo de chegada e tamanho dos objetos. Ao final de cada item, modelos matemáticos são propostos para simular o ambiente da $W e b$.

No capítulo 5 será abordado uma revisão bibliográfica de algumas implementações de benchmarkings para servidores Web. Neste capítulo também será apresentado o W4Gen (World Wide Web Workload Generator), uma ferramenta desenvolvida para gerar cargas de trabalho sintéticas, para avaliação de modelos de servidores Web e, como modificar a implementação para incluir novas características à carga de trabalho.

No capítulo 6 será discutido a avaliação de desempenho do modelo de servidor Web com diferenciação de serviços, comparando os resultados obtidos com a avaliação de traces, como o da copa do mundo de 1998 e os modelos de carga de trabalho reproduzido pelo W4Gen.

Por fim, no capítulo 7 será apresentado as conclusões finais dessa dissertação, destacando as contribuições e propostas para trabalhos futuros. 


\section{Infra-estrutura da Web}

\subsection{Considerações Iniciais}

A Internet é a rede mundial de computadores, composta de diversas redes menores e distintas que se comunicam e cooperam entre si (MEIRA et al., 2002). Ela consiste em um grande número de redes interconectadas, incluindo redes de pequeno, médio e grande porte.

Devido à sua grande popularidade, estar conectado a Internet é essencial para o comércio, indústria e educação. Atualmente, ela é acessível por milhões de computadores no mundo, com uma variedade de tecnologias, protocolos e computadores que, em conjunto, resultam em uma rede altamente heterogênea (TANENBAUM, 2002).

Desenvolvida para oferecer uma rede de comunicação que pudesse continuar funcionando mesmo em tempos de guerra, ela evoluiu de maneira bem diferente daquela imaginada por seus idealizadores. Baseada na arquitetura de protocolos TCP/IP, o projeto da Internet é ideal para uma rede descentralizada e robusta.

Neste capítulo será discutida a infra-estrutura da Internet, destacando o principal serviço oferecido, a World Wide Web, que é o maior responsável pelo seu desenvolvimento. Neste capítulo também será apresentada a pilha de protocolo TCP/IP, utilizado como padrão na Internet e em quase todas as Intranets. Ao final, aborda-se o paradigma clienteservidor, o protocolo HTTP (Hypertext Transfer Protocol) e, no nível mais abstrato, a arquitetura de implementação dos servidores Web. A próxima seção inicia o texto com uma breve história sobre o surgimento da Internet e a sua evolução nas últimas décadas.

\section{$2.2 \quad$ Internet}

Na década de 60, no auge da guerra fria, a tradicional rede de telefonia era considerada vulnerável. A perda de uma linha encerraria a conversa entre militares localizados em 
diferentes pontos da Terra. A procura por um meio de comunicação confiável, capaz de suportar até mesmo ataques de bombas nucleares, proporcionou pesquisas nos EUA originando a ARPAnet. Ao final dos anos 70, com o desenvolvimento de novas pesquisas e o uso nas universidades, aproximadamente 200 mil novas máquinas foram agregadas a ela (KUROSE; ROSS, 2006). Essa explosão transformou o projeto da ARPANet na Internet.

Financiada pelo departamento de defesa dos Estados Unidos (Department of Defense), a Internet, até a década de 90, era usada basicamente por pesquisadores, acadêmicos e estudantes universitários. Essas pessoas utilizavam a rede para comunicar-se com localidades diferentes: cidades, estados e países. Transferir arquivos locais para computadores remotos, trocar notícias e utilizar o correio eletrônico era algumas das aplicações operando sobre a Internet. Embora os serviços fossem muito úteis, ela não era conhecida fora do ambiente acadêmico.

O surgimento da WWW (World Wide Web), conhecida somente por Web, permitiu aos usuários localizar e visualizar documentos baseados em hipertexto sobre uma diversidade de assuntos. A $W e b$ foi a principal responsável pela expansão do uso da Internet e, para grande parte de seus usuários, se confunde com a própria Internet. A cada ano, novas pessoas e serviços são agregados a essa extensa rede e não há sinais dessa tendência se reverter num futuro próximo. Um exemplo disso é a utilização da Internet para redes de telefonia, rádio e televisão, entre outras (MAHONEN et al., 2004).

A WWW, desde a sua expansão na década de 90, tornou-se rapidamente o serviço mais utilizado em toda a rede mundial de computadores. Em 1992, o tráfego da Web era quase inexistente, com uma vazão de dados de apenas 74 Mbytes por mês (ARLITT; WILLIAMSON, 1996). Por volta de 1995, a Web foi responsável pela maior parte do tráfego, superando a todos os outros serviços disponíveis (COMER, 2000). No primeiro semestre de 1996, aproximadamente 40 mil novas redes foram conectadas a Internet (KUROSE; ROSS, 2006), provocando um crescimento acima do normal. Algumas das razões dessa explosão incluem: a facilidade de uso da $W e b$; a disponibilidade de uma interface gráfica amigável e simples; a disseminação de informações sobre diversos assuntos; e o uso de protocolos padronizados como o TCP/IP. Na próxima seção será apresentado o padrão de comunicação da Internet.

\subsubsection{Protocolo TCP/IP}

O TCP/IP é um conjunto de protocolos ou regras desenvolvidas para a troca de informações entre computadores, que compartilham recursos por meio da rede (TANEN- 
BAUM, 2002). Devido à simplicidade, os protocolos que compõem o TCP/IP se tornaram um padrão para a interligação, tanto para redes locais (LANs - Local Area Network) quanto para redes de longas distâncias (WANs - Wide Area Network).

Com o crescimento desordenado da Internet, inúmeras tecnologias foram incorporadas ao longo do tempo. Os protocolos TCP/IP se destacam por funcionar sobre uma grande variedade de arquiteturas e tecnologias de comunicação, desde as redes por difusão até as redes de passagem de tokens. Esse agrupamento de tecnologias fornece ao TCP/IP um potencial de comunicação capaz de transferir dados entre diversos computadores. Além disso, ele permite programar aplicações com um elevado grau de abstração em relação à forma como realmente a comunicação ocorre. Isto pode ser observado por meio das API (Application Programming Interface) de sockets, que facilitam a programação e aumentam a portabilidade das aplicações (STEVENS, 1997).

Algumas das principais características do TCP/IP que o diferencia dos demais protocolos são (COMER, 2000; HUNT, 2002):

- Uso de padrões abertos. O protocolo TCP/IP está disponível livremente na Internet por meio das $\mathrm{RFCs}^{1}$ (Request for Comments), promulgadas pelo IETF (Internet Engineering Task Force).

- Independência da tecnologia de rede. O TCP/IP se comunica por meio da comutação de pacotes entre as partes e não está ligado a nenhuma tecnologia específica, tanto de Hardware como de Software. Por isso, o TCP/IP opera sobre uma variedade de protocolos da camada física e de enlace de dados.

- Protocolos padronizados. Os protocolos da pilha TCP/IP estão padronizados em todos os níveis. Tais padrões facilitam a criação de novas aplicações e atualizações envolvendo a rede. É importante salientar que modificações em um nível não afetam outros níveis.

- Interconexão total. Todo host recebe um endereço único permitindo o acesso de qualquer parte da rede, além de definir sua identificação.

- Confirmações fim-a fim. O TCP/IP possui um mecanismo de reconhecimento permitindo a origem identificar se uma mensagem foi corretamente recebida. Tais reconhecimentos ocorrem entre a origem e o destino final das mensagens e não somente entre pares ao longo da rede.

\footnotetext{
${ }^{1}$ Um conjunto de documentos técnicos e notas que discutem muitos aspectos das redes de computadores, incluindo protocolos, procedimentos, programas, conceitos, opiniões, entre outros.
} 


\subsubsection{Arquitetura TCP/IP}

A Internet é um sistema complexo com componentes e aplicações, além de vários tipos de meios físicos e de enlace de dados. Para organizar essa infra-estrutura é preciso uma arquitetura de camadas, permitindo discutir parcelas de um grande sistema. Responsável por funções bem específicas, a comunicação ocorre por meio de fluxos virtuais entre camadas do mesmo nível em diferentes máquinas. Além de facilitar o ensino-aprendizagem, cada nível é responsável por funções bem determinadas, simplificando sua implementação e modificação.

Para transportar os pacotes de dados da origem para o destino, cada camada na origem deve comunicar-se com sua camada par no destino. Durante esse processo, os protocolos de cada camada trocam informações, denominadas unidades de dados de protocolo (PDU - Protocol Data Unit).

O modelo de referência OSI (Open Systems Interconnection), apresentado na figura 2.1, possui sete camadas e cada uma tem uma função particular na rede. Já a arquitetura TCP/IP, também apresentada na figura 2.1, possui quatro camadas: Aplicação, Transporte, Internet e Acesso à rede (TANENBAUM, 2002). Algumas das camadas do TCP/IP têm o mesmo nome no modelo OSI. É essencial não confundir as funções em ambos modelos, pois elas contêm diferentes papéis na comunicação. Para compreender melhor a Internet, discute-se a seguir cada uma das camadas do TCP/IP.

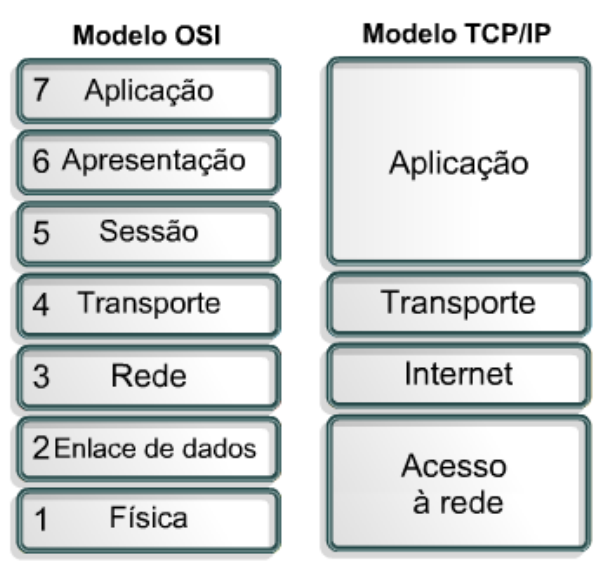

Figura 2.1: Modelo de referência OSI e TCP/IP.

\section{Camada de Aplicação}

A camada de aplicação do modelo TCP/IP trata dos protocolos de alto nível, questões de representação dos dados, codificação e controle de diálogos (KUROSE; ROSS, 2006). O 
conjunto de protocolos TCP/IP combina todas as questões relacionadas às aplicações em uma única camada. Ele garante que esses dados sejam empacotados corretamente antes de passá-los adiante para a camada de Transporte.

Um protocolo da camada de Aplicação define como os processos de uma aplicação trocam mensagens entre si. Exemplos incluem: transferência de arquivos (FTP - File Transfer Protocol), correio eletrônico (SMTP - Simple Mail Transfer Protocol), login remoto (TELNET), resolução de nomes (DNS - Domain Name Service), entre diversos outros.

Dentre os inúmeros serviços que operam na Internet, a World Wide Web é a principal aplicação e o foco deste trabalho, com destaque para o protocolo HTTP, responsável pela troca de mensagens entre clientes e servidores.

\section{Camada de Transporte}

Localizada entre a camada de Aplicação e de Internet, a camada de Transporte é uma peça central da arquitetura de redes. Os protocolos oferecem serviços de transporte, desde o host de origem até o destino, formando uma conexão lógica entre o emissor e o receptor (conexão fim-a-fim).

Responsáveis por segmentar e remontar os dados das aplicações enviados dentro do mesmo fluxo, os protocolos da camada de transporte enviam segmentos por meio de uma nuvem composta de roteadores e de diversos tipos de enlace de dados (TANENBAUM, 2002), conforme ilustra a figura 2.2. Para tratar da troca de informações, os dois protocolos conhecidos dessa camada são o TCP (Transmission Control Protocol) e o UDP (User Datagram Protocol).

O protocolo TCP, descrito na RFC 793 (POSTEL, 1981c) fornece um circuito virtual entre aplicações do usuário final ou, mais precisamente, entre dois processos executando em hosts conectados por meio de uma rede. Antes de qualquer transmissão de dados, uma conexão lógica entre os hosts deve ser estabelecida, trocando mensagens de controle, conhecida como three-way handshake (COMER, 2000). As características desse protocolo incluem (COMER, 2000): orientado a conexão; confiável; divisão das mensagens em segmentos menores e remontagem no destino; reenvio de todas as mensagens não recebidas; reagrupamento das mensagens a partir de segmentos recebidos; e sobrecarga no cabeçalho do segmento.

Já o UDP, descrito na RFC 768 (POSTEL, 1980) é um protocolo simples de troca de 
datagramas. A comunicação ocorre sem nenhuma confiabilidade e o processamento de erros e as retransmissões devem ser tratadas por outros protocolos da camada superior (Aplicação). O UDP pode iniciar sua transmissão tão logo seja necessário, eliminando a sobrecarga inicial no estabelecimento da conexão. Com isso, o UDP é aconselhável para aplicações na qual a velocidade é um ponto crítico e também em situações em que pequenas perdas de datagramas durante a transmissão são aceitáveis como, por exemplo, as aplicações de áudio e vídeo (COMER, 2000). As principais características do UDP são (COMER, 2000): sem conexão; não confiável; não reagrupa as mensagens de entrada; não utiliza confirmações; não fornece controle de fluxo; e pouca sobrecarga no cabeçalho do segmento.

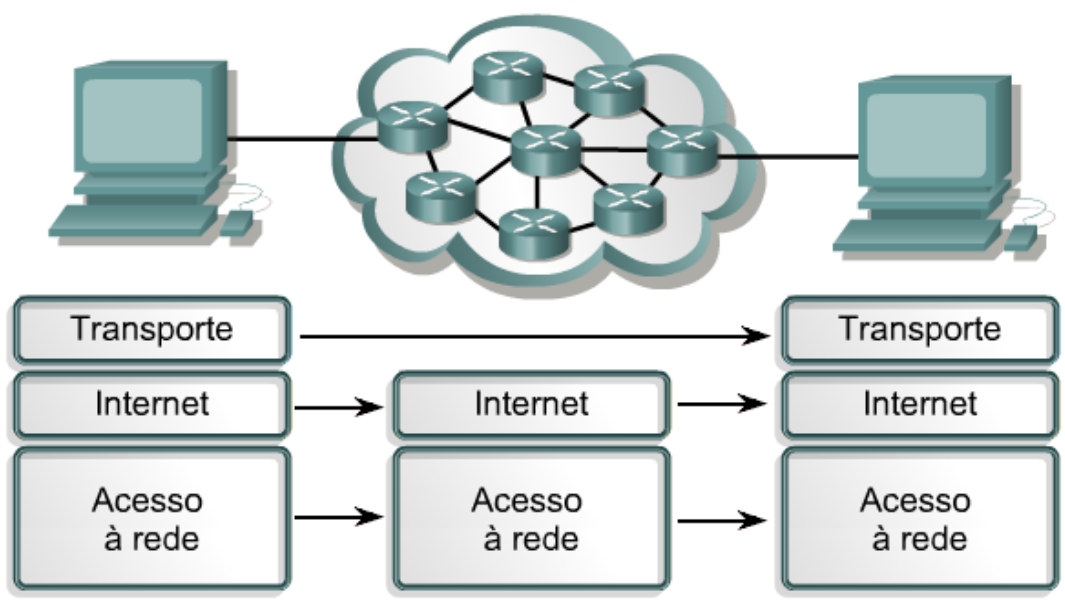

Figura 2.2: Comunicação lógica da camada de Transporte.

\section{Camada de Internet}

A camada de Internet é uma das mais complexas da pilha de protocolos TCP/IP. A sua principal finalidade é escolher o melhor caminho para os pacotes se deslocarem na rede. Para realizar esse processo, os roteadores ${ }^{2}$ comparam o endereço de destino do pacote às rotas disponíveis em sua tabela de roteamento e, assim, determinam qual a melhor rota com base no protocolo de roteamento vigente.

A entrega dos pacotes, no entanto, é feito pelo protocolo IP (Internet Protocol). Definido na RFC 791 (POSTEL, 1981b), ele é a implementação mais utilizada de um esquema de endereçamento de rede hierárquico. Sem conexão, de melhor entrega possível e não confiável, o IP não estabelece conexão com circuito dedicado antes da transmissão, como ocorre quando se realiza uma ligação telefônica. Ele determina a rota mais eficiente

\footnotetext{
${ }^{2}$ Equipamento usado para realizar a comunicação entre diferentes protocolo e redes de computadores.
} 
para os dados com base no protocolo de roteamento. O fato de ser não confiável e de não oferecer melhor entrega não implica que o sistema não funcione bem, porém o IP não verifica se os dados chegaram ao destino. Se necessário, a verificação é controlada pelos protocolos da camada superior, como o TCP.

À medida que as informações fluem pelas camadas do modelo TCP/IP, elas são processadas. Na camada de Internet, os segmentos (dados mais o cabeçalho da camada de transporte) são encapsulados em pacotes. O IP determina o conteúdo do cabeçalho do pacote, que inclui informações sobre endereçamento e controle, mas não trata os dados. Além do IP, os seguintes protocolos operam na camada de Internet:

- O ICMP (Internet Control Message Protocol), definido na RFC 792 (POSTEL, 1981a), oferece recursos de controle e de mensagens.

- O ARP (Address Resolution Protocol), definido na RFC 826 (PLUMmer, 1982), determina o endereço da camada de enlace, o endereço MAC (Media Access Control), para endereços IP conhecidos.

- O RARP (Reverse Address Resolution Protocol), definido na RFC 903 (FINLAYSON et al., 1984), ao contrário do ARP, ele determina os endereços IP quando o endereço MAC é conhecido.

\section{Camada de Acesso à Rede}

A camada de acesso à rede encontra-se no nível mais baixo da hierarquia. Sua função é cuidar de todas as questões necessárias para um pacote IP estabelecer uma ligação física com a rede. Isso inclui detalhes de tecnologia de redes locais e de longas distâncias e todos os detalhes contidos nas camadas física e de enlace de dados do modelo OSI (TANENBAUM, 2002).

Drivers de placas de redes, de modem e de outros dispositivos operam na camada de acesso à rede. Essa camada também define os procedimentos para estabelecer uma interface com o hardware de rede e o acesso ao meio de transmissão. Devido à complexa interação entre as especificações de hardware, software e meios de transmissão, há muitos protocolos em operação nesse nível. É nessa camada que se confere a flexibilidade aos protocolos TCP/IP, operando sobre diversos tipos de mídias.

As funções da camada de acesso à rede incluem o mapeamento de endereços IP para endereços físicos e o encapsulamento de pacotes IP em quadros (TANENBAUM, 2002), com 
base no tipo de interface de rede, ou seja, ela define como realizar a conexão com os meios físicos.

A operação da Internet ocorre por meio da pilha de protocolos TCP/IP. Na próxima seção será apresentado o HTTP, o protocolo padrão utilizado pela Web.

\subsection{Protocolo HTTP}

No núcleo da $W e b$ as informações são trocadas entre servidores e usuários. Como existem milhares de computadores conectados à rede e inúmeras formas de conexão entre eles, para que haja uma comunicação, dois computadores devem trocar mensagens. Essa troca requer um conjunto de regras em comum, ou seja, um protocolo. Tais regras mantêm a Internet operando regularmente. Na pilha TCP/IP há uma elevada quantidade de protocolos coordenando a comunicação. Cada protocolo é diferente e projetado para satisfazer uma necessidade particular.

O HTTP é o protocolo usado pela WWW para realizar a comunicação entre milhões de computadores conectados a Internet, definindo como as mensagens são formatadas e transmitidas. Como citado em Meira et al. (2002), o HTTP possui um conjunto de regras determinando como os navegadores e os servidores Web se comunicam, utilizando uma conexão TCP. Ele é um protocolo, em nível de aplicação, que assume a existência de um serviço de transporte confiável e orientado a conexão (COMER, 2000). O HTTP também é considerado stateless (ORFALI et al., 1999), ou seja, o servidor não guarda informações de estado atual dos clientes. Caso haja alguma falha durante a comunicação é responsabilidade do cliente encaminhar novamente os dados.

O fato do HTTP não guardar o estado entre as transações é um problema em alguns casos (MEIRA et al., 2002). Para solucionar essa deficiência, uma extensão do protocolo faz uso do recurso de $\operatorname{cookies}^{3}$, permitindo os servidores definir informações armazenadas pelo navegadores.

\subsubsection{O Protocolo de Requisição-Resposta}

O HTTP define métodos, argumentos, mensagens envolvidas em uma troca de requisição-resposta, resultados e as regras para a representação das mensagens (COULOURIS et al., 2001). Uma requisição consiste de uma linha informando a ação a ser executada

\footnotetext{
${ }^{3}$ Cookie são blocos de informações cujo servidores podem enviar para os navegadores em campos especiais do protocolo HTTP, junto com a resposta da requisição.
} 
no servidor, seguida de uma ou mais linhas de cabeçalho contendo os parâmetros e pelo corpo da mensagem, esse último opcional. Segundo Coulouris et al. (2001), a mensagem de requisição possui os seguintes campos:

- Request line. Armazena o método HTTP invocado, a localização do objeto no servidor e a versão do protocolo HTTP utilizado.

- Request header. Contém campos que permitem ao cliente utilizar para o envio de informações para o servidor.

- Corpo da mensagem. Possui dados adicionais para serem entregues ao servidor. Esse campo pode não ser utilizado, como ocorre com o método POST.

Uma mensagem de requisição, além da URL (Universal Resource Locator) do objeto desejado e da versão do protocolo, define também um conjunto de métodos para indicar o propósito das requisições. Esses métodos funcionam como comandos enviados ao servidor. A tabela 2.1 resume os métodos implementados pelo HTTP.

Tabela 2.1: Métodos implementados no protocolo HTTP/1.1.

\begin{tabular}{|c|l|}
\hline \hline Método & Descrição \\
\hline \hline GET & $\begin{array}{l}\text { Indica ao servidor que o cliente deseja receber o } \\
\text { conteúdo do objeto identificado pela URI contido } \\
\text { na requisição. }\end{array}$ \\
\hline \hline HEAD & $\begin{array}{l}\text { Semelhante ao GET, porém a resposta contém } \\
\text { apenas a meta-informação sobre o objeto requi- } \\
\text { sitado e não o seu conteúdo. }\end{array}$ \\
\hline \hline POST & $\begin{array}{l}\text { Usado pelo cliente para armazenar no servidor in- } \\
\text { formações contidas no corpo da requisição. }\end{array}$ \\
\hline \hline DELETE & $\begin{array}{l}\text { O cliente pede ao servidor para armazenar os da- } \\
\text { dos da mensagem como um objeto a ser identifi- } \\
\text { cado pelo URI enviado. }\end{array}$ \\
\hline \hline Oede para o servidor remover o objeto definido no \\
URI.
\end{tabular}

Para as mensagens de respostas, o HTTP determina os seguintes campos (COULOURIS et al., 2001):

- Response header. Armazena o código de resposta e a versão do protocolo. 
- Request header. Vários campos que informam as características do servidor e do objeto retornado ao cliente.

- Corpo da mensagem. Informações sobre o objeto retornado.

Portanto, as mensagens de resposta possuem a versão do protocolo e o código de resposta. O protocolo HTTP oferece uma lista de códigos para os servidores Web informarem ao cliente o grau de sucesso ao tentar atender a requisição. A tabela 2.2 resume os possíveis códigos. Essa informação, utilizada na simulação para avaliar o desempenho, faz parte da carga de trabalho sintética gerado pelo W4Gen, a qual será discutida nos próximos capítulos.

Tabela 2.2: Classe de código de resposta do protocolo HTTP.

\begin{tabular}{|c|l|}
\hline \hline Classe & Descrição \\
\hline \hline $1 \mathrm{xx}$ & $\begin{array}{l}\text { Indica que a requisição foi recebida e está em fase } \\
\text { de processamento. }\end{array}$ \\
\hline \hline $2 \mathrm{xx}$ & $\begin{array}{l}\text { Indica que a requisição foi recebida, entendida e } \\
\text { processada com sucesso. }\end{array}$ \\
\hline \hline $3 \mathrm{xx}$ & Redireciona o cliente para uma outra URL. \\
\hline \hline $4 \mathrm{xx}$ & Indica que a requisição do cliente está inválida. \\
\hline \hline $5 \mathrm{xx}$ & $\begin{array}{l}\text { Indica a incapacidade do servidor de processar a } \\
\text { requisição. }\end{array}$ \\
\hline \hline
\end{tabular}

\subsubsection{Evolução do HTTP}

O HTTP tem sido usado na Web desde 1990. Na versão inicial, o HTTP/0.9 era referenciado como um protocolo simples para a recuperação de dados da Internet. Com o HTTP/1.0 foram introduzidas mensagens de descrição própria, usando uma variante do Internet Mail MIME. Mesmo assim, ao longo dos anos, problemas foram surgindo devido a suas fraquezas. Para cada requisição realizada ao servidor, uma conexão TCP é aberta, apresentando uma sobrecarga extra ao acessar Web sites cujo conteúdo possui diversos objetos, tais como, imagens, animações, entre outros. A figura 2.3 apresenta a troca de mensagens utilizando a versão HTTP/1.0.

Em 1998, a W3C(World Wide Web Consortium) criou o HTTP/1.1, conhecido também como HTTP-NG (HTTP New Generation), uma versão compatível com as anteriores e com modos mais eficazes. Essa versão usa o esquema de conexões persistentes, o que permite várias transações HTTP utilizar uma mesma conexão TCP, aumentado a eficiência da comunicação e evitando a fase de estabelecimento e término de conexões intermediárias, 
o three-way handshake. Ele também possui uma característica conhecida como pipelining. Nesse caso, várias requisições são enviadas em seqüência dentro de um mesmo fluxo, sem aguardar pelas respostas. Os novos comandos de cache introduzido também reduzem o tráfego de rede e permite ao protocolo maior eficiência. Outra vantagem é a transferência de informações compactas, reduzindo em até 10 vezes o volume de informações na rede. A figura 2.3 também apresenta o esquema de troca de mensagens realizada entre cliente e servidor.

HTTP/1.0 possui uma série de conexốes, uma para cada Requisição/Resposta.

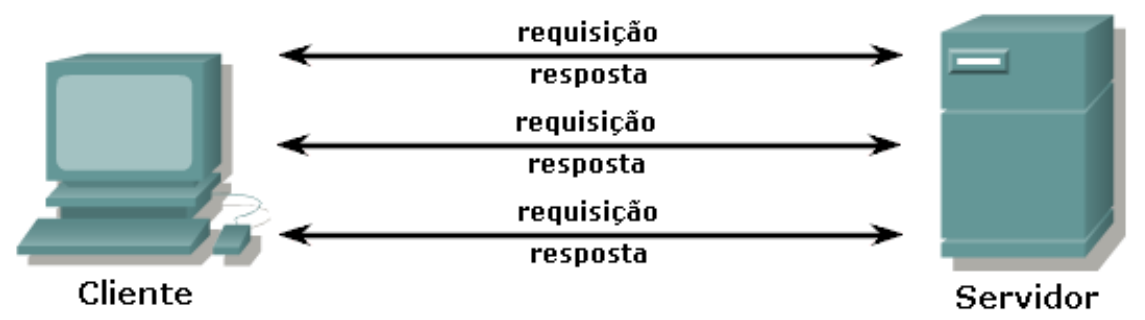

HTTP/1.1 possui várias sessões ativas utilizando uma única conexão.
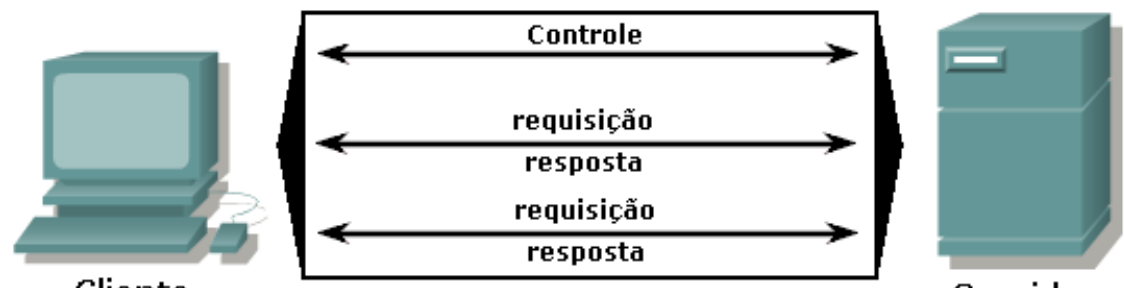

Cliente

Servidor

Figura 2.3: Funcionamento do protocolo HTTP/1.0.

Na próxima seção será abordado a implementação dos servidores Web e como os processos são criados para tratar as requisições dos clientes.

\subsection{Arquitetura de Servidores $W e b$}

Os servidores compõem um conjunto de componentes importantes da WWW. Por essa razão é muito importante entender sua arquitetura, pois são eles que tratam os pedidos dos usuários.

Um servidor Web está sempre em um laço infinito aguardando por requisições de clientes (ORFALI et al., 1999). Para isso, o servidor deve ser projetado para suprir a demanda imposta pelos usuários. Modelos arquiteturais propõem soluções para melhorar 
o nível de concorrência e, conseqüentemente, aumentar o throughput. A seguir, discutemse os modelos de implementação dos servidores $W e b$.

\subsubsection{Organização dos Servidores}

\section{Servidor Iterativo}

O modelo de servidor iterativo propõe aguardar as requisições vindas dos clientes e tratá-las uma de cada vez, conforme sua ordem de chegada. Nenhum tipo de concorrência é estabelecido nesse modelo e, na prática, seria muito ineficiente. Tais características implicam em um modelo didático que surge como forma básica para compreensão de propostas mais complexas.

\section{Um Processo por Requisição}

O modelo de um processo por requisição cria uma cópia de um processo pai que aguarda por requisições em uma porta pré-definida. Em sistemas UNIX, uma chamada à system call fork() (STEVEns, 1997) realiza todo esse trabalho. Sempre que uma nova requisição chega ao servidor, ele cria uma cópia do processo e transfere a responsabilidade para o filho retornando, em seguida, ao laço infinito de espera. Com isso, em determinados instantes, existirão várias cópias do servidor executando concorrentemente, limitadas apenas pela capacidade da máquina.

Na prática, o modelo apresentado pode não oferecer um serviço eficiente. O desempenho é degradado pelo custo elevado na criação de novos processos, já que as transações são simples e não precisam de um processo para cada nova requisição (YEAGER; MCGRATH, 1996).

\section{Um Servidor Multithreaded}

Uma outra abordagem é ter um processo servidor tratando mais de uma requisição por vez, todas elas dentro do mesmo espaço de memória do programa. Ao invés de criar um novo processo, como proposto anteriormente, para cada nova requisição que chega uma nova thread é criada para tratá-la. Cada thread possui uma cópia privada da conexão de rede na qual ela é responsável, porém todas elas compartilham o mesmo espaço de memória, código de programa e dados globais. Segundo Tanenbaum (2003), como as 
threads se encontram dentro de um mesmo processo, a mudança de contexto ocorre mais rapidamente.

O uso de threads além de aumentar o desempenho permite as requisições serem concorrentemente executadas. Essa abordagem, contudo, é muito mais complexa se comparada à proposta de processos. Outro fator negativo é o uso de bibliotecas específicas para um dado sistema operacional, comprometendo a portabilidade (YEAGER; MCGRATH, 1996).

\section{Processos Ajudantes}

O modelo de um processo por requisição é conhecido como número infinito de processos e o modelo de multhreaded de somente um processo. Uma alternativa a essas propostas é criar um número pequeno de processos ao iniciar a execução do servidor. O processo dispatcher, responsável por gerenciar as requisições, aguarda as solicitações dos clientes e, ao receber uma requisição, transfere o pedido para um processo ocioso. Após a atribuição, o dispatcher retorna ao laço de espera.

Como nos outros modelos, ele também possui algumas desvantagens. O processo dispatcher pode tornar-se um gargalo do sistema, caso o número de requisições seja superior à quantidade de solicitações que ele possa tratar. Nesse caso, o desempenho de todo o servidor está relacionado ao poder de processamento do dispatcher (YEAGER; MCGRATH, 1996). Por essa razão, ele deve ser escrito com muito cuidado para ser robusto e não comprometer o sistema como um todo.

Embora os modelos cumpram suas funções, já existem sinais de saturação (CHEN; MOHAPATRA, 2002). O crescimento do comércio eletrônico (E-commerce) exemplifica essa nova tendência, exigindo cada vez mais dos servidores Web (WANG et al., 2004). Para suprir essa nova demanda de clientes, modelos, tais como, SWDS (TEIXEIRA et al., 2005) apresentam-se como alternativas de servidores $W e b$ com qualidade de serviço.

\subsection{Considerações Finais}

Nesse capítulo apresentou uma visão geral sobre a Internet, em particular a Web, descrevendo a estrutura da pilha de protocolos TCP/IP, responsável pelo seu funcionamento. Também foi abordado o HTTP, um protocolo simples para a recuperação de dados e padrão para a transferência de informações da $W W W$. Por fim, apresentou-se alguns exemplos da arquitetura de implementação dos servidores Web, um dos principais com- 
ponentes e responsáveis por alguns dos problemas de desempenho da Internet. Portanto, esse capítulo

No próximo capítulo será discutida a qualidade de serviço, apresentando as duas principais arquiteturas da Internet, os serviços integrados e diferenciados. Nele também será abordado o modelo de servidor Web com diferenciação de serviços (SWDS), proposto em Teixeira (2004), e seus mecanismos de diferenciação. 


\section{Qualidade de Serviço na Internet}

\subsection{Considerações Iniciais}

Como apresentado no capítulo anterior, a Internet utiliza o TCP/IP para trocar informações. Dentro desse conjunto de protocolos, o IP é o principal responsável pela transmissão de dados. Ele trabalha com o conceito de melhor esforço (Best-effort) que tenta realizar a entrega dos pacotes da melhor maneira possível (COMER; DROMS, 2003). Nesse ambiente, nenhuma garantia é fornecida para as aplicações de que os dados chegarão ao destino. Se algo acontece durante a transmissão e os pacotes são perdidos ou atrasados, cabe à estação final (aplicação) resolver a situação e solicitar a retransmissão.

Atualmente, o cenário de fluxo de dados da Internet e das Intranets está muito acima do que se imaginava nos primórdios da criação do IP. A idéia do melhor esforço não garante níveis de entrega de dados para aplicações que realmente exigem maior capacidade de transferência. Enquanto aplicativos tradicionais, como o FTP e a $W e b$, toleram algum atraso e exigem que os pacotes não contenham erros, outras aplicativos, tais como videoconferência, são sensíveis ao atraso. Para suprir essas necessidades, a qualidade de Serviço $\left(Q_{o S}\right)$ surgiu como resposta a essa demanda exigida por diversas aplicações e ambientes.

No nível de aplicação, o modelo de SWDS (TEIXEIRA, 2004) constitui uma proposta para fornecer serviços diferenciados na $W e b$, introduzindo características de qualidade de serviço. Composto de um classificador, controle de admissão e um cluster de servidores $W e b$, ele destaca-se por sua flexibilidade, conferida ao mecanismos de controle de admissão e diferenciação de serviços.

Este capítulo realiza uma breve discussão sobre o conceito de qualidade de serviço, com destaque para as principais arquiteturas da Internet: a IntServ e a DiffServ. Apresenta ainda o modelo de servidor Web com Diferenciação de Serviços (SWDS), uma proposta desenvolvida em 2004 (TEIXEIRA, 2004), cujo objetivo é melhorar o atendimento de requisições de mais alta prioridade, baseado em acordos realizados entre o cliente e a 
empresa contratada. Por fim, discutem-se os mecanismos de diferenciação de serviços e os algoritmos implementados e testados no modelo de SWDS para cumprir com as exigências da qualidade de serviço.

\subsection{Qualidade de Serviço}

Define-se QoS (Quality of Service) como a capacidade dos elementos de rede (Roteadores e Switchs) em fornecer uma medida de atraso e garantia de entrega de banda, mantendo os acordos de tráfego (STARDUST, 1999). Ela está relacionada com a garantia de atraso na entrega de pacotes (delay) e com pequenas perdas para determinados tipos de aplicações (ZHAO et al., 1999).

Sem realizar a reserva da disponibilidade de rede para conexões específicas na Internet, os próximos tópicos discutem as duas principais arquiteturas de $Q_{o S}$ desenvolvidas para suprir essas necessidades da carga de trabalho da rede, os Serviços Integrados e os Serviços Diferenciados.

\subsubsection{Serviços Integrados}

A arquitetura da Internet denominada Serviços Integrados (IntServ), definida na RFC 1633 (BRADEN et al., 1994), é uma estrutura desenvolvida pelo IETF para prover qualidade de serviço individualizada às sessões de aplicações. Ela visa fornecer uma rede comutada por pacotes e um serviço mais próximo da abstração de circuitos virtuais. Segundo Kurose \& Ross (2006), as principais características são:

- Recursos Reservados. Os elementos de rede devem saber a quantidade de recursos (buffers, largura de banda) já reservada pelas sessões em andamento.

- Estabelecimento da Chamada. Uma sessão com qualidade de serviço deve certificar se a reserva de recursos é suficiente em cada elemento da rede, durante a transmissão entre a origem e o destino.

Para cumprir com essas exigências, as aplicações podem utilizar o RSVP (Resource Reservation Protocol), um protocolo de controle, definido na RFC 2205 (BRADEN et al., 1997), que atua sobre o IP permitindo a reserva de recursos para seus fluxos de dados.

Para fornecer qualidade de serviço, o RSVP cria um caminho entre a origem e o destino, perguntando a todos os elementos intermediários se são capazes de fornecer uma 
QoS desejada para a aplicação. Caso algum nó rejeite o pedido do protocolo, seja por falta de recursos ou de suporte, a comunicação não é estabelecida. Uma outra abordagem é a arquitetura de serviços diferenciados.

\subsubsection{Serviços Diferenciados}

Definido na RFC 2475 (BLAKE et al., 1998), a abordagem DiffServ agrega os fluxos em poucas classes de serviço. Dessa forma, ela permite operar em diferentes classes de forma distinta na Internet, classificando os pacotes como mecanismo para obter QoS.

Baseada no esquema de prioridades relativas, o serviço diferenciado garante que todo o tráfego gerado por uma aplicação, em um nível de prioridade maior, receba preferência em relação a uma classe inferior (XIAO; NI, 1999). Para isso, a abordagem utiliza o campo DS (Differentiated Service), encontrado no protocolo IP, para definir a qual classe o pacote pertence (KUROSE; ROSS, 2006).

O modelo DiffServ marca os pacotes nos pontos de ingresso da rede. Essa abordagem mantém a estrutura básica da Internet e deixa a complexidade de comunicação sempre na fronteira da rede. É importante ressaltar que o Serviço Diferenciado não necessita de um protocolo específico para operar, como ocorre no IntServ, já que o mesmo utiliza o campo (DS) dentro do datagrama IP. O que existe é somente uma análise para determinar qual tratamento será aplicado ao pacote. Os roteadores precisam somente distinguir um certo número de classes de serviço pré-definidas.

Prover $Q o S$ não é uma atividade simples de ser realizada, independente do tamanho da rede na qual ela será implementada, muito menos para a Internet. Para que qualidade se integre à rede é necessária a cooperação de todas as camadas, como também de todos os elementos que a compõem, ou seja, desde a origem até o destino (STARDUST, 1999). A próxima seção introduz a idéia de qualidade de serviço associada ao nível de aplicação.

\subsubsection{Serviços Diferenciados em Nível de Aplicação}

O modelo atual de serviços da Web, trata todas as requisições que chegam para o servidor $W e b$ de forma igualitária, sem nenhum tipo de priorização ou diferenciação das requisições. A disciplina utilizada é a $\mathrm{FCFS}^{1}$, onde uma única fila de requisições é mantida aguardando o momento de ser atendida, de acordo com sua ordem de chegada. Embora

\footnotetext{
${ }^{1}$ Primeiro a chegar e ser atendido
} 
os servidores Web possam agilizar o processo através do controle de concorrência, como destacou a seção 2.4, o atendimento continua de maneira uniforme.

O comportamento atual da Web, entretanto, mostra que nem todo o tráfego ou transação é igual e necessita ter a mesma prioridade (ANDREOLINI et al., 2004). Nesse aspecto, é essencial fornecer uma diferenciação de serviços com níveis de qualidade para os inúmeros tipos de requisições e aplicações existentes (CHEN; MOHAPATRA, 2002). Como pode ser constatado no estudo de Zhang et al. (2002), prover QoS somente no nível de rede, não permite ao servidor $W e b$ garantir que requisições de mais alta prioridade não sejam descartadas em momentos de sobrecarga. O mesmo caso também não se aplica no sentido inverso. Para fornecer uma diferenciação para o tráfego, é necessário implementar QoS em todos as camadas ou níveis de comunicação, havendo um comprometimento fim-a-fim de todos os elementos envolvidos no processo. Portanto, é imprescindível que os servidores Web sejam capazes de reconhecer as diferentes demandas dos usuários, de modo a estarem aptos a distribuir seus recursos em classes de serviços. Sendo assim, a próxima seção introduz o modelo de Servidor Web com Diferenciação de serviço (SWDS), proposto em (TEIXEIRA et al., 2005).

\subsection{Servidor Web com Diferenciação de Serviços}

O modelo SWDS, proposto por Teixeira (2004), visa o fornecimento de serviços diferenciados na $W e b$, em nível de aplicação, particularmente no contexto de servidores. Esse modelo representa uma arquitetura cujo objetivo é prover serviços diferenciados a seus inúmeros clientes. A proposta é atender as requisições de acordo com a necessidade e disciplinas de QoS. A arquitetura do modelo SWDS, mostrada na figura 3.1, possui os seguintes módulos: (1) o Classificador; (2) um Controle de Admissão; e (3) um Cluster de servidores Web. A seguir, explica-se cada um dos seus componentes.

\section{Classificador}

O Classificador é o primeiro componente do modelo, responsável por receber as requisições que chegam ao sistema e associá-las a uma das classes de serviços, de acordo com critérios pré-estabelecidos. Após essa fase, a requisição entra no sistema em uma determinada categoria e recebe o tratamento à qual pertence. 


\section{Controle de Admissão}

O Controle de Admissão recebe as requisições classificadas e gerencia a sua aceitação pelo servidor $W e b$, considerando as políticas de atendimento e as informações da carga de trabalho do sistema. Se o cluster estiver sobrecarregado, uma requisição poderá ser rejeitada ou ter suas exigências de qualidade de serviço reduzidas, de modo que possa ser aceita em uma classe de menor prioridade.

\section{Cluster de Servidores Web}

Após ser aceita no sistema, a requisição é atribuída a um dos elementos do cluster de servidor Web, sendo atendida conforme o algoritmo de escalonamento ou diferenciação de serviços. Ao final, os resultados são retornados ao cliente que originou a solicitação.

O modelo, idealizado em Teixeira (2004), determina que cada nó do cluster seja formado por um servidor $W e b$, composto de CPU, interface de rede e disco, com múltiplas filas de prioridades, a fim de acomodar as diferentes classes de serviço. No entanto, nada impede que seja abstraído para processos ou CPUs em um computador paralelo.

As próximas seções apresentam idéias mais concretas de como classificar as requisições e o funcionamento do controle de admissão.

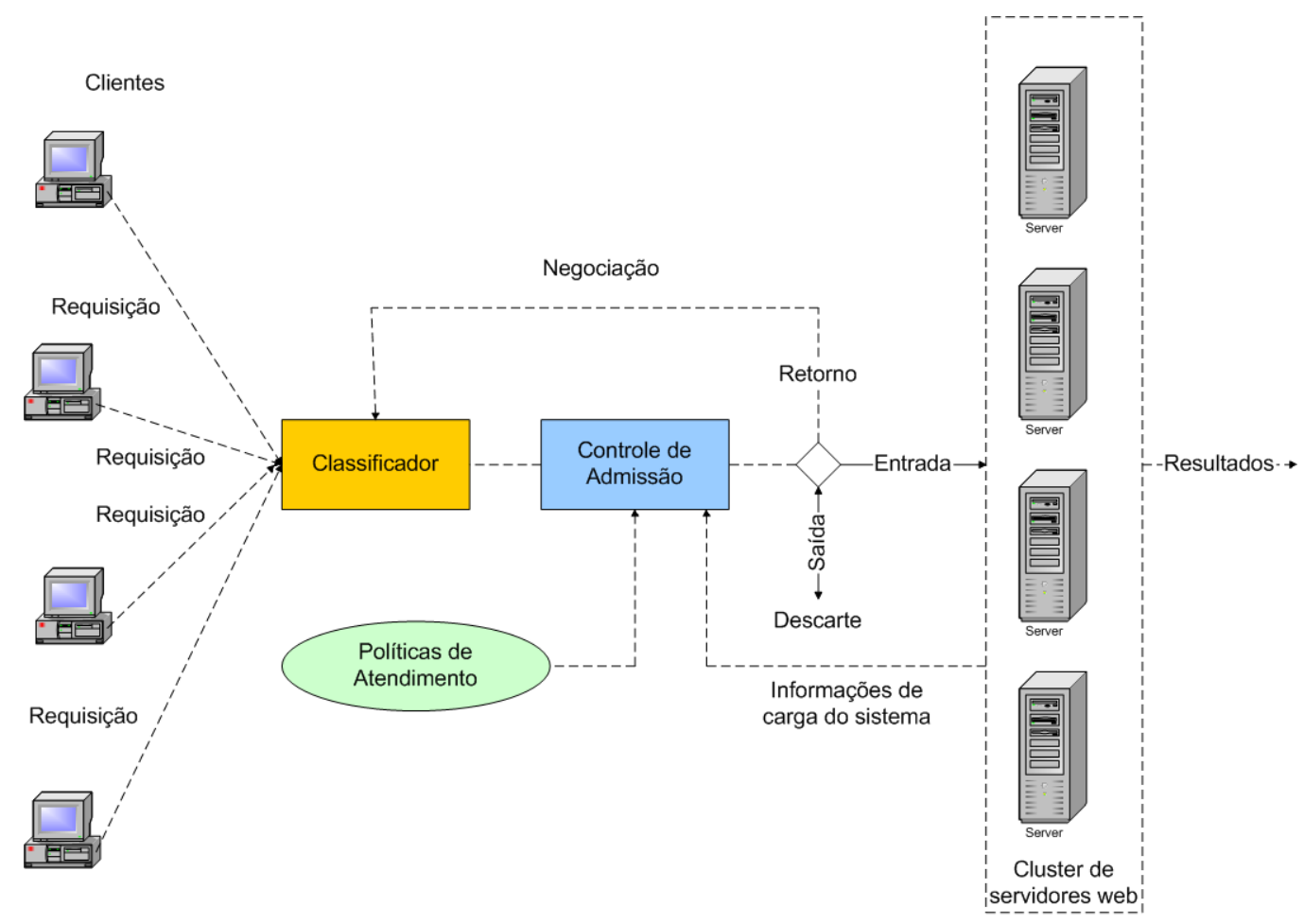

Figura 3.1: Modelo de servidor Web com diferenciação de serviços (SWDS). 


\subsubsection{Classificação das Requisições}

A população de usuários de servidores Web é bastante diversificada, com diferentes necessidades e expectativas. O primeiro componente do sistema, o classificador, deve diferenciar essas necessidades, identificando as informações da requisição HTTP e atribuindoas à melhor classe de serviço. Essa classificação pode ser realizada pelo próprio servidor Web ou pelo cliente, através de um contrato de prestação de serviço e, para cada categoria, associa-se um determinado nível de atendimento.

A noção de classe visa fornecer diferenciação de serviços às requisições. Cada categoria agrupa um conjunto de clientes com as mesmas necessidades de atendimento. Algumas características que definem esse grupo incluem, por exemplo, utilização do sistema, tempo de resposta médio, throughput, requisições completadas, entre outros. Os seguintes critérios podem ser utilizados para classificar as requisições de acordo com as expectativas:

- Origem da requisição. As requisições podem ser classificadas em remotas, vindas de outros domínios, ou locais, provenientes do mesmo domínio.

- Conteúdo solicitado. O tipo de arquivo também pode ser considerado como critério de classificação. Exemplos incluem: HTML, Imagem, Dinâmico, Binário, Áudio, Vídeo, entre outros.

- Urgência no atendimento. Diferencia o tráfego do servidor Web como real, emitidos por clientes, ou especulativo, emitidos de forma automática a partir de um servidor proxy ou originadas através de pré-busca (prefetching).

- Políticas de atendimento diferenciadas. Os clientes podem ser separados segundo políticas externas, tais como, usuários que pagam pelo serviço e usuários que utilizam o serviço gratuito.

O modelo SWDS, simulado em Teixeira (2004), classifica as requisições de acordo com uma distribuição de probabilidade acumulada. Os critérios citados anteriormente são meramente ilustrativos e visam somente apresentar a diversidade de informações que podem ser utilizadas para diferenciar uma requisição quando implementado em um ambiente real. A próxima seção apresenta o controle de admissão, o segundo componente do modelo, responsável pela aceitação dentro do SWDS. 


\subsubsection{Controle de Admissão}

Os picos (sobrecarga) existentes no comportamento atual da Internet compromete a diferenciação de serviços (níveis de $Q o S$ implementados) (TEIXEIRA et al., 2004). Sendo assim, o módulo de controle de admissão, presente no servidor SWDS, gerencia a entrada de novas requisições no servidor, mantendo em níveis aceitáveis a carga de trabalho do sistema. Para isso, as informações da carga vigente são atualizadas, evitando falhas no sistema.

A figura 3.2 é apresentada a arquitetura do controle de admissão e os seus elementos (TEIXEIRA et al., 2004). A seguir é comentado o objetivo de cada componente no funcionamento do sistema.

- Área de Variáveis Globais. Guarda as informações do estado do sistema e as métricas para o controle de admissão. Essa área pode ser ampliada de acordo com as necessidades.

- Área de Buffers. Compreende os buffers utilizados como, por exemplo, para limitar o número de clientes atendidos pelo servidor $W e b$ em uma determinada classe.

- Coleta de Informações. Recolhe as informações atualizadas da carga de trabalho do sistema, utilizada como base para a tomada de decisão.

- Mecanismos de Controle. São os mecanismos do controle de admissão implementados no servidor SWDS que determinam qual será o tratamento dispensado as requisições dos clientes. Os mecanismos implementados são: tamanho das filas, tempo de resposta e a utilização do sistema. Maiores informações, consulte Teixeira (2004).

O controle de admissão foi projetado para trabalhar de forma flexível, adaptando-se aos diferentes mecanismos de controle de sobrecarga. Além de coletar as informações da carga de trabalho atual, ele também recebe como parâmetro de entrada as políticas de atendimento estabelecidas pela gerência.

A próxima seção discute alguns dos mecanismos de diferenciação de serviços implementados no servidor SWDS, cuja configuração será utilizada para testar as cargas de trabalho sintéticas gerado pelo W4Gen. 


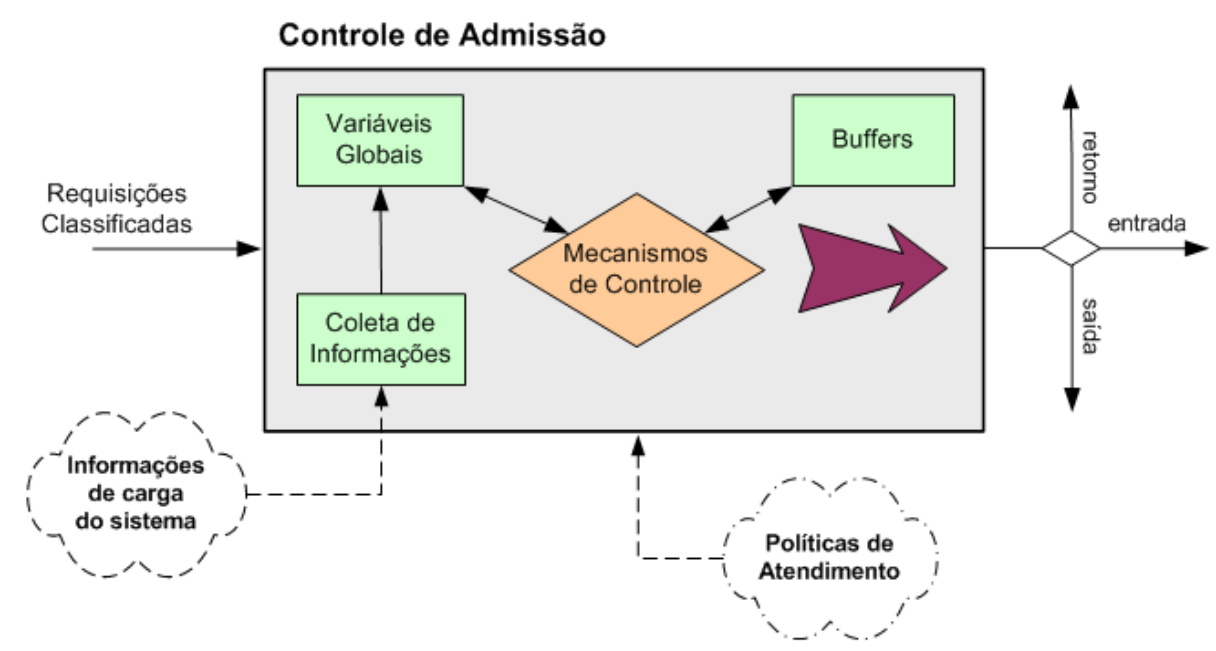

Figura 3.2: Modelo do controle de admissão (TEIXEIRA, 2004).

\subsubsection{Mecanismos de Diferenciação de Serviços}

A diferenciação de serviços é realizada por meio de algoritmos específicos. Dentre eles, destacam-se duas variantes. A primeira delas aplica-se sobre o controle de admissão (na fase de despacho das requisições HTTP), determinando a forma como as requisições serão distribuídas entre os nós do cluster. Nesse caso, o controle de admissão assume o papel de um escalonador e atribui os pedidos a grupos de processos. No interior das filas dos nós do cluster, o atendimento segue o comportamento do primeiro a chegar é o primeiro a ser atendido (FCFS). Exemplos dessa abordagem são os algoritmos de RSV (Mecanismo de Reserva de Recursos) (TEIXEIRA, 2004) e RSVAdap (Mecanismo de Reserva Adaptativa de Recursos), proposto em Barbato et al. (2005).

A segunda variante, entretanto, age diretamente na fila de escalonamento dos nós, alterando a ordem de processamento das requisições. Para alimentar cada nó, os algoritmos de prioridades rigoroso e de prioridade adaptativo (PRIAdap), como são chamados nessa abordagem, utilizam outros algoritmos de balanceamento de carga, tais como, Round Robin (RR), Shortest Queue First (SQF) para distribuir as requisições entre o cluster e, assim, conseguir diferenciar o serviço.

\subsection{Considerações Finais}

Devido à diversidade de aplicações que trafegam sobre a Internet, observa-se a presença de diferentes características e demandas. Com o crescimento no volume de informações e de usuários já a alguns anos atrás, surgiu a necessidade de realizar um con- 
trole de atraso garantindo acordos de tráfego. Assim, este capítulo apresentou o conceito de $Q o S$ descrevendo as duas principais arquitetura da Internet aplicáveis em nível de rede, o IntServ e o DiffServ. Também foi discutida a qualidade de serviço em nível de aplicação, destacando o modelo de servidor Web com diferenciação de serviços (SWDS), uma proposta desenvolvida em 2004, para provimento de níveis de qualidade na WWW, além dos mecanismos de diferenciação de serviços implementados no SWDS. Esse modelo foi utilizado para validar os dados reproduzidos pelo gerador de carga de trabalho.

O próximo capítulo discute os resultados da análise das cargas de trabalho de traces de servidores $W e b$ e apresenta modelos matemáticos para simular os diversos ambientes. 


\section{Caracterização da Carga de Trabalho da Web}

\subsection{Considerações Iniciais}

Este capítulo apresenta os resultados do estudo de caracterização da carga de trabalho de servidores Web. Para isso, nove logs de servidores Web Apache foram utilizados, alguns deles coletados da própria $W e b$, enquanto outros disponíveis através do administrador de redes de instituições ou empresas.

A finalidade é identificar o comportamento comum dos usuários e, assim, utilizar funções de distribuição de probabilidade para modelar o ambiente. A caracterização também serviu de embasamento para o desenvolvimento de um gerador de cargas de trabalho sintéticas, o W4Gen, para avaliação de desempenho de modelos de servidores $W e b$, apresentado no próximo capítulo. Observa-se que alguns dos resultados encontrados são similares na literatura.

A quantidade de traces utilizados no estudo de caracterização da Web também permitiu classificá-los em categorias, com base no conteúdo do site, ou seja, no tipo de serviço prestado ao cliente. Seguindo essa lógica, três classes foram identificadas e analisadas isoladamente, obtendo o comportamento em cada categoria. Os resultados, também implementados no W4Gen, permitem a ferramenta gerar cargas de trabalho específicas para alguns dos ambientes da WWW.

Para atingir esses objetivos, a seção 4.2 discute alguns dos trabalhos relacionados na área de caracterização da carga de trabalho e apresenta, ao final, um comparativo de sua evolução. A seção 4.3 discute o formato do log Apache e mostra o resumo dos dados brutos antes da análise e após o pré-processamento. Essa etapa foi necessária para eliminar informações incorretas. Já a seção 4.4 apresenta, em detalhes, os resultados das análises dos nove logs segundo quatro características: o intervalo de chegada das requisições; a classe de objeto, o código de resposta retornado pelo servidor Web e o tamanho do objeto 
e sugere modelos matemáticos para representar a carga de trabalho. A seção 4.5 discute as mesmas análises da seção anterior, porém aplicados a cada uma das três categorias identificadas no conjunto de logs.

\subsection{Trabalhos Relacionados}

A Internet é um sistema em constante expansão, motivando inúmeras pesquisas cujo objetivo é identificar características comuns dos usuários da $W e b$, com o intuito de solucionar problemas e melhorar o seu desempenho. Uma análise cautelosa é fundamental para o bom planejamento e implantação de servidores $W e b$, à medida que proporciona implementações de novos modelos, idéias com baixo custo para empresas e instituições, e novas técnicas, melhorando a capacidade de atendimento e a redução do tempo de resposta ao cliente.

O desempenho de um servidor Web está vinculado ao tipo de tráfego ao qual ele é submetido. Entender sua natureza é o primeiro dos diversos passos para melhorar a qualidade de serviço oferecida aos usuários (WANG et al., 2003). No estudo de Calzarossa \& Serazzi (1993) algumas diretrizes gerais são apresentadas no processo de análise da carga de trabalho de um sistema. Dentre elas, destacam-se a necessidade de identificar qual o tipo de carga pretende-se analisar, já que em um ambiente distribuído e complexo, como a $W e b$, existem inúmeros tipos e parâmetros, e o nível de detalhamento empregado na descrição da carga de trabalho, por exemplo, o tamanho dos arquivos transferidos a cada requisição processada.

Diversos são os trabalhos publicados na área de caracterização da carga de trabalho da Web, tais como, Arlitt \& Williamson (1996), Arlitt \& Jin (1999), Wang et al. (2004), Bent et al. (2004), Modesto et al. (2005). Nas próximas seções serão discutidos alguns dos principais trabalhos reunidos na literatura e, ao final, apresenta-se uma evolução da carga da $W e b$, resumindo os dados de cada autor na última década.

\subsubsection{A Busca de Invariantes}

Um dos primeiros trabalhos nesta área, identificando o que se chama de invariantes, deve-se a Arlitt \& Williamson (1996). Segundo eles, uma invariante é uma característica da carga de trabalho que representa uma verdade universal, aplicáveis a todo o sistema, ou seja, são comportamentos comuns que aparecem em todos os dados analisados. Em seus estudos, seis registros de logs de servidores $W e b$ foram utilizados, sendo três de ambi- 
entes acadêmicos, dois de instituições de pesquisa e um de um provedor comercial. Esses registros são compostos de ordens de grandezas que variam de menos de mil requisições por dia a mais de 350 mil e, tempos que variam de uma semana a um ano de atividade. $\mathrm{Na}$ avaliação desses arquivos foram encontrados dez invariantes, as quais são apresentadas na tabela 4.1.

Tabela 4.1: Invariantes da carga de trabalho da Web (ARLITT; WILLIAMSON, 1996).

\begin{tabular}{|c|c|c|}
\hline Invariante & Nome & Descrição \\
\hline 1 & Taxa de sucesso & $\begin{array}{l}\text { Taxa de sucesso de requisições ao servidor } \\
\text { foi, aproximadamente, } 88 \% \text {. }\end{array}$ \\
\hline 2 & Tipos de arquivo & $\begin{array}{l}\text { Arquivos HTML e imagens representam } \\
\text { de } 90 \% \text { a } 100 \% \text { das requisições. }\end{array}$ \\
\hline 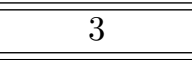 & Tamanho médio de transferência & Tamanho médio menor que 21 Kbytes. \\
\hline 4 & Requisições distintas & $\begin{array}{l}\text { Menos de } 3 \% \text { das requisições são para ar- } \\
\text { quivos distintos. }\end{array}$ \\
\hline 5 & Referências únicas & $\begin{array}{l}\text { Aproximadamente um terço dos arquivos } \\
\text { e bytes são acessados uma única vez. } \\
\end{array}$ \\
\hline 6 & Distribuição dos tamanhos & $\begin{array}{l}\text { A distribuição do tamanho dos arquivos } \\
\text { segue o modelo de Pareto com média } 0,40 \\
<\mathrm{a}<0,63 \text {. }\end{array}$ \\
\hline 7 & Concentração das referências & $\begin{array}{l}10 \% \text { dos arquivos acessados correspondem } \\
\text { a } 90 \% \text { das requisições ao servidor e a } 90 \% \\
\text { dos bytes transferidos. }\end{array}$ \\
\hline 8 & Tempos entre referências & $\begin{array}{l}\text { Os tempos entre as referências aos arqui- } \\
\text { vos são exponencialmente distribuídos e } \\
\text { independentes. }\end{array}$ \\
\hline 9 & Requisições remotas & $\begin{array}{l}\text { Sites remotos representam mais de } 70 \% \\
\text { dos acessos ao servidor e mais de } 60 \% \text { dos } \\
\text { bytes transferidos. }\end{array}$ \\
\hline 10 & Uso na WAN & $\begin{array}{l}10 \% \text { dos domínios dão origem a mais de } \\
75 \% \text { dos acessos. }\end{array}$ \\
\hline
\end{tabular}

A primeira invariante da tabela 4.1 afirma que o grau de sucesso no atendimento das requisições aproxima-se de $88 \%$ (código de resposta 200), mostrando quase sempre a procura por arquivos existentes no servidor.

A característica aleatória dos tipos de arquivos foi levada em consideração, classificandoos nas seguintes categorias: HTML, Imagem, Áudio, Vídeo, Formatados, Dinâmicos e Outros. A segunda invariante mostra o número elevado de requisições voltadas para arquivos HTML e Imagem, com mais de $90 \%$ dos pedidos. Isso revela que na época, páginas estáticas tinham maior aceitação em relação aos dados atuais, discutidos nas próximas seções.

O tamanho dos arquivos também são considerados no estudo, como afirma a invariante 6. Segundo Arlitt \& Williamson (1996), a função Pareto, com parâmetro variando 
entre 0,40 e 0,63, representam adequadamente o comportamento na Web. A grande concentração dos pedidos encontra-se abaixo dos 21 Kbytes, mostrando a transferência de arquivos muito pequenos.

O tempo de referência aos arquivos, ou seja, o intervalo de tempo entre requisições é dependente da carga de trabalho no servidor e varia em cada log. Arlitt \& Williamson (1996) também constataram que um terço dos arquivos são referenciados uma única vez. Além disso, de todos os arquivos do servidor, somente 10\% são referenciados por quase $90 \%$ das requisições e dos bytes transferidos, como afirma a invariante 7. Esse comportamento, explicado através da lei de $Z_{i p f^{1}}$ (ZIPF, 1972), mostra que a maioria das referências estão agrupadas em uma pequena fração de todos os objetos.

A concentração geográfica das requisições originadas pelos clientes possui uma característica interessante. Como concluído em Arlitt \& Williamson (1996), a maior parte surge de locais remotos, e cerca de $10 \%$ dos domínios, originaram três quartos das requisições estudadas, ou seja, uma grande concentração dos pedidos dentro de uma população pequena de usuários.

Os autores publicaram o trabalho em 1996 utilizando, como base, logs de servidores Web coletados em 1995. Alguns anos depois, em 1999, Choi \& Limb (1999) publicaram novos estudos utilizando dados coletado de 1998. A análise da taxa de sucesso revelou que $75,87 \%$ das requisições pertencem à classe de código de status $2 \mathrm{xx}$, ou seja, os pedidos foram processados. Comparando esses dados com os valores apresentados por Arlitt \& Williamson (1996), houve uma queda durante os três anos que distanciam tais estudos. Os restantes dos pedidos estão distribuídos entre as classes 3xx, 4xx e outros, com 21,78\%, $0,87 \%$ e $1,58 \%$, respectivamente. Isso mostra ainda a existências de poucas requisições com erros, referenciando páginas inexistentes. Segundo as pesquisas de Choi \& Limb (1999), os objetos mais comum também eram imagens e arquivos HTML.

\subsubsection{Log da Copa do Mundo de 1998}

Em 1999, Arlitt \& Jin (1999) divulgaram um relatório técnico com detalhes dos estudos realizados com o $\log$ da copa do mundo de 1998. Os dados foram coletados durante o período de três meses, intervalo que incluiu todos os jogos dos times de futebol. Durante esse tempo, trinta servidores foram usados, distribuídos em quatro localizações do pla-

\footnotetext{
${ }^{1} \mathrm{~A}$ freqüência de qualquer característica é inversamente proporcional a seu grau na tabela de freqüência. Assim, o valor mais freqüente aparecerá duas vezes mais do que o segundo valor. O segundo valor aparecerá duas vezes mais do que o quarto valor e assim por diante.
} 
neta. Os pedidos do site superaram a taxa de 1 bilhão de requisições ao todo, com média de 11.000 por minuto, provando ser muito popular na época. Os resultados apresentados mostram que 80,52\% das requisições retornaram o código resposta 200 (com sucesso) e corresponderam a 97,86\% do total de bytes transferidos. Não modificado, ou seja, código de resposta 304 representou 18,75\%, indicando que a consistência de cache teve grande impacto nos servidores $W e b$. As requisições da classe 4xx totalizaram 0,64\% e 5xx não apresentou valores. Os dados estão resumidos na tabela 4.2.

Tabela 4.2: Resumo dos códigos de respostas da Copa de 1998 (ARLITT; JIN, 1999).

\begin{tabular}{|c|c|c|}
\hline \hline $\begin{array}{c}\text { Código } \\
\text { de Resposta }\end{array}$ & Requisições (\%) & $\begin{array}{c}\text { Bytes } \\
\text { transferidos (\%) }\end{array}$ \\
\hline \hline 200 & 80,52 & 97,86 \\
\hline \hline 206 & 0,09 & 2,08 \\
\hline \hline 304 & 18,75 & 0,00 \\
\hline \hline $4 \mathrm{xx}$ & 0,64 & 0,06 \\
\hline \hline $5 \mathrm{xx}$ & 0,00 & 0,00 \\
\hline \hline Outros & 0,00 & 0,00 \\
\hline \hline
\end{tabular}

Oito categorias de objetos foram criadas para agrupar as diversas requisições do site da Copa do mundo. As Imagens representaram 88,16\% do total, transferindo um volume de $35,02 \%$. HTML contribui com 9,85\% dos pedidos, no entanto, a quantidade de bytes superaram as Imagens, com 38,60\%. Dinâmicos não atingiram $0,1 \%$ do total e a classe Compacto, apesar de corresponder 0,08\%, produziu um volume superior a $20 \%$. Isso revela o uso maior da capacidade de transferência da rede e acesso freqüente ao disco. A tabela 4.3 resume as informações coletadas de cada classe.

Tabela 4.3: Resumo dos objetos da Copa de 1998 (ARLITT; JIN, 1999).

\begin{tabular}{|c|c|c|}
\hline \hline Objetos & Requisições (\%) & $\begin{array}{c}\text { Bytes } \\
\text { transferidos (\%) }\end{array}$ \\
\hline \hline Imagem & 88,16 & 35,02 \\
\hline \hline HTML & 9,85 & 38,60 \\
\hline \hline Áudio & 0,02 & 0,10 \\
\hline \hline Vídeo & 0,00 & 0,82 \\
\hline \hline Compacto & 0,08 & 20,33 \\
\hline \hline Java & 0,82 & 0,83 \\
\hline \hline Dinâmico & 0,02 & 0,38 \\
\hline \hline Outros & 1,05 & 3,92 \\
\hline \hline
\end{tabular}

Arlitt \& Jin (1999) também observaram o tamanho dos arquivos analisando somente requisições com o código de resposta 200. Seus resultados indicaram que, em sua grande maioria, os arquivos concentram-se entre 256 bytes a 1 Mbytes. Ao comparar os dados 
reais com as funções de distribuição de probabilidade, eles concluíram que uma Lognormal, com média 10,13 e desvio padrão 2,19, oferecerem valores aproximados. Para exemplificar o tamanho dos objetos, a figura 4.1 apresenta o gráfico de freqüência acumulada da função Lognormal com os parâmetros sugeridos.

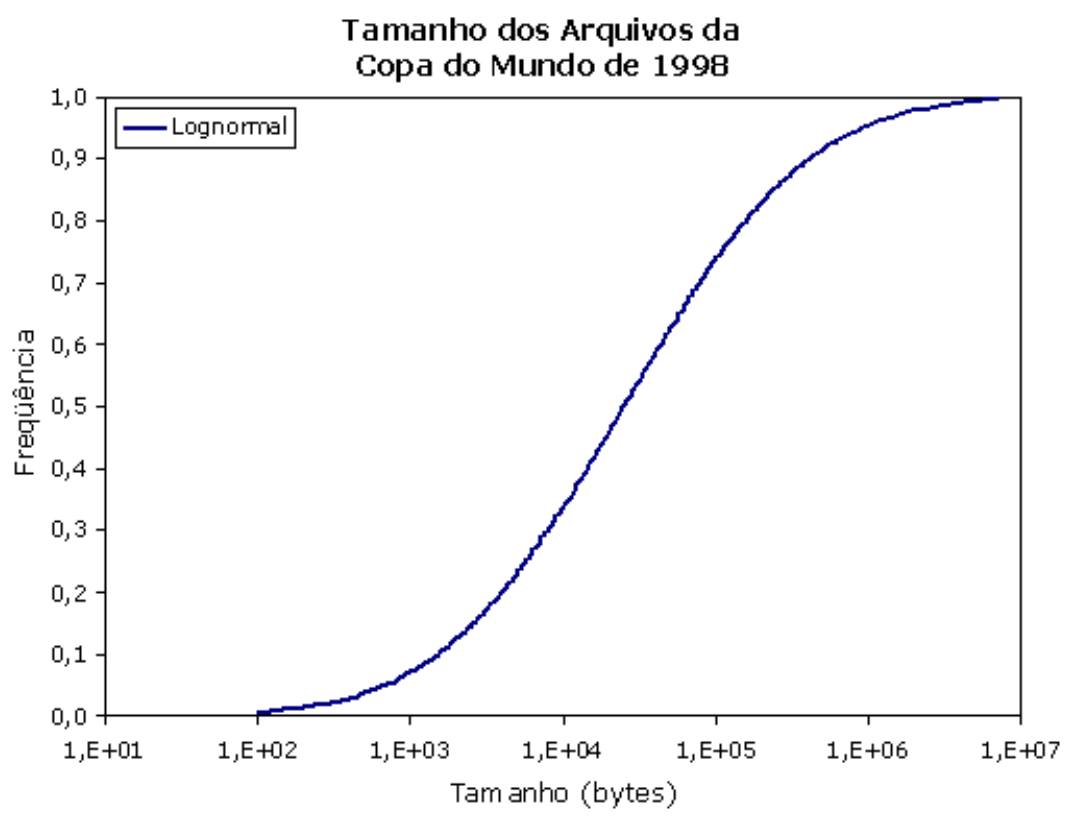

Figura 4.1: Modelo matemático para o tamanho dos objetos da Copa do mundo de 1998.

\subsubsection{Outros Trabalhos}

Weber \& Hariharan (2003) estudaram um log de 16 dias, coletado em 2001. Eles observaram a presença de $68,22 \%$ das requisições para a classe $2 \mathrm{xx}, 31,55 \%$ para $3 \mathrm{xx}$ e $0,22 \%$ para 4xx. Já a classe 5xx não obteve requisições, confirmando uma alta disponibilidade do servidor. Pinheiro (2001) também utilizou cargas de trabalho de 2001 e obteve dados similares. A grande maioria dos pedidos está localizada na classe 2xx e 3xx. A novidade é a existência de requisições com códigos de respostas 5xx, superando até mesmo os erros do cliente (classe 4xx). Isso pode representar uma pequena sobrecarga no servidor Web.

Weber \& Hariharan (2003) analisaram um log de uma instituição bancária, com 13,5 milhões de requisições durante todo o período de coleta. Os resultados mostraram que $30 \%$ são referências para objetos Dinâmicos. Esse valor elevado corresponde a diferentes opções disponíveis no Web site da instituição. A proporção maior, contudo, foi para requisições de Imagens, representado $60 \%$ dos pedidos. Em Pinheiro (2001), Imagem e Dinâmico corresponderam a 64,21\% e 16,23\%, respectivamente. O restante dos pedidos inclui Binários, Áudio, Vídeo, e Outros objetos encontrados na Web. 
Sites de e-commerce tem uma significante presença atualmente na Internet. As empresas, para melhorar o atendimento dos clientes, exigem sempre mais desempenho dos servidores. Para prover qualidade de serviço, Wang et al. (2003) realizaram uma caracterização específica da carga de trabalho desses sites. Os dados do estudo foram coletados de dois servidores, usados para armazenar uma empresa de aluguel de carros, em 2001. $\mathrm{Na}$ análise, eles observaram uma presença elevada de requisições para objetos Imagem, obtendo um total de 88,11\%. Em segundo lugar estão os Dinâmicos, com 7,11\%. A tabela 4.4 resume os dados coletados em Wang et al. (2003). Observe, nesse caso, que objetos HTML representaram menos de $1,5 \%$ dos pedidos ao servidor $W e b$.

Tabela 4.4: Resumo dos objetos do trace de e-commerce (WANG et al., 2003).

\begin{tabular}{|c|c|c|}
\hline \hline Objeto & $\begin{array}{c}\text { Requisições } \\
\text { (\%) }\end{array}$ & $\begin{array}{c}\text { Bytes } \\
\text { transferidos (\%) }\end{array}$ \\
\hline \hline Imagem & 88,11 & 46,36 \\
\hline \hline Asp & 7,11 & 37,19 \\
\hline \hline HTML & 1,14 & 3,32 \\
\hline \hline Js & 1,00 & 11,16 \\
\hline \hline Css & 2,08 & 1,61 \\
\hline \hline Outros & 0,56 & 0,36 \\
\hline \hline
\end{tabular}

Os trabalhos citados anteriormente consideraram uma quantidade limitada de $W e b$ sites, analisando alguns logs. No entanto, Bent et al. (2004) publicaram um estudo caracterizando a carga de trabalho de uma Rede de Entrega de Conteúdos $\left(\mathrm{CDN}^{2}\right)$. O trace analisado consiste de 21 horas de requisições e respostas HTTP de um grande provedor de serviços comercias, de julho de 2003. Bent et al. (2004) mostram que requisições com o código de resposta 200 totalizam 64\%, enquanto 304 obteve 29\%. Erros no servidor, classe 5xx, apareceram com uma porcentagem pequena, 0,4\%. Os objetos Imagem e Dinâmico representam $77 \%$ e 8,6\% respectivamente. Observa-se que não houve um crescimento dos objetos Dinâmicos em relação aos estudos de Wang et al. (2003), porém ele superou muito outros, tais como, Arlitt \& Williamson (1996) e Arlitt \& Jin (2000).

\subsubsection{Evolução da $W e b$}

Os gráficos da figura 4.2 apresentam a evolução dos códigos de respostas e dos tipos de objetos da carga de trabalho da Web, considerando os dados dos traces de servidores HTTP coletados da literatura. Observa-se no gráfico 4.2(a) uma queda substancial na quantidade de requisições atendidas com sucesso de 88\%, em 1995 para 64,1\%, em 2003.

\footnotetext{
${ }^{2}$ Repositório contendo um grande número de sites comerciais e pessoais.
} 
Em Modesto et al. (2005), contudo, ao avaliar a Web brasileira através de ferramentas de busca de sites, o número cresceu para $86,45 \%$, mostrando que a $W e b$ se preocupa com a consistência dos links, entretanto não representa o comportamento real dos usuários. Já os códigos de respostas 3xx cresceram de 9,14\% em 1995 para 31,6\%, em 2003. Isso mostra a presença maior de cache entre o cliente e o servidor Web. A classe 4xx oscilou durante a última década, mas não obteve variações significantes. Em 1995, as requisições do tipo 5xx não foram constatadas e, em 2003, ela já representa um percentual de quase 0,5\%. Alguns dos motivos desse tipo de erro pode ser a presença de uma sobrecarga no servidor $W e b$.

Na figura 4.2(b) também são apresentados os dados coletados baseado nas classes de objetos mais comuns: HTML, Imagem, Dinâmico e Outros. O gráfico mostra um crescimento dos pedidos referenciando objetos Dinâmicos de 1,80\%, em 1995, para 8,60\% em 2003. As requisições HTML, no entanto, sofreram uma queda ao logo do tempo, passando de 40,50\% para 5,20\%. Observa-se, em 2001, que o número de requisições HTML foi muito inferior. Isso mostra que sites de e-commerce (WANG et al., 2003), possui a tendência de não referenciar HTML. Já as Imagens cresceram ao longo dos anos, com algumas oscilações nesse intervalo. Os Outros objetos também alcançaram uma porcentagem maior desde 1995 , de apenas $3,28 \%$ para $9,20 \%$, em 2003, superando HTML e Dinâmico.

Conforme discutido, a avaliação da carga da Web encontrada na literatura apresenta dados coletados de 1995 até 2003. Surgiu, assim, a necessidade de complementar esse estudo com dados mais atuais. Nas próximas seções deste capítulo serão apresentados a análise dos traces. O primeiro passo refere-se a discussão do formato dos dados utilizados para determinar o comportamento da $W e b$, como também o seu processo de redução.

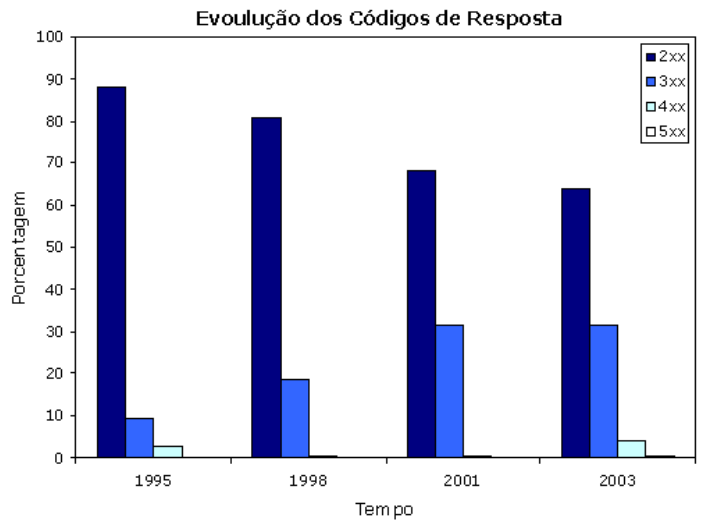

(a)

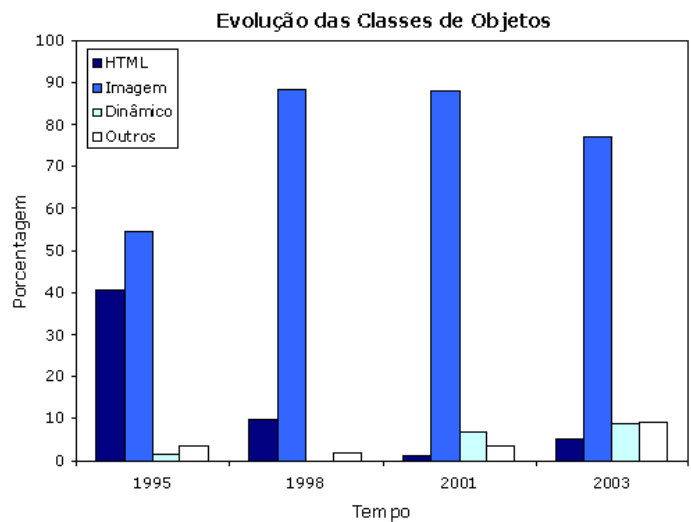

(b)

Figura 4.2: Evolução da carga de trabalho dos servidores $W e b$. 


\subsection{Coleção de Dados}

Esta seção apresenta uma visão geral sobre o formato padrão dos traces de servidores Web Apache e, um resumo dos nove logs utilizados no desenvolvimento da pesquisa para caracterizar a carga de trabalho da Web. Além disso, descreve-se o processo de redução executado nos dados originais para eliminar as requisições inválidas.

\subsubsection{Formato do $\log$ Apache}

Os sistemas de serviço da Web, tais como, o Apache e o IIS usam técnicas para reter informações do seu comportamento, visando garantir a eficiência e obter retorno das informações sobre a atividade, desempenho e problemas que, eventualmente, possam surgir. Os logs, arquivos em formato textual, permitem ao administrador ter um documento informando todo o tipo de ocorrência observado no sistema. Assim, é possível verificar erros, tentativa de acesso a locais restritos, sobrecarga do sistema, entre outros.

A cada interação do usuário com o servidor Web informações à respeito do processo de atendimento das requisições são gravados no log. Dentre os diversos tipos de servidores $W e b$, esse trabalho concentra-se os esforços na análise de traces de servidores Apache devido a alta disponibilidade de suas informações na Web. Segundo Netcraft (2006), os servidores Apaches, atualmente, possuem uma alta demanda, com 68,70\% comparada às outras aplicações e, logo, os logs são obtidos mais facilmente.

O servidor Apache trabalha, basicamente, com dois formatos de arquivos, o Error Log e o Access Log $^{3}$ (APACHE, 2005). O Error Log grava qualquer erro ou anomalia encontrada na aplicação. Um exemplo de mensagem típica gravada no arquivo é apresentado abaixo.

[Wed Dec 25 14:30:54 2002] [error] [client 143.107.232.205] client denied by server

configuration: /home/htdocs/teste

O primeiro item da linha informa a data e o tempo de chegada. O segundo campo, [error], mostra o tipo de erro reportado, dentro do conjunto de erros especificados na diretiva LogLevel. O terceiro elemento, também entre colchetes, [client 143.107.232.205], informa o endereço IP do cliente que acessou o servidor Web. No exemplo, além desses campos, uma mensagem relatando a negação de serviço é gravada no log juntamente com a localização do diretório ou arquivo não acessado.

\footnotetext{
${ }^{3}$ Os nomes dos arquivos podem ser modificados através de uma diretiva do arquivo de configuração do Apache.
} 
O outro arquivo utilizado pelo Apache, o Access Log, armazena as informações de todos os pedidos do servidor, ou seja, identifica todas as requisições atendidas e com erros, incluindo as requisições gravadas no Error Log. Esse arquivo pode armazenar informações básicas, no formato comum ${ }^{4}$ ou completo ${ }^{5}$. Na versão completa, além das informações básicas, o tipo de navegador do cliente e o sistema operacional são gravados. A seguir um exemplo de uma requisição do servidor Apache, no formato comum:

143.107.232.222 - - [02/May/2005:11:45:16 +0200] "GET /objeto.html HTTP/1.1" 20013573

O primeiro elemento da linha identifica o endereço IP do cliente que gerou a requisição. O segundo e o terceiro campo informam, respectivamente, o identd e o userid das máquinas clientes. Nesse caso, nenhum dado foi gravado, representado por um hífen. Esses campos não são muito utilizados, pois de todos os logs estudados, nenhum contêm essas informações. Segundo Apache (2005), o identd não é confiável e deve ser considerado somente em redes internas, onde o controle de usuário é mais preciso. O userid informa à pessoa que requisitou a página da $W e b$, por meio da autenticação HTTP, adequado para identificar sessões dos clientes.

A data e o tempo de chegada também são gravados no log. Na requisição anterior, os campos entre colchetes [02/May/2005:11:45:16 +0200] representam, respectivamente, a data e a hora da chegada da requisição. O símbolo +0200 ao final determina a zona (região) do cliente, baseado no GMT.

Após os colchetes, entre aspas, estão algumas das principais informações utilizadas para caracterizar a carga de trabalho da $W e b$. O primeiro elemento, representado sempre por letras maiúsculas, determina o método utilizado para pedir o documento. Separado por um espaço em branco, o caminho e o nome arquivo requisitado são gravados. Neste ponto, é possível definir o tipo de objeto pela extensão do nome do arquivo. A versão do protocolo utilizado para a comunicação aparece ao final. Por fim, o código de resposta da requisição HTTP e o tamanho do arquivo, em bytes, finalizam o conjunto de informações.

Para identificar o comportamento dos usuários da Internet utilizou-se os access logs, no formato comum. Eles possuem a maioria dos dados necessários para determinar e caracterizar a carga de trabalho. O log, no entanto, não fornece informações adicionais como o tempo gasto na transferência do arquivo, o tempo de processamento da requisição, ou mesmo o tempo gasto com acesso a disco no servidor, impossibilitando determinar quais recursos de máquina são mais utilizados para cada grupo de objetos.

\footnotetext{
${ }^{4}$ Common Log Format.

${ }^{5}$ Custom Log Format.
} 


\subsubsection{Informações Gerais dos Logs}

O conjunto de dados utilizados no estudo de caracterização do tráfego da Web é composto de logs de servidores Apache. O arquivo, em formato textual, contém dados descrevendo o comportamento do usuário diante da aplicação final, o servidor Web. Alguns deles, como do CISC $^{6}$ (Centro de Informática de São Carlos), da Prefeitura de Londrina ${ }^{7}$ e do $\operatorname{Br} 10^{8}$ foram obtidos por meio de intermediações com as pessoas responsavéis pela administração do servidor $W e b$ da instituição ou empresa. Os demais logs utilizados, tais como, Cdmil (2005), Tum (2005), Copi (2005), Stanford (2005), Veenet (2005) e Connectmed (2005) foram coletados na literatura, com alguns deles ainda disponivéis na $W e b$ para o download.

A tabela 4.5 apresenta as informações sobre os logs no seu estado inicial, sem nenhum pré-processamento das requisições inválidas. Como pode ser destacado, os logs possuem diferentes magnitudes, variando de apenas 760 mil requisições (CISC) para até 9 milhões de requisições (Connectmed) e transferindo de 3,4 GB (CISC) até 266 GB de dados (Stanford). Outro destaque é o estudo de dados mais recente, observado por meio das datas de início e término.

Tabela 4.5: Resumo das informações dos logs antes do pré-processamento.

\begin{tabular}{|c|c|c|c|c|c|}
\hline \multirow{2}{*}{ Identificação } & \multirow{2}{*}{ Sigla } & \multirow{2}{*}{$\begin{array}{c}\text { Número } \\
\text { de requisições }\end{array}$} & \multirow{2}{*}{$\begin{array}{c}\text { Dados } \\
\text { transferidos (GB) }\end{array}$} & \multicolumn{2}{|c|}{ Data } \\
\hline & & & & Início & Término \\
\hline Cisc & Cis & 760.693 & 3,413 & $08 / 10 / 2002$ & $07 / 04 / 2003$ \\
\hline $\begin{array}{l}\text { Prefeitura } \\
\text { de Londrina }\end{array}$ & Pre & 907.374 & 9,366 & 03/10/2003 & $13 / 10 / 2003$ \\
\hline$\overline{\mathrm{Br} 10}$ & $\overline{\mathrm{Br}}$ & 1.800 .784 & 9,426 & 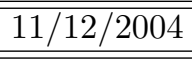 & $25 / 01 / 2005$ \\
\hline Cdmil & $\mathrm{Cdm}$ & 1.908 .109 & 19,315 & $22 / 01 / 2004$ & $07 / 04 / 2005$ \\
\hline Tum & Tum & 2.284 .935 & 92,254 & $02 / 09 / 2002$ & $29 / 03 / 2005$ \\
\hline Copi & Cop & 3.075 .420 & 28,651 & $16 / 08 / 2004$ & $15 / 03 / 2005$ \\
\hline Stanford & $\overline{\mathrm{Sta}}$ & 4.494 .456 & 266,708 & $02 / 10 / 2001$ & $29 / 03 / 2005$ \\
\hline Veenet & $\begin{array}{l}\text { Vee } \\
\end{array}$ & 5.598 .479 & 73,079 & $24 / 07 / 2001$ & $15 / 03 / 2005$ \\
\hline Connectmed & Con & 9.019 .607 & 29,597 & $01 / 01 / 2003$ & $28 / 02 / 2003$ \\
\hline
\end{tabular}

Os logs estão organizados em três categorias: Acadêmico, Notícia/Informativo e Tradicional. Um site Acadêmico possui registros de usuários, serviços de biblioteca por meio da geração de páginas dinâmicas ${ }^{9}$, áreas estáticas com informações da instituição, além das páginas pessoais de professores e alunos. Os sites Notícia/Informativo ${ }^{10}$ incluem

\footnotetext{
${ }^{6} \mathrm{http}: / /$ www.icmc.usp.br

${ }^{7}$ http://www.londrina.pr.gov.br

${ }^{8} \mathrm{http}: / /$ www.br10.com.br

${ }^{9}$ Pesquisas ao acervo da universidade.

${ }^{10}$ Web-publishing.
} 
informações periodicamente atualizadas, como a temperatura do dia, dados financeiros, notícias da região ou do mundo, uma área restrita aos usuários cadastrados, propagandas por meio de banners, download de arquivos, entre outras. Já um site Tradicional possui poucas atualizações e utiliza-se de muitos recursos estáticos. Nessa categoria inclui páginas pessoais e de empresas de pequeno porte cujo objetivo é simplesmente apresentar o seu perfil e os produtos aos clientes. A tabela 4.6 apresenta a classificação dos traces, com base no conteúdo do site. As próximas seções apresentam os resultados das análises de todos logs e de cada uma das categorias.

Tabela 4.6: Resumo da classificação dos traces.

\begin{tabular}{|c|c|c|c|}
\hline \hline \multirow{2}{*}{ Identificação } & \multirow{2}{*}{ Classificação } & \multicolumn{2}{|c|}{ Data } \\
\cline { 3 - 4 } & Anício & Término \\
\hline \hline Cisc & Acadêmico & $08 / 10 / 2002$ & $07 / 04 / 2003$ \\
\hline \hline $\begin{array}{c}\text { Prefeitura } \\
\text { de Londrina }\end{array}$ & Notícia/Informativo & $03 / 10 / 2003$ & $13 / 10 / 2003$ \\
\hline \hline Br10 & Notícia/Informativo & $11 / 12 / 2004$ & $25 / 01 / 2005$ \\
\hline \hline Cdmil & Notícia/Informativo & $22 / 01 / 2004$ & $07 / 04 / 2005$ \\
\hline \hline Tum & Acadêmico & $02 / 09 / 2002$ & $29 / 03 / 2005$ \\
\hline \hline Copi & Tradicional & $16 / 08 / 2004$ & $15 / 03 / 2005$ \\
\hline \hline Stanford & Acadêmico & $02 / 10 / 2001$ & $29 / 03 / 2005$ \\
\hline \hline Veenet & Tradicional & $24 / 07 / 2001$ & $15 / 03 / 2005$ \\
\hline \hline Connectmed & Notícia/Informativo & $01 / 01 / 2003$ & $28 / 02 / 2003$ \\
\hline \hline
\end{tabular}

\subsubsection{Redução dos Dados}

Os dados utilizados neste estudo compreendem nove logs de servidores Web Apache. $\mathrm{Na}$ análise todos os traces precisaram ser pré-processados, eliminando todas as requisições consideradas inválidas e ordenando-as em ordem cronológica de chegada. A ordenação foi necesária para montar adequadamente os histogramas de cada uma das características estudadas neste trabalho.

A redução dos dados consistiu na remoção requisições inválidas. Exemplos de requisição inválida são a ausência do método utilizado pelo cliente para pedir o documento armazenado no servidor, a falta da versão do protocolo usado na comunicação, a omissão do código de resposta retornado pelo servidor e requisições com o conteúdo fora do padrão Apache, como foi discutido na seção anterior.

A tabela 4.7 apresenta os dados após o pré-processamento das linhas irregulares. Observa-se que a quantidade de requisições eliminadas variou de apenas 0,002\% para o trace Br10, para até 3,467\% para o trace Cdmil. 
O número de requisições média por dia é outra importante propriedade, mostrando a diversidade dos logs analisados. Conforme apresentado na tabela 4.7, houve uma variação de apenas 2.368 requisições por dia, $\log$ do Tum (poucos acessos), para até 153 mil, do Connectmed (quantidade razoável de acessos). Isso explica o fato da Internet ser um ambiente dinâmico e inadequado caracterizá-lo em sua totalidade. A partir do pré-processamento dos dados, um estudo do comportamento das cargas de trabalho dos servidores $W e b$ foi realizado, a ser discutido nas próximas seções.

Tabela 4.7: Resumo das informações dos logs após o pré-processamento.

\begin{tabular}{|c|c|c|c|c|}
\hline \hline Identificação & $\begin{array}{c}\text { Número } \\
\text { de requisições }\end{array}$ & $\begin{array}{c}\text { Dados } \\
\text { transferidos (GB) }\end{array}$ & $\begin{array}{c}\text { Linhas } \\
\text { eliminadas (\%) }\end{array}$ & $\begin{array}{c}\text { Requisições } \\
\text { por dia }\end{array}$ \\
\hline \hline Cisc & 759.428 & 3,411 & 0,166 & 4.291 \\
\hline \hline $\begin{array}{c}\text { Prefeitura } \\
\text { de Londrina }\end{array}$ & 907.193 & 9,366 & 0,020 & 82.472 \\
\hline \hline Br10 & 1.800 .749 & 9,426 & 0,002 & 39.147 \\
\hline \hline Cdmil & 1.841 .959 & 19,288 & 3,467 & 4.186 \\
\hline \hline Tum & 2.209 .447 & 91,974 & 3,304 & 2.368 \\
\hline \hline Copi & 3.043 .700 & 11,744 & 1,031 & 14.425 \\
\hline \hline Stanford & 4.476 .428 & 266,597 & 0,401 & 3.587 \\
\hline \hline Veenet & 5.582 .774 & 72,910 & 0,281 & 4.239 \\
\hline \hline
\end{tabular}

\subsection{Caracterização da Carga de Trabalho}

Essa seção apresenta detalhes do estudo de caracterização da carga de trabalho de servidores Web Apache, coletados de nove logs de diferentes magnitudes, variando de poucas requisições por dia (log do Tum) a centenas de milhares de solicitações (log do Connectemed). Ao final de cada análise, funções de distribuição de probabilidade são propostas para representar a carga de trabalho e, assim, utilizá-los os resultados dos modelos matemáticos para implementar o W4Gen.

A seção 4.4.1 comenta algumas das características básicas coletadas na análise, como a versão do protocolo HTTP (HyperText Transfer Protocol) suportado pelos clientes Web e do método usado para requisitar um documento. As outras seções apresentam a análise do código de resposta, as classes de objetos, o intervalo de chegada e do tamanho dos objetos, informações essenciais utilizadas por diversos trabalhos para a avaliação de desempenho, tais como, Teixeira et al. (2003), Traldi et al. (2004), Barbato et al. (2005), Mourão (2005), Estrella (2006). 


\subsubsection{Características Gerais}

Como pode ser identificado na tabela 4.8, o HTTP/1.1 é, atualmente, a versão do protocolo mais utilizada, com 65,43\% das requisições dos clientes. Já a versão HTTP/1.0 contribui com o restante, 34,57\%. Observa-se que, no entanto, o trace Tum e Veenet possuem valores invertidos, ou seja, o protocolo mais utilizado em ambos é ainda o HTTP/1.0. As datas comprovam a presença de requisições no período de 2001 e 2002, quando, provavelmente, o número de usuários utilizando navegadores desatualizados era maior. Para os outros logs mais recentes, o uso do protocolo HTTP/1.1 supera o HTTP/1.0, garantindo uma média de utilização superior. Requisições utilizando o protocolo HTTP/0.9 não foram encontradas.

A figura 4.3 compara os resultados obtidos com a análise da carga de trabalho da copa do Mundo de 1998 (ARLITT; JIN, 2000) e com os resultados deste trabalho. Observa-se uma troca da utilização das versões dos protocolos ao longo dos últimos anos, com a presença marcante do HTTP/1.1.

Tabela 4.8: Resumo das versões do protocolo HTTP.

\begin{tabular}{|c|c|c|}
\hline \hline Identificação & HTTP/1.0 (\%) & HTTP/1.1 (\%) \\
\hline \hline Cisc & 22,97 & 77,03 \\
\hline \hline $\begin{array}{c}\text { Prefeitura } \\
\text { de Londrina }\end{array}$ & 27,97 & 72,03 \\
\hline \hline Br10 & 19,97 & 80,03 \\
\hline \hline Cdmil & 18,35 & 81,65 \\
\hline \hline Tum & 69,30 & 30,70 \\
\hline \hline Copi & 18,16 & 81,84 \\
\hline \hline Stanford & 34,54 & 65,46 \\
\hline \hline Veenet & 74,04 & 25,96 \\
\hline \hline Connectmed & 25,83 & 74,17 \\
\hline \hline Média & $\mathbf{3 4 , 5 7}$ & $\mathbf{6 5 , 4 3}$ \\
\hline \hline Mediana & $\mathbf{2 5 , 8 3}$ & $\mathbf{7 4 , 1 7}$ \\
\hline \hline Desvio Padrão & $\mathbf{2 1 , 6 9}$ & $\mathbf{2 1 , 6 9}$ \\
\hline \hline
\end{tabular}

Com os recursos otimizados do protocolo HTTP/1.1, como os novos comandos avançados de cache, os usuários de navegadores mais recente se beneficiam com a utilização de servidores proxy. Essa característica ajuda a explicar o crescimento, nos últimos anos do código de respostas da classe 3xx.

A análise também comparou os métodos utilizados. Na tabela 4.9 são mostrados os resultados obtidos de cada trace. Observa-se que, na média, 98,02\% das requisições utilizam o método GET, indicando a recuperação de uma URL (documento) pelo usuário. In- 
cluído nesta categoria, existem os métodos GET condicional, requisições com o cabeçalho If-Modified-Since, e o GET parcial, com o cabeçalho Range. Infelizmente não é possível, somente com as informações dos logs, determinar o número de GET específico para cada item, o que ajudaria na análise do impacto dos clientes e proxy na carga de trabalho do servidor. Os outros 1,98\% das requisições estão distribuídos entre os métodos POST, OPTIONS e HEAD.

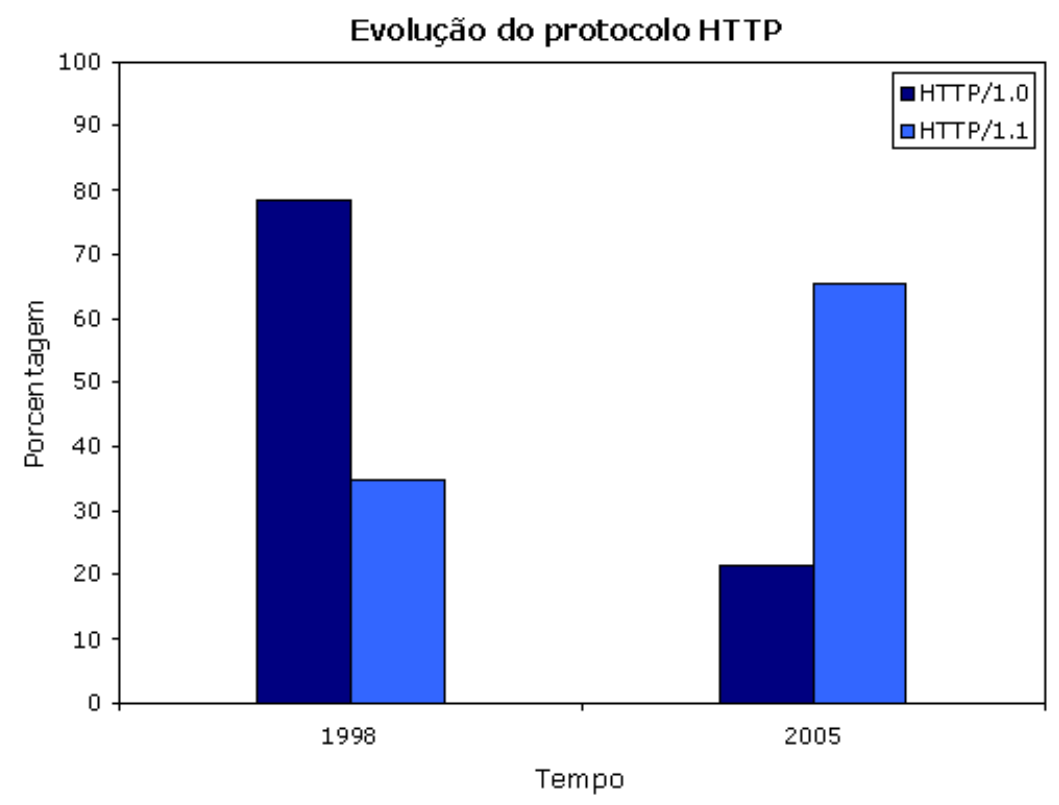

Figura 4.3: Comparação das versões do protocolo HTTP nos últimos anos.

Os clientes utilizam o método POST para enviar dados ao servidor através da URL. Na tabela 4.9, observa-se que $0,43 \%$ das requisições são do tipo POST. Todos os logs, no entanto, contribuíram com uma porcentagem, mesmo pequena, para obtenção dessa média, com destaque para o $\log$ da Prefeitura de Londrina, com 2,32\%. O mesmo não ocorre com o método HEAD. A média de 1,52\% é influenciada pelo trace Cdmil, cujo valor corresponde a 10,78\% do seu total. O método OPTIONS aparece com uma porcentagem pequena das requisições, ficando com apenas 0,02\%. Outros métodos, tais como, PUT e CONNECT ocorreram com um percentual muito inferior e seus valores foram desconsiderados.

Esses resultados, portanto, evidenciaram que, apesar da $W e b$ ter evoluído em muitos aspectos, ela ainda é utilizada para o download de informações, como destaca os trabalhos anteriores de Arlitt \& Williamson (1996), Arlitt \& Jin (2000), Pinheiro (2001). Cabe ressaltar, entretanto, que tais logs não apresentam características de e-commerce, o que provavelmente modificaria o comportamento dos valores. 
Tabela 4.9: Resumo dos métodos mais utilizado pelo protocolo HTTP.

\begin{tabular}{|c|c|c|c|c|}
\hline \hline Identificação & GET & POST & OPTIONS & HEAD \\
\hline \hline Cisc & 99,77 & 0,08 & 0,08 & 0,06 \\
\hline \hline $\begin{array}{c}\text { Prefeitura } \\
\text { de Londrina }\end{array}$ & 97,65 & 2,32 & 0,02 & 0,01 \\
\hline \hline Br10 & 99,94 & 0,06 & 0,00 & 0,00 \\
\hline \hline Cdmil & 89,06 & 0,16 & 0,00 & 10,78 \\
\hline \hline Tum & 98,72 & 0,09 & 0,01 & 1,16 \\
\hline \hline Copi & 99,34 & 0,02 & 0,01 & 0,62 \\
\hline \hline Stanford & 99,41 & 0,05 & 0,07 & 0,45 \\
\hline \hline Veenet & 99,38 & 0,05 & 0,01 & 0,56 \\
\hline \hline Connectmed & 98,93 & 1,04 & 0,01 & 0,02 \\
\hline \hline Média & $\mathbf{9 8 , 0 2}$ & $\mathbf{0 , 4 3}$ & $\mathbf{0 , 0 2}$ & $\mathbf{1 , 5 2}$ \\
\hline \hline Mediana & $\mathbf{9 9 , 3 4}$ & $\mathbf{0 , 0 8}$ & $\mathbf{0 , 0 1}$ & $\mathbf{0 , 4 5}$ \\
\hline \hline Desvio Padrão & $\mathbf{3 , 4 3}$ & $\mathbf{0 , 7 8}$ & $\mathbf{0 , 3 0}$ & $\mathbf{3 , 5 0}$ \\
\hline \hline
\end{tabular}

\subsubsection{Código de Resposta}

O próximo passo da análise apresenta a média dos códigos de respostas dos logs de acesso de servidores $W e b$. Observa-se a presença de quatro classes, conforme mostra a tabela 4.10. A classe 2xx, representada por alguns autores como Successful, indica a presença de um objeto válido no servidor, ou seja, a requisição foi recebida corretamente, compreendida e aceita. A classe 3xx representa a necessidade de realizar um redirecionamento para completar o pedido. Essas ações podem ser realizadas pelos agentes usuários (browsers) sem a necessidade de interação do usuário (homem). Já a classe 4xx informa a presença de erros na requisição do cliente como, por exemplo, a tentativa de acesso a regiões inexistentes no servidor, enquanto a 5xx a incapacidade do servidor de processar a requisição. Isso pode ser conseqüência, por exemplo, da falta de um suporte a um novo recurso (o servidor não reconhece o método usando pelo browser) ou de uma sobrecarga do servidor $W e b$.

Tabela 4.10: Resumo dos códigos de respostas do protocolo HTTP.

\begin{tabular}{|c|c|c|c|}
\hline \hline $\begin{array}{c}\text { Código } \\
\text { de Resposta }\end{array}$ & Média (\%) & Mediana & $\begin{array}{c}\text { Desvio } \\
\text { Padrão }\end{array}$ \\
\hline \hline $2 \mathrm{xx}$ & 64,96 & 62,08 & 8,52 \\
\hline \hline $3 \mathrm{xx}$ & 25,79 & 22,88 & 11,46 \\
\hline \hline $4 \mathrm{xx}$ & 9,23 & 4,32 & 10,53 \\
\hline \hline $5 \mathrm{xx}$ & 0,01 & 0,00 & 0,01 \\
\hline \hline
\end{tabular}

Conforme apresentado na tabela 4.10, o número de requisições médias bem sucedidas é superior a todas as outras classe com, aproximadamente, 65\%. A classe 3xx representa 
$25,79 \%$, indicando a necessidade de realizar novas ações para completar o pedido. Isso inclui os códigos de respostas 302 (Found), uso temporário de uma URL diferente e 304 (Not Modified), solicitação de um objeto não modificado desde o tempo especificado no campo if-Modified-Since.

Com base nos dados discutidos anteriormente, este trabalho também propõe-se uma função de distribuição de probabilidade representando, de forma adequada, os resultados obtidos. A figura 4.4 mostra a média das requisições por classe de código de resposta e a distribuição geométrica, com parâmetro igual a 0,61.

A distribuição Geométrica foi obtida por meio de sucessivos testes com algumas distribuições, a fim de buscar a melhor opção para representar essa característica. A função de distribuição é utilizada pelo W4Gen para reproduzir o comportamento da Web, gerando cargas de trabalho sintéticas para avaliação de desempenho, como será explicado no próximo capítulo.

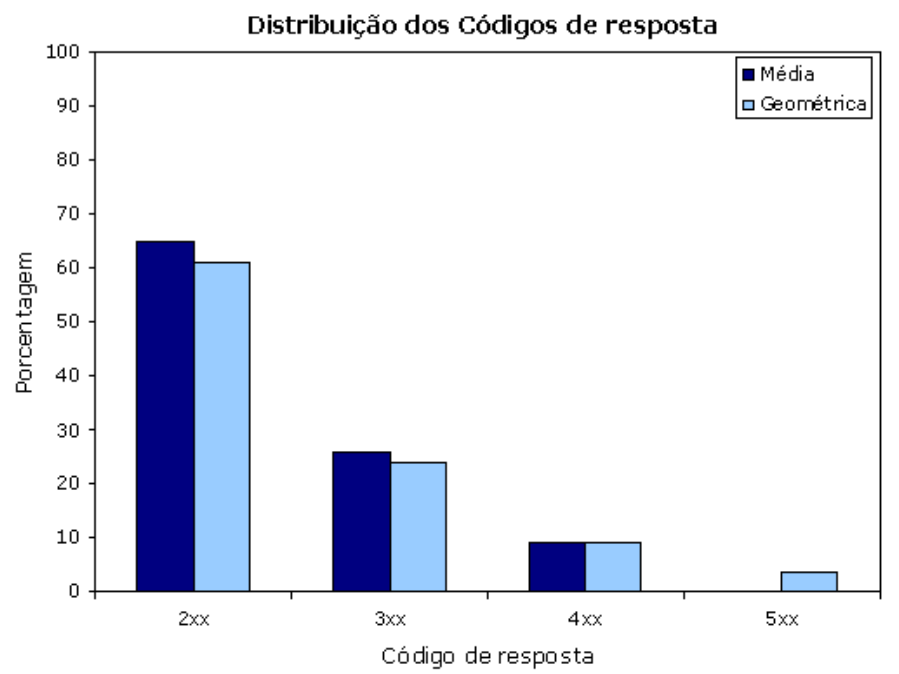

Figura 4.4: Modelo de distribuição Geométrico para os códigos de resposta.

\subsubsection{Classe de Objeto}

A popularidade da World Wide Web e o desenvolvimento de aplicações têm aumentado nos últimos anos (KUROSE; ROSS, 2006). Esse fenômeno motivado por muitas pesquisas na área, cujo objetivo é melhorar a qualidade da Web, inclui a criação de novas tecnologias e facilidades capazes de prender os usuários por horas em frente ao computador.

Devido a essa diversidade presente na Internet, a classe de objetos é um importante aspecto para caracterizar a carga de trabalho e, principalmente, avaliar o desempenho. 
Assim, para facilitar a compreensão e análise dos dados coletados, uma classificação segundo o tipo de objeto foi realizada, baseado na extensão do arquivo em cada requisição do servidor. A tabela 4.11 apresenta as classes e suas respectivas extensões.

Tabela 4.11: Classificação das extensões de arquivos.

\begin{tabular}{|c|c|c|}
\hline \hline $\begin{array}{c}\text { Classe } \\
\text { de Objetos }\end{array}$ & Sigla & Extensões \\
\hline \hline Imagem & img & $\begin{array}{c}\text { bdf, bmp, gif, ico, jpe, jpeg, } \\
\text { jpg, pbm, png, tif, tiff e xbm }\end{array}$ \\
\hline \hline $\begin{array}{c}\text { Linguagem } \\
\text { de Marcação }\end{array}$ & htm & htm, html shtml, wml, e xml \\
\hline \hline Dinâmico & din & asp, aspx, cfm, cgi, cgi-bin, jsp, php, php3 e pl \\
\hline \hline Texto & tex & $\begin{array}{c}\text { asc, bib, css, dat, idx, inf, } \\
\text { java, log, map, ram, smi, tex, txt }\end{array}$ \\
\hline \hline Documento & doc & $\begin{array}{c}\text { doc, dvi, eps, fdr, hfo, mso, pdf, pps } \\
\text { ppt, ps, pub, rtf, vsd, wbk, wpd, wri, xls }\end{array}$ \\
\hline \hline $\begin{array}{c}\text { Script Cliente } \\
\text { e Animação }\end{array}$ & src & class, dcr, js, swf e vbs \\
\hline \hline Áudio & aud & aif, asf, au, mid, mp3, mp4 e wav \\
\hline \hline $\begin{array}{c}\text { Binário e } \\
\text { Compactado }\end{array}$ & bin & $\begin{array}{c}\text { arj, bin, cab, cmd, db, dll, emz } \\
\text { exe, gz, jar, rpm, tar, tgz, wmf, wmz e zip }\end{array}$ \\
\hline \hline Vídeo & vid & avi, mov, mpe, mpg, mpeg e wmv \\
\hline \hline
\end{tabular}

Para melhorar a visibilidade dos gráficos apresentados nesse trabalho, as classes de objetos foram resumidas em siglas, evitando a poluição dos gráficos com textos. A tabela 4.11 mostra as siglas utilizadas nas figuras.

A figura 4.5(a) mostra os resultados obtidos durante a avaliação das classes de objetos. O gráfico mostra o aumento do número de requisições dinâmicas em relação a alguns trabalhos apresentado na seção 4.2. O tráfego, de quase de 15\%, apresenta-se próximo ao trabalho de Pinheiro (2001), utilizando logs de 2001. Esse aumento da última década ocorre, principalmente, em razão da popularização de scripts executado no lado servidor, como o PHP (Hypertext Preprocessor), JSP (JavaServer Pages) e ASP (Active Server Pages). O crescimento também permite identificar possíveis pontos de sobrecarga no servidor, tais como, o processador.

Os objetos da classe Linguagem de Marcação alcançaram 28\% do total das referências, transferindo, aproximadamente, $34 \%$ dos bytes. Sites de e-commerce, no entanto, possui uma demanda muito pequena para páginas estáticas (WANG et al., 2003). Outros tipos, como sites de conteúdo Acadêmico e Tradicional, ainda utilizam muito essa classe de objeto como mostra a próxima seção, caracterizando os logs por categoria.

Os objetos da classe Documento, Binário/Compactado, Áudio e Vídeo foram refe- 
renciados poucas vezes, como mostra o gráfico da figura 4.5(a). Todavia, o volume de transferência apresentou-se elevado, indicando que mesmo sendo requisitado poucas vezes esses objetos podem ser suficientes para produzir sobrecargas na rede e no servidor, principalmente a classe Documento, na qual o volume foi superior a $11 \%$.

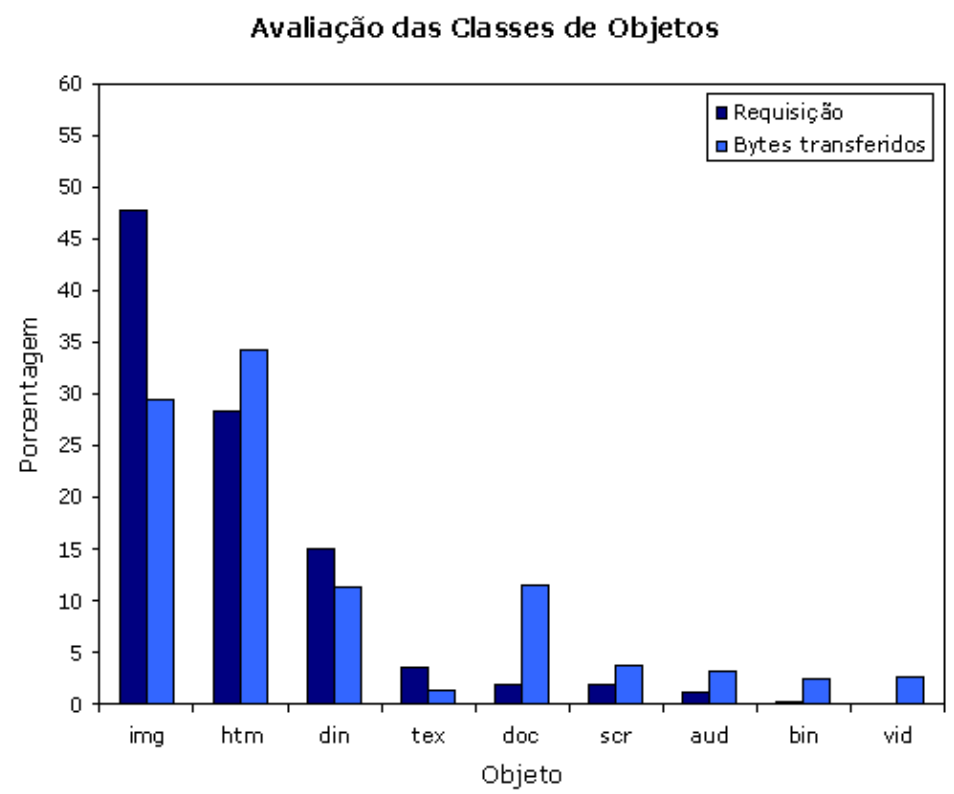

(a)

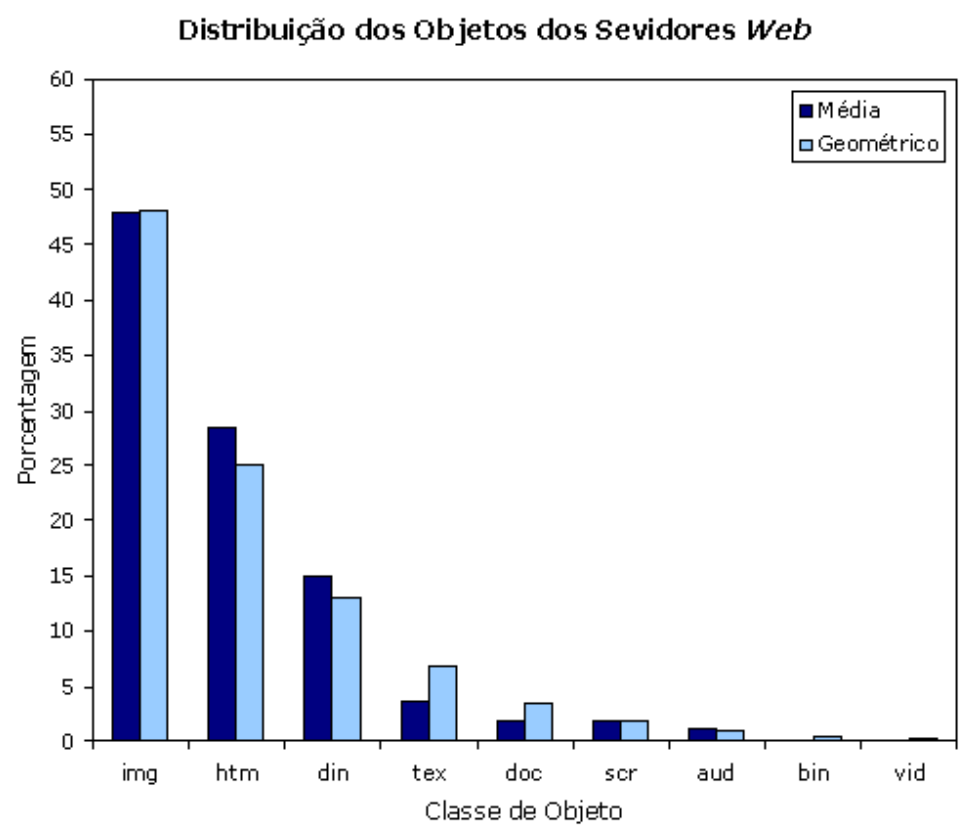

(b)

Figura 4.5: Análise das classes de objetos dos traces de servidores Web.

Os Scripts Cliente/Animação são objetos executados na máquina cliente, ou seja, no browser do usuário. Analisando essa classe, observa-se que o número de referências obteve 
resultados pequenos, 1,84\% das requisições e correspondeu a 3,69\% dos bytes transferidos. Em Pinheiro (2001), esses resultados também foram parecidos. Já as Imagens representam a maioria das requisições, com 47,88\% das referências, mas o volume de dados é relativamente pequeno se comparado à classe Linguagem de Marcação. A classe Texto obteve poucas referências, $3,6 \%$ e a quantidade de bytes não superou $1,5 \%$.

Com base na análise dos dados apresentados, propõe-se um modelo de distribuição de probabilidade representando, de forma mais adequada, os resultados obtidos. A figura 4.5(b) mostra a média das requisições por classe de objetos e o modelo Geométrico, com parâmetro igual a 0,48. A função de distribuição está implementada no W4Gen, permitindo a ele gerar cargas de trabalho sintéticas para avaliação de desempenho de servidores $W e b$.

\subsubsection{Intervalo de Chegada}

A diferença de tempo entre duas requisições consecutivas feitas ao servidor determinase intervalo de chegada. A próxima etapa da análise verificou essa variação de tempo, baseando-se na classificação dos objetos apresentadas na tabela 4.11. As figuras 4.6, 4.7 e 4.8 exibem os gráficos de freqüência acumulada dos resultados obtidos para cada uma das classes analisadas, identificando os intervalos de tempo encontrados entre duas requisições do mesmo tipo. Em Newman (2003), apresenta-se explicações do uso das funções de distribuições de probabilidade na forma acumulada para minimizar os problemas de cauda pesada (heavy-tail).

$\mathrm{Na}$ análise dos gráficos, observa-se que mais de $90 \%$ das requisições para objetos Imagem possuem intervalos de tempos entre referências da mesma classe igual ou menor a $10^{2}$ segundos, isto é, o intervalo entre dois pedidos não excede esse limite de tempo. As Imagens é a categoria que possui o maior número de requisições, como destaca a seção 4.4.3. Do total, $80 \%$ concentram-se em tempo menores que 10 segundos e pedidos com intervalos iguais a 0 e 1 representam quase $70 \%$. Em projetos de cache, essa característica é importante para aumentar o desempenho do sistema, mostrando que as imagens talvez sejam objetos adequados para ocupar o seu espaço. O tempo máximo encontrado entre dois pedidos não excede $10^{4}$ segundos.

A Linguagem de Marcação, diferente das Imagens, possui uma concentração menor de referências entre os $10^{2}$ primeiros segundos com, aproximadamente, $80 \%$ dos pedidos e $20 \%$ com intervalos iguais a zero e 1 segundo. Os intervalos de tempo máximo não excedem os $10^{3}$ segundos, uma alta concentração comparada às outras classes. 
A classe Texto, que inclui arquivos que definem o estilo das páginas Web, é pouco referenciada como destacou-se anteriormente. Com características parecidas a classe de objetos Linguagem de Marcação, os intervalos de tempos estão distribuídos entre os $10^{4}$ segundos, com aproximadamente $50 \%$ das requisições entre intervalos menores que $10^{2}$ segundos e pouco mais de $20 \%$ com intervalos iguais a zero e 1 .

As outras classes possuem intervalos de tempos superiores ao encontrado nas classes Imagem, Linguagem de Marcação e Texto. Observa-se que, nas figuras 4.6 e 4.8, o intervalo máximo entre dois pedidos variam de quase 200 mil segundos, para o Dinâmico a 3 milhões de segundos para os objetos Áudio. Esse intervalo de tempo extenso mostra que os logs analisados, em média, não possuem uma característica para sobrecarregar o servidor Web, como o log da copa do mundo de 1998.

Os objetos Documento, Binário/Compactado, Áudio e Vídeo, em geral, são arquivos extensos e podem causar maior tráfego na rede e no disco dos servidores Web. Portanto, requisições com tempos de chegada iguais a zero e 1 segundo correspondem a 18,5\%, $26,8 \%, 24,1 \%$ e $17,1 \%$ respectivamente.

A classe Dinâmico são scripts executados no lado dos servidores $W e b$, exigindo mais dos processadores. Com $40 \%$ das requisições em intervalos entre zero e 1 segundo e $58 \%$ com, no máximo, 10 segundos essa classe requer uma atenção especial, já que ela pode sobrecarregar o servidor se exigir muito processamento. Os Script Cliente/Animação concentram $46 \%$ dos pedidos entre intervalos de, no máximo, 10 segundos e pouco mais de $30 \%$ em intervalos iguais a 0 e 1 segundo.

A partir dos resultados coletados, o objetivo foi propor modelos matemáticos representando, de forma mais condizente, o intervalo de chegada das requisições. Nas figuras 4.6, 4.7 e 4.8 apresenta, não somente a média dos nove logs analisados separados por classes de objetos, mas também as respectivas funções de distribuição de probabilidade.

Os resultados mostram três funções de distribuição sugeridas para simular as nove classes de objetos, com parâmetros diferentes para cada categoria. O resumo das funções de distribuição utilizadas e seus respectivos parâmetros para cada classe é apresentado na tabela 4.12 . 

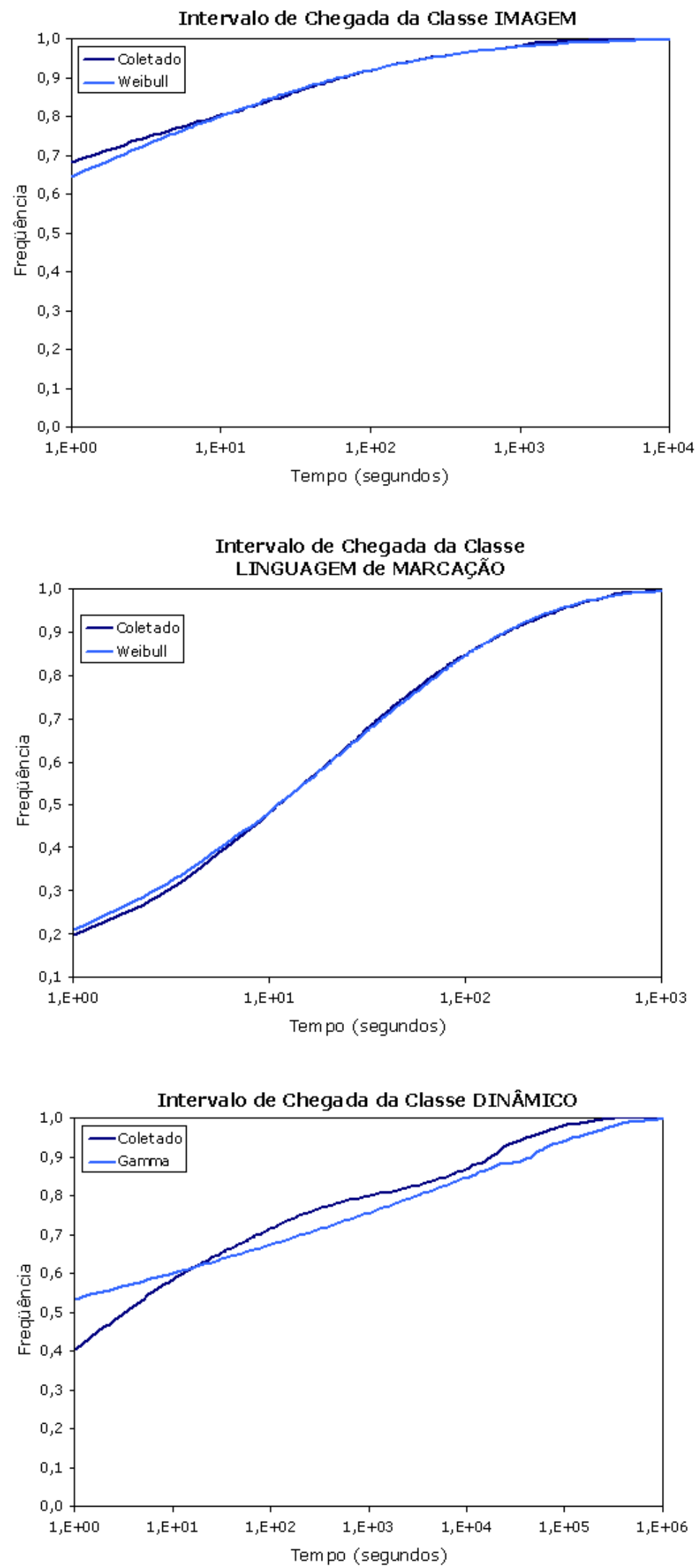

Figura 4.6: Intervalo de chegada médio dos objetos Imagem, HTML e Dinâmico. 

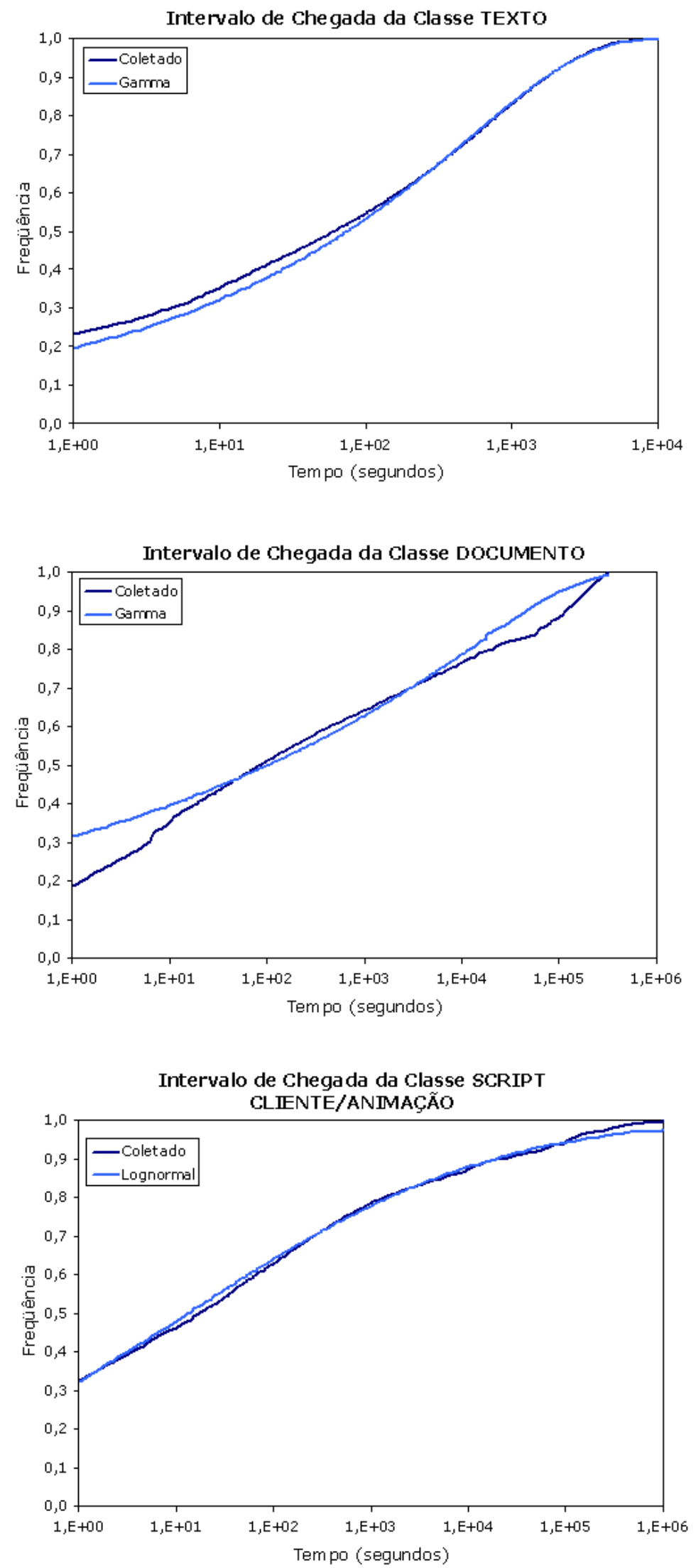

Figura 4.7: Intervalo de chegada médio dos objetos Texto, Documento e Script Cliente. 

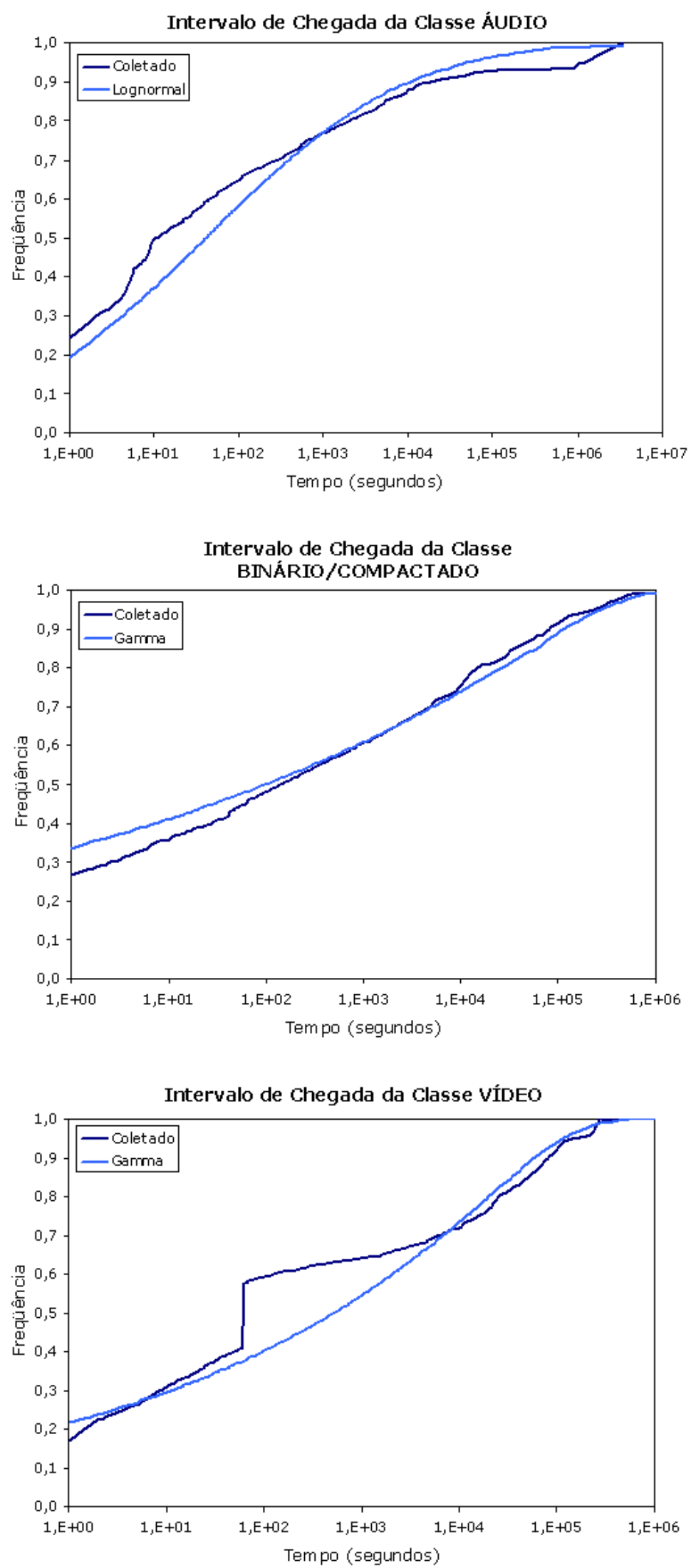

Figura 4.8: Intervalo de chegada médio dos objetos Áudio, Binário e Vídeo. 
Tabela 4.12: Modelos matemáticos para simular os intervalos de chegada.

\begin{tabular}{|c|c|cc|c|c|}
\hline \hline $\begin{array}{c}\text { Classe } \\
\text { de Objetos }\end{array}$ & $\begin{array}{c}\text { Função de } \\
\text { Distribuição }\end{array}$ & \multicolumn{2}{|c|}{ Parâmetros } & Média & $\begin{array}{c}\text { Desvio } \\
\text { Padrão }\end{array}$ \\
\hline \hline Imagem & Weibull & $\alpha: 0,19$ & $\beta: 0,81$ & 153 & 2.880 \\
\hline \hline $\begin{array}{c}\text { Linguagem } \\
\text { de Marcação }\end{array}$ & Weibull & $\alpha: 0,45$ & $\beta: 25,07$ & 62 & 162 \\
\hline \hline Dinâmico & Gamma & $\alpha: 0,05$ & $\theta: 470.354$ & 23.517 & 105.174 \\
\hline \hline Texto & Gamma & $\alpha: 0,22$ & $\theta: 2.610$ & 574 & 1.224 \\
\hline \hline Documento & Gamma & $\alpha: 0,10$ & $\theta: 173.958$ & 17.395 & 55.010 \\
\hline \hline $\begin{array}{c}\text { Scripts Cliente } \\
\text { e Animação }\end{array}$ & Lognormal & $\mu: 2,59$ & $\sigma: 5,66$ & $1,21 E+08$ & $1,09 E+15$ \\
\hline \hline Áudio & Lognormal & $\mu: 3,73$ & $\sigma: 4,32$ & $4,70 E+05$ & $5,31 E+09$ \\
\hline \hline $\begin{array}{c}\text { Binário e } \\
\text { Compactado }\end{array}$ & Gamma & $\alpha: 0,09$ & $\theta: 563.767$ & 50.739 & 169.130 \\
\hline \hline Vídeo & Gamma & $\alpha: 0,13$ & $\theta: 154.949$ & 20.143 & 55.867 \\
\hline \hline
\end{tabular}

\subsubsection{Tamanho do Objeto}

Uma carga de trabalho representativa da Web ajuda a julgar o desempenho de modelos através da simulação. Para compreendê-la a próxima etapa da análise discute os resultados obtidos para o tamanho dos arquivos avaliados por classes de objetos, conforme a divisão apresentada na seção 4.4.3.

As figuras 4.9, 4.10 e 4.11 mostram os gráficos em freqüência acumulada, separados por classe de objetos, dos diversos tamanhos de arquivos encontrados na Web. Observe que o eixo das abscissas está em escala logarítmica, permitindo visualizar melhor os dados e, determinar o segmento aonde se localizam a maioria das ocorrências.

A classe Imagem possui tamanhos de objetos pequenos como mostra o gráfico da figura 4.9. Observa-se que acima de $90 \%$ das requisições possuem objetos menores que $10^{5}$ bytes (98 Kbytes), e menos de $6 \%$ para tamanhos menores que 100 bytes. Os trabalhos de Arlitt \& Williamson (1997) e Pinheiro (2001) indicaram a concentração das referências próximos desses resultados, ou seja, o tamanho dos arquivos localizam-se entre 100 bytes a 100 Kbytes, com poucas referências para objetos menores que 100 bytes e maiores que 100 Kbytes. Isso confirma a influência da categoria Imagem no tamanho dos arquivos, quase sempre superior a todas as outras classes, como apresenta a figura 4.2(b).

Os objetos da categoria Linguagem de Marcação segue o comportamento das Imagens. A maioria dos objetos localiza-se no intervalo de 100 bytes a 98 Kbytes, e com menos de $10 \%$ das referências para tamanhos inferiores a 1 Kbytes (próximo de $10^{3}$ bytes). Arquivos com tamanho acima a 98 Kbytes não excede $2 \%$. 

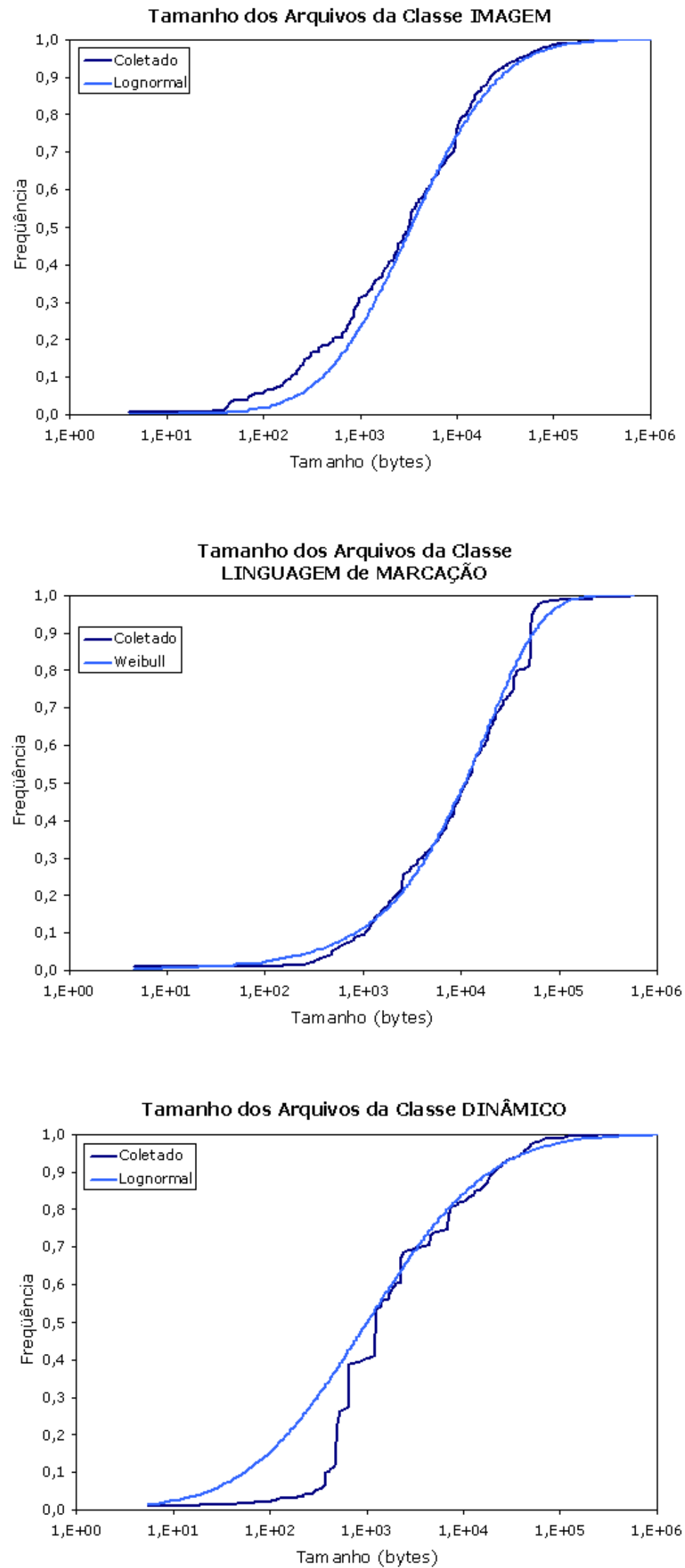

Figura 4.9: Tamanho médio dos objetos Imagem, HTML e Dinâmico. 

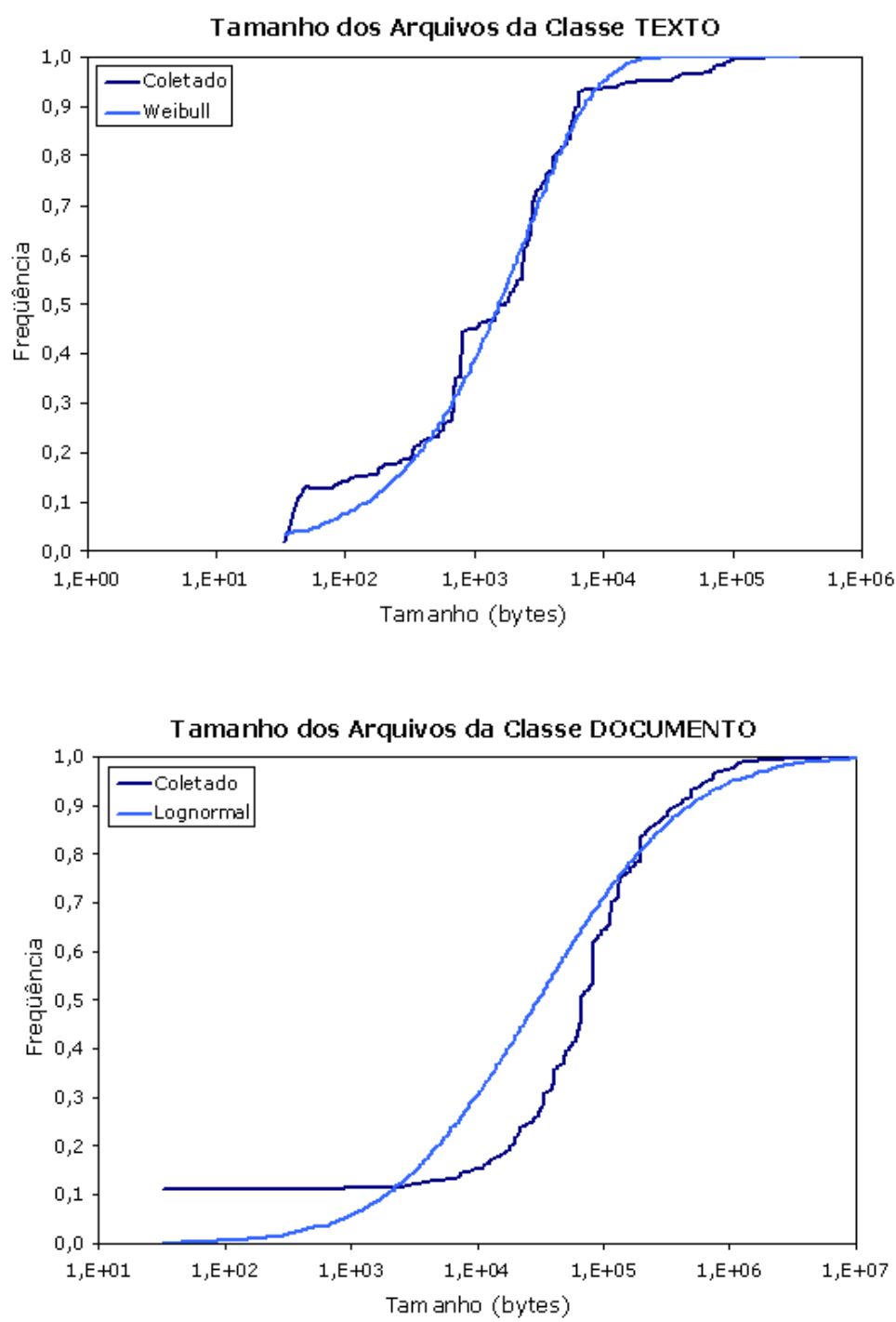

Tamanho dos Arquivos da Classe SCRIPT CLIENTE/ANIMAÇÃO

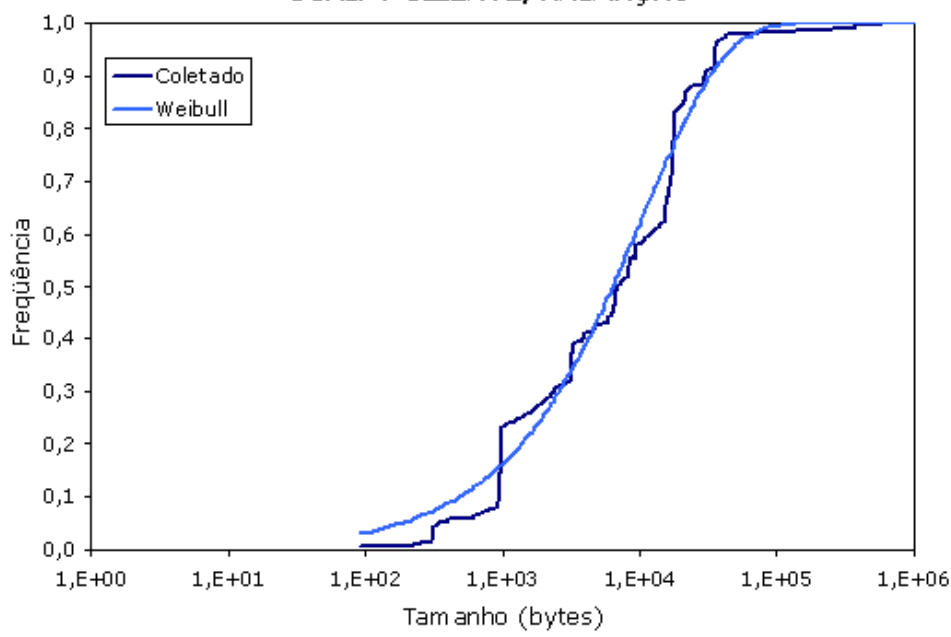

Figura 4.10: Tamanho médio dos objetos Texto, Documento e Script cliente. 

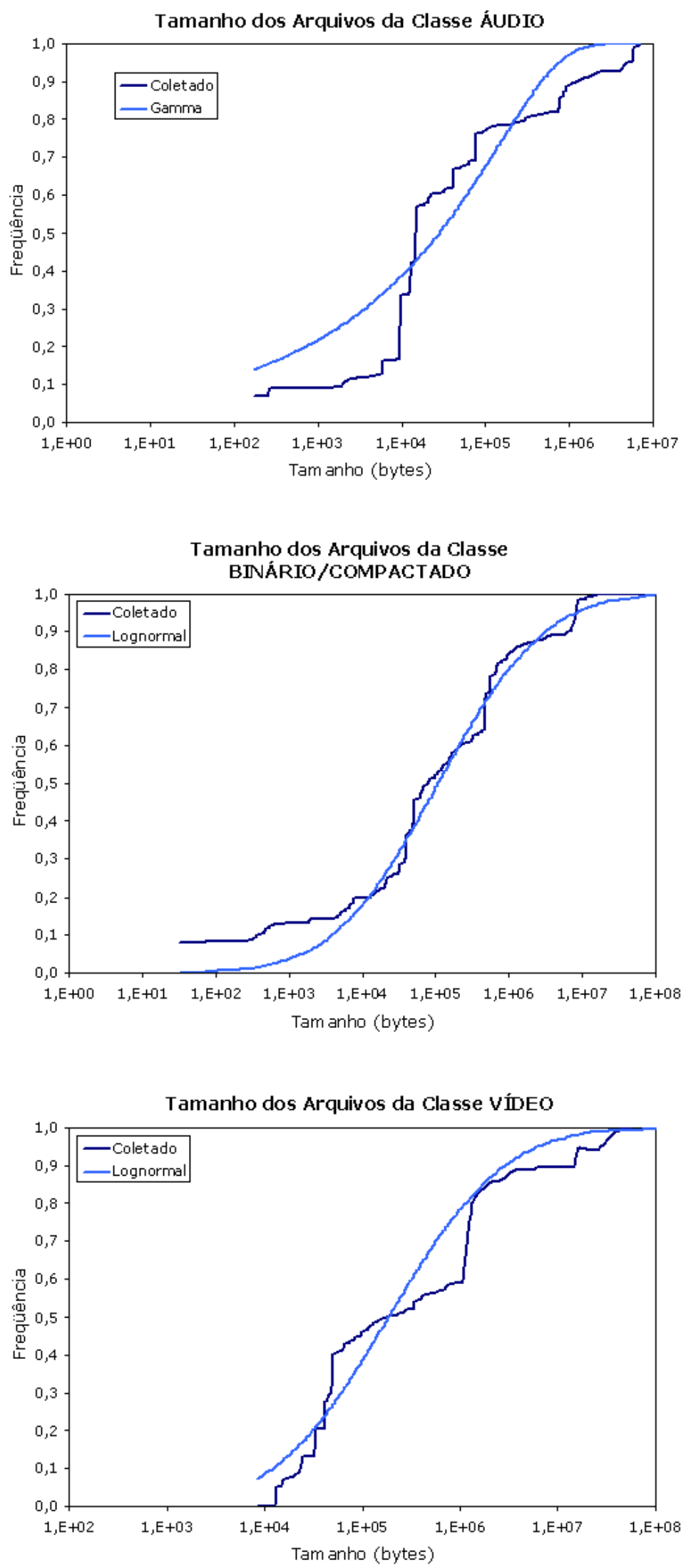

Figura 4.11: Tamanho médio dos objetos Áudio, Binário e Vídeo. 
A classe Texto caracteriza-se por conter tamanhos de arquivos que variam de apenas 50 bytes a 98 Kbytes (aproximadamente $10^{5}$ ), com poucas requisições fora desse limite. Os objetos Documento, ao contrário das outras categorias analisadas até o momento, a grande maioria dos arquivos está entre 10 Kbytes $\left(10^{4}\right)$ a 977 Kbytes $\left(10^{6}\right)$, com $10 \%$ para tamanhos menores que 10 Kbytes. Esses valores muito superiores a Imagem, Linguagem de Marcação e Texto explica o alto volume de transferência apresentado na figura 4.5(a).

Os objetos Dinâmicos, semelhante a Linguagem de Marcação, concentra os tamanho de arquivos entre 100 bytes e 98 Kbytes. É possível identificar a existência, porém muito pequena, de arquivos fora desse limite. Já os Scripts Cliente/Animação possui arquivos variando de 100 bytes a 98 Kbytes com tamanhos máximos que não excede os 977 Kbytes.

Os arquivos da classe Binário/Compactado mostram os seus pesos no volume final de dados transferidos. Os tamanhos variam de 100 bytes a 9,5 Mbytes (próximo de $10^{7}$ bytes), com poucos arquivos fora desse limite. A categoria Áudio possui valores próximos, no entanto, não se observa casos de tamanhos superiores a 9,5 Mbytes. Já a classe Vídeo, cujos valores alcançaram a marca dos 95 Mbytes (aproximadamente $10^{8}$ bytes), destaca-se pela falta de arquivos pequenos, menores que 10 Kbytes.

A partir da análise dos dados, sugere-se modelos matemáticos simulando os inúmeros tamanhos de objetos da Web. As figuras 4.9, 4.10 e 4.11 apresentam os gráficos das nove classes de objetos e a melhor função de distribuição que modela aos dados coletados.

Das funções de distribuição de probabilidade, três são recomendadas para simular os tamanhos dos objetos da Web: a Lognormal, a Weibull e a Gamma. Para cada classe utilizando a mesma função, sugere-se parâmetros diferentes, visto que o tamanho dos arquivos não são equivalentes. A tabela 4.13 resume as funções e os parâmetros utilizados. O W4Gen implementa esses resultados para reproduzir a carga de trabalho e permitir avaliar o desempenho de modelos de servidores Web.

Na próxima seção será apresentado os resultados para cada uma das três categorias identificadas no conjunto de logs, observando também o comportamento do código de resposta, classe de objeto, intervalo de chegada e do tamanho do objeto.

\subsection{Caracterização por Categoria}

A caracterização da carga de trabalho da $W e b$ é uma parte importante no projeto de avaliação de desempenho. Ela permite compreender o comportamento dos usuários e 
aprender quais mudanças afetam o desempenho. Com isso, é possível comparar resultados e extrair informações, adaptando melhor o sistema ao ambiente real.

Tabela 4.13: Modelos Matemáticos para simular o tamanho dos objetos.

\begin{tabular}{|c|c|cc|c|c|}
\hline \hline $\begin{array}{c}\text { Classe } \\
\text { de Objetos }\end{array}$ & $\begin{array}{c}\text { Função de } \\
\text { Distribuição }\end{array}$ & \multicolumn{2}{|c|}{ Parâmetros } & Média & $\begin{array}{c}\text { Desvio } \\
\text { Padrão }\end{array}$ \\
\hline \hline Imagem & Lognormal & $\mu: 8,12$ & $\sigma: 1,65$ & 13.111 & 49.440 \\
\hline \hline $\begin{array}{c}\text { Linguagem } \\
\text { de Marcação }\end{array}$ & Weibull & $\alpha: 0,74$ & $\beta: 17.998$ & 21.670 & 29.759 \\
\hline \hline Dinâmico & Lognormal & $\mu: 6,92$ & $\sigma: 2,28$ & 13.618 & 182.705 \\
\hline \hline Texto & Weibull & $\alpha: 0,80$ & $\beta: 2.481$ & 2.811 & 3.543 \\
\hline \hline Documento & Lognormal & $\mu: 10,32$ & $\sigma: 2,17$ & 319.480 & $3,35 E+06$ \\
\hline \hline $\begin{array}{c}\text { Scripts Cliente } \\
\text { e Animação }\end{array}$ & Weibull & $\alpha: 0,73$ & $\beta: 10.551$ & 12.854 & 17.992 \\
\hline \hline Áudio & Gamma & $\alpha: 0,25$ & $\theta: 619.778$ & 154.944 & 309.889 \\
\hline \hline $\begin{array}{c}\text { Binário e } \\
\text { Compactado }\end{array}$ & Lognormal & $\mu: 11,60$ & $\sigma: 2,61$ & $3,29 E+06$ & $9,91 E+07$ \\
\hline \hline Vídeo & Lognormal & $\mu: 12,14$ & $\sigma: 2,13$ & $1,81 E+06$ & $1,74 E+07$ \\
\hline \hline
\end{tabular}

A Internet e, principalmente a $W e b$, evoluiu muito ao longo dos anos. Esse crescimento proporcionou a criação de diversos tipos de sites, com o mais variado conteúdo. Nessa classificação existem os e-commerce, sites que buscam vender produtos por meio da Web, os Web-publising, que trazem notícias atualizadas, entre outras categorias. A fim de quantificar melhor a carga de trabalho, essa etapa classificou por conteúdo os nove traces e aplicou as mesmas análises da seção anterior para cada uma delas.

\subsubsection{Categoria Acadêmico}

Esta seção discute os resultados obtidos da caracterização da carga de trabalho de servidores Web Acadêmicos, por meio da análise do código de resposta, da classe de objeto, do intervalo de chegada e do tamanho do objeto. Ao final de cada item, modelos matemáticos são propostos para simular o ambiente de sites acadêmicos da $W e b$.

\section{Código de Resposta}

O primeiro passo da análise por categoria apresenta os resultados obtidos do código de resposta dos servidores Web. A figura 4.12 contém o gráfico da média dos três logs coletados de sites acadêmicos. A classe $2 \mathrm{xx}$ representa a maior parte dos pedidos, com $68,73 \%$. As requisições de redirecionamento (3xx), erros no pedido do cliente (4xx) e os erros no servidor (5xx) assumem os valores $24,5 \%, 6,75 \%$ e $0,01 \%$ respectivamente. 
Baseado nos resultados é possível identificar um modelo matemático que determine o comportamento de chegada dos códigos de respostas dos servidores Web de conteúdo Acadêmico. A figura 4.12 apresenta não somente a média, mas também a função Geométrica, com parâmetro 0,65 .

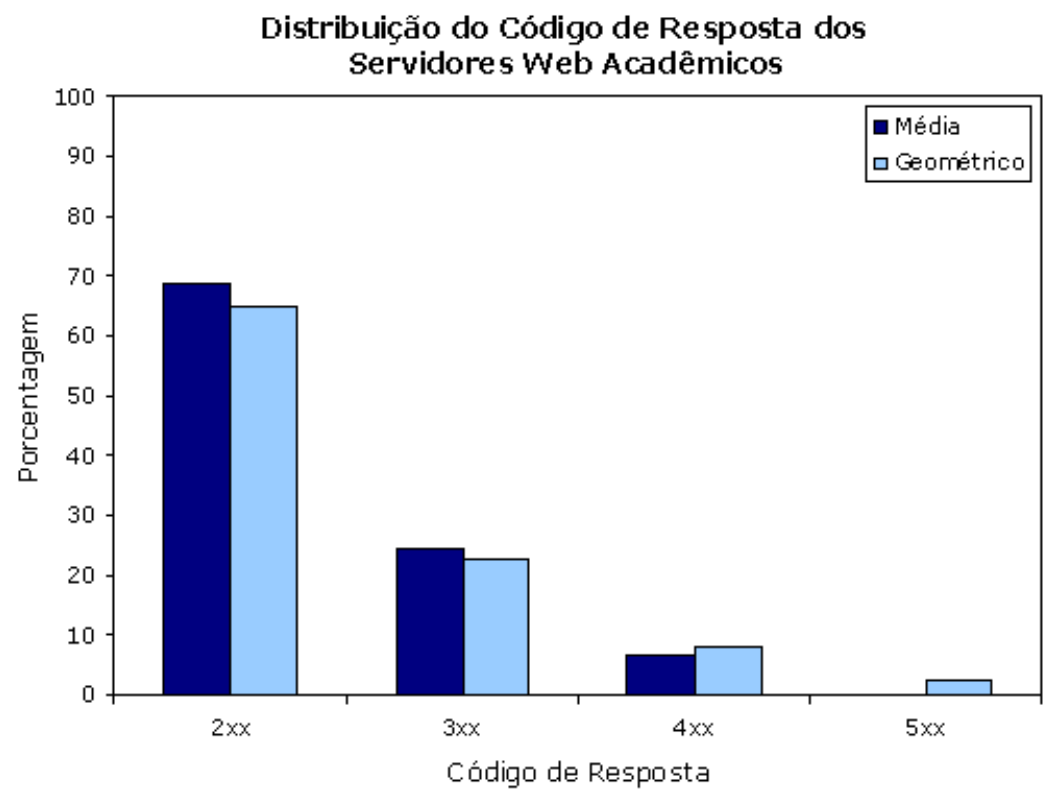

Figura 4.12: Análise dos códigos de respostas da categoria Acadêmico.

\section{Classe de Objeto}

$\mathrm{Na}$ análise por categoria, é possível identificar comportamentos específicos de sites da Web e extrair informações preciosas para melhorar o atendimento dos clientes. Do ponto de vista dos objetos, esse passo ajuda a recuperar dados importantes, como a proporção de páginas estáticas e dinâmicas, e determinar se os requisitos básicos do servidor serão adequados para satisfazer as necessidades da instituição ou empresa. A figura 4.13(a) apresenta a média dos objetos requisitados em servidores Web de conteúdo Acadêmico e a quantidade de bytes transferidos para cada uma das classes.

O objeto Linguagem de Marcação ${ }^{11}$ possui o maior número de referências, 44,15\% superando até mesmo a classe Imagem. Esse comportamento não ocorre na média geral, discutido na seção anterior e nos outros estudos da seção 4.2. As Imagens representam 42,89\%. Apesar dos valores próximos, a quantidade de bytes transferidos por ambas variou de 22,55\% (objeto Imagem) para 36,91\% (objeto Linguagem de Marcação). Já as requisições para objetos dinâmicos correspondem a 3,26\% do total, com volume de

\footnotetext{
${ }^{11}$ Páginas estáticas.
} 
dados de apenas 3,16\%. Isso revela que páginas dinâmicas não são muito utilizadas nessa categoria. O Documento, apesar de totalizar 5\% das requisições, corresponde ao segundo maior volume de bytes transferidos, com, aproximadamente, 30\%. Requisições de Áudio também exige uma alta demanda. Com 0,37\% das requisições, ela transferiu 4,82\%.

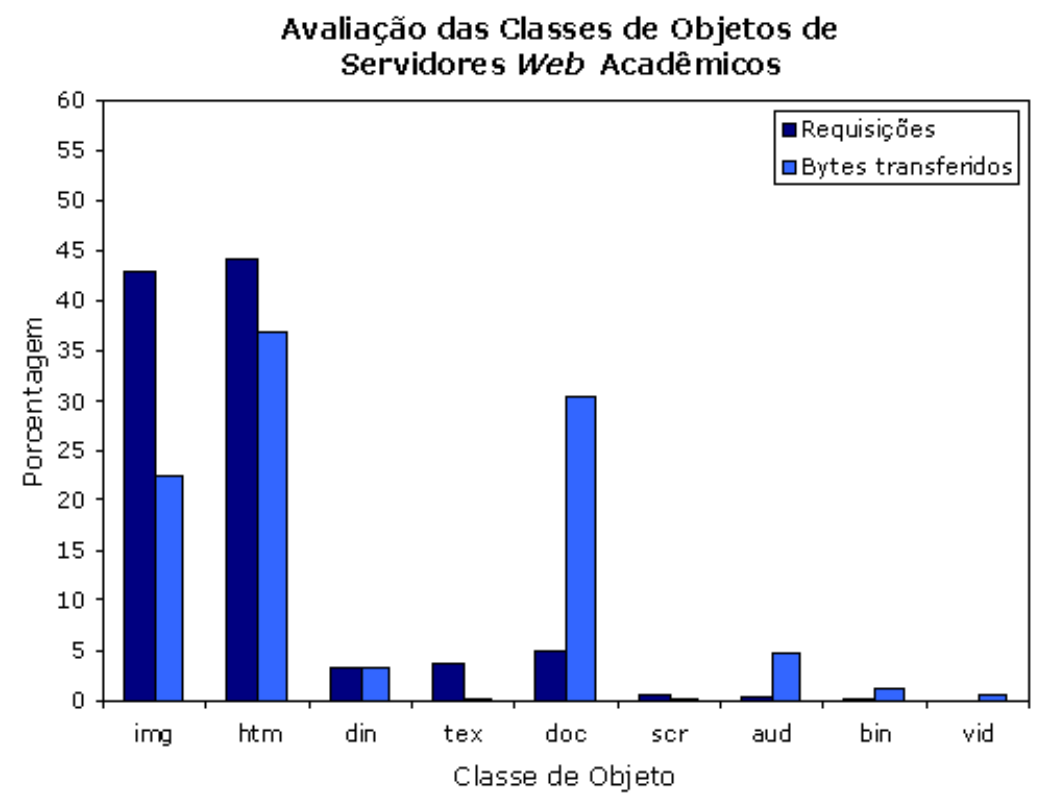

(a)

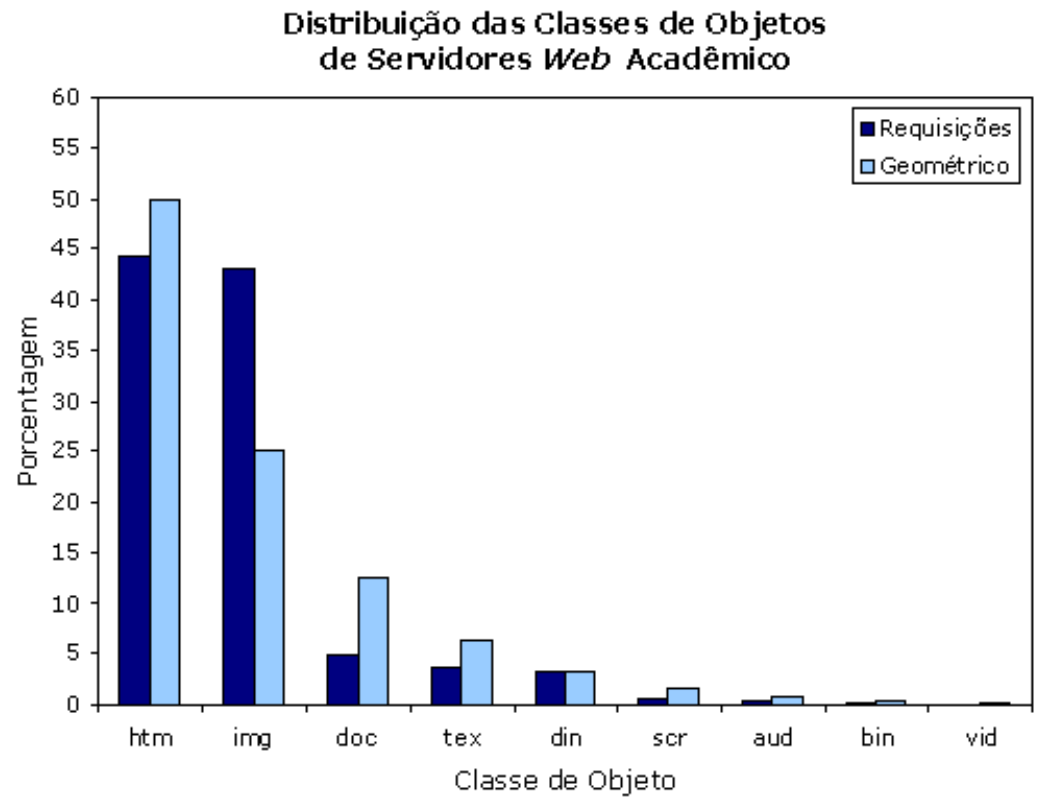

(b)

Figura 4.13: Análise das classes de objetos da categoria Acadêmico.

Com base nos dados coletadas, propõe-se um modelo matemático para simular o comportamento das classes de objetos requisitadas nos Servidores Web de conteúdo 
Acadêmico. A figura 4.13(b) apresenta a média e a função Geométrica, com parâmetro 0,50 .

\section{Intervalo de Chegada}

A análise por categoria também verificou o comportamento de chegada das requisições ao servidor $W e b$ baseado na classificação dos objetos. As figuras 4.14, 4.15 e 4.16 mostram os resultados coletados da avaliação e apresenta propostas de modelos matemáticos para simular o ambiente da $W W W$.

Os intervalos de chegada zero e 1 segundo são mais relevantes para o desempenho, pois são eles que podem sobrecarregar os recursos do servidor Web, degradando o tempo de resposta. Portanto, a classe Imagem registrou a maior demanda entre tais tempos, com mais de $60 \%$ dos pedidos e tempo máximos que podem chegar a $10^{4}$ segundos. Para representar esse comportamento, sugere-se a função Weibull para simular o ambiente de chegada das requisições.

A Linguagem de Marcação, diferentemente da Imagem, possui uma concentração muito menor nos intervalos de zero e 1 segundos, como mostra o gráfico da figura 4.14. A classe Dinâmico e Documento, ao contrário, possui, aproximadamente, 30\% das requisições concentrados entre zero e 1 segundo e tempos máximos que superam $10^{5}$ segundos.

O objeto Texto possui a menor concentração de requisições que chegam ao servidor Web em intervalos iguais a zero e 1 segundo, com menos de $5 \%$ do total. Nesse caso os tempos estão distribuídas entre 10 e $10^{4}$ segundos. Script Cliente/Animação e Binário/Compactado possuem, respectivamente, $44 \%$ e $48 \%$ dos pedidos em intervalos de zero e 1 e tempos máximos que excedem os $10^{5}$ segundos. Por fim, a classe Vídeo registrou $14 \%$ das requisições com tempos de até 1 segundo e valores acima de $10^{5}$ representam $5 \%$ do total.

Na tabela 4.14 estão resumidas as informações das funções de distribuição de probabilidade e os seus respectivos parâmetros utilizados para modelar os comportamento de chegada das requisições da categoria Acadêmico. 

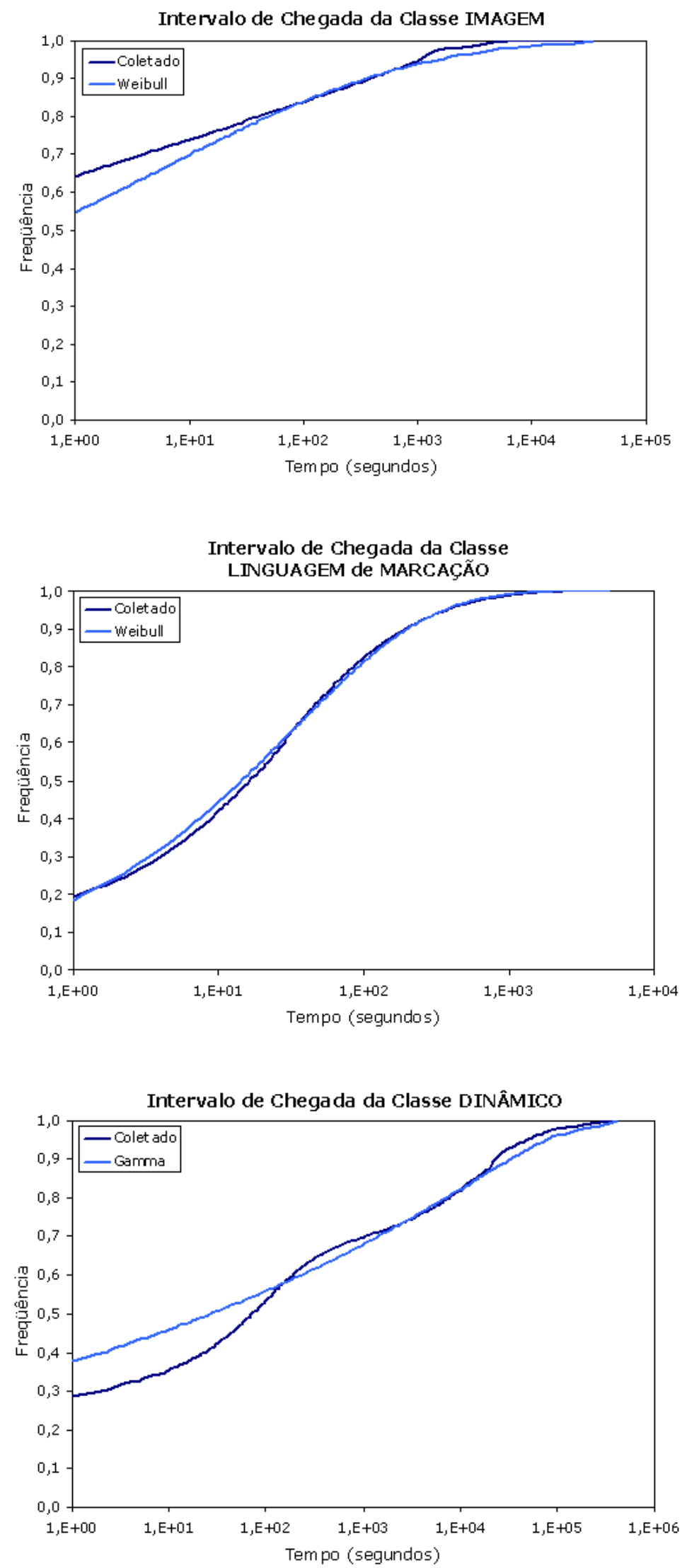

Figura 4.14: Intervalo de chegada dos objetos Imagem, HTML e Dinâmico da categoria Acadêmico. 

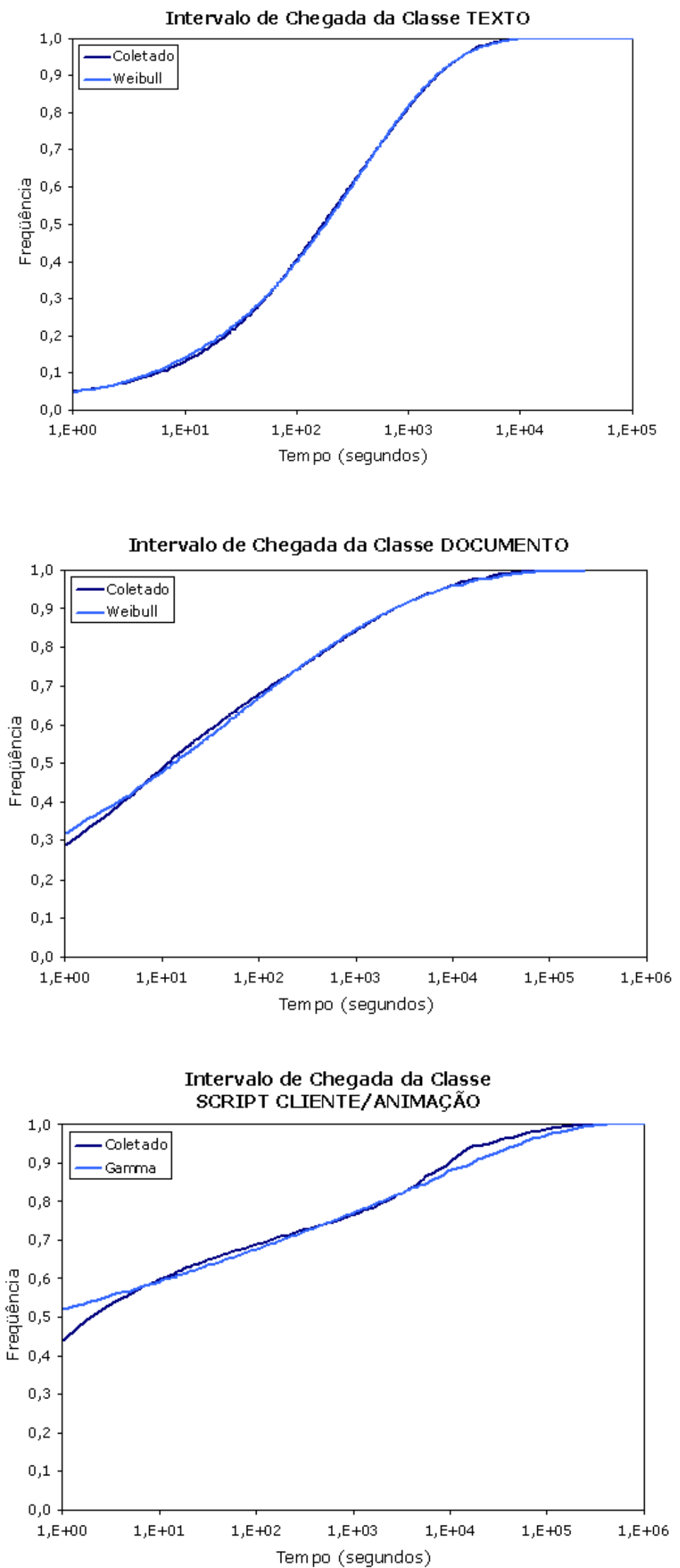

Figura 4.15: Intervalo de chegada dos objetos Texto, Documento e Script Cliente da categoria Acadêmico. 

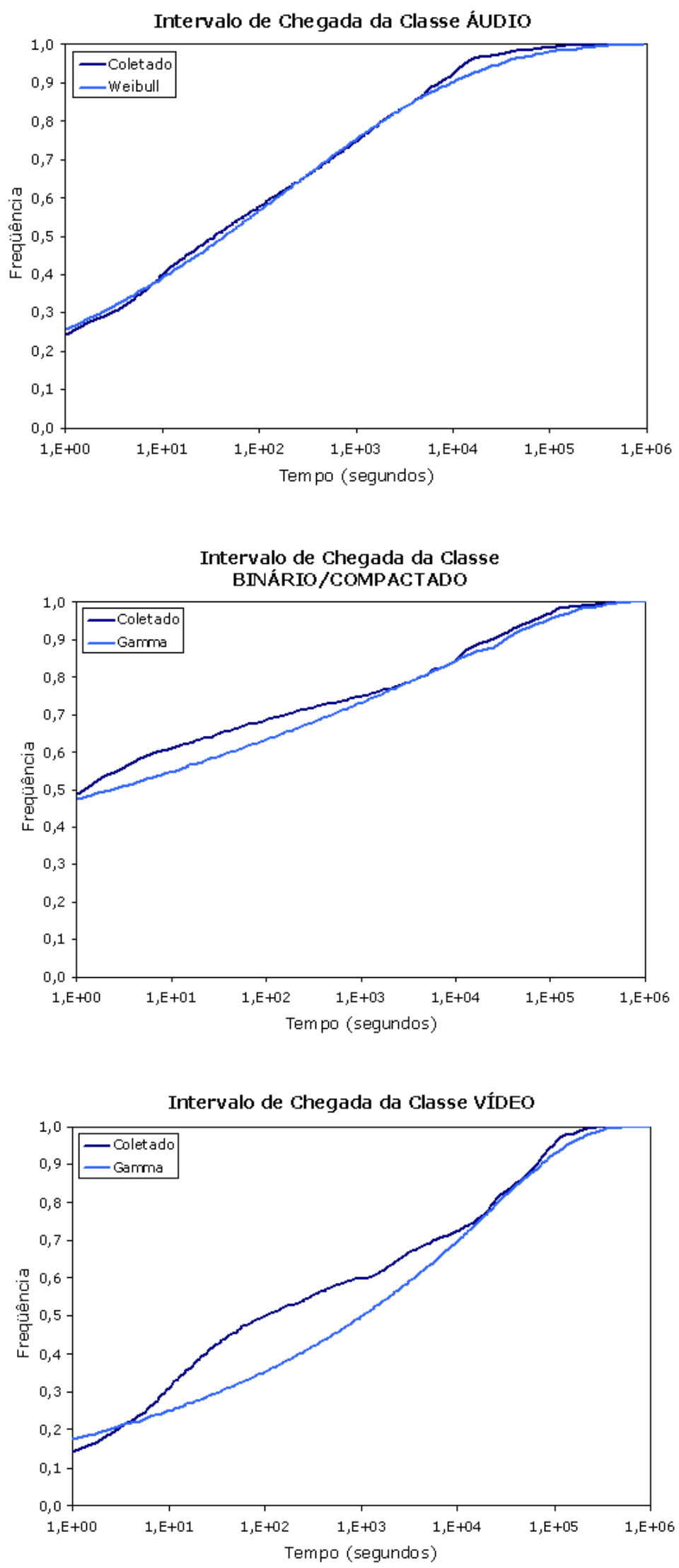

Figura 4.16: Intervalo de chegada dos objetos Áudio, Binário e Vídeo da categoria Acadêmico. 
Tabela 4.14: Modelos matemáticos para o intervalo de chegada da categoria Acadêmico.

\begin{tabular}{|c|c|cc|c|c|}
\hline \hline $\begin{array}{c}\text { Classe } \\
\text { de Objeto }\end{array}$ & $\begin{array}{c}\text { Função de } \\
\text { Distribuição }\end{array}$ & \multicolumn{2}{|c|}{ Parâmetros } & Média & $\begin{array}{c}\text { Desvio } \\
\text { Padrão }\end{array}$ \\
\hline \hline Imagem & Weibull & $\alpha: 0,18$ & $\beta: 3,66$ & 1.164 & 26.466 \\
\hline \hline $\begin{array}{c}\text { Linguagem } \\
\text { de Marcação }\end{array}$ & Weibull & $\alpha: 0,46$ & $\beta: 32,19$ & 76 & 192 \\
\hline \hline Dinâmico & Gamma & $\alpha: 0,09$ & $\theta: 159.197$ & 14.327 & 47.759 \\
\hline \hline Texto & Weibull & $\alpha: 0,52$ & $\beta: 366$ & 683 & 1.446 \\
\hline \hline Documento & Weibull & $\alpha: 0,23$ & $\beta: 65$ & 2.669 & 27.736 \\
\hline \hline $\begin{array}{c}\text { Script Cliente } \\
\text { e Animação }\end{array}$ & Gamma & $\alpha: 0,06$ & $\theta: 164.783$ & 9.887 & 40.363 \\
\hline \hline Áudio & Weibull & $\alpha: 0,22$ & $\beta: 227$ & 12.787 & 150.973 \\
\hline \hline $\begin{array}{c}\text { Binário e } \\
\text { Compactado }\end{array}$ & Gamma & $\alpha: 0,06$ & $\theta: 248.251$ & 14.895 & 60.808 \\
\hline \hline Video & Gamma & $\alpha: 0,15$ & $\theta: 164.544$ & 24.681 & 63.727 \\
\hline \hline
\end{tabular}

\section{Tamanho do Objeto}

A avaliação por categoria também verificou o tamanho dos objetos dos servidores $W e b$ de conteúdo Acadêmico. A figura 4.17, 4.18 e 4.19 apresentam os resultados coletados dos traces e os modelos matemáticos sugeridos para simular o ambiente.

Nas classes Imagem e Linguagem de Marcação, os objetos mais requisitados da categoria, registraram tamanhos de arquivos entre $10^{2}$ a $10^{5}$ bytes (aproximadamente 98 Kbytes), com uma porcentagem pequena fora desse limite. Já as classes Dinâmico e Texto contém arquivos que variam entre $10^{2}$ e $10^{4}$ bytes. No entanto, a classe Texto registrou $4 \%$ das requisições acima de $10^{4}$ bytes.

Por outro lado, a classe Documento possui arquivos extensos, entre $10^{4}$ e $10^{6}$ bytes. Script Cliente/Animação possui mais de $50 \%$ acima de $10^{4}$ bytes. Já a classe Binário/Compactado caracteriza-se por ter arquivos com tamanhos que variam de 256 bytes até $10^{7}$ bytes (9,5 Mbytes), com mais de $20 \%$ acima de $10^{6}$ (977 Kbytes). Por fim, Áudio e Vídeo possuem tamanhos semelhantes entre $10^{4}$ e $10^{7}$ bytes, mostrando não serem objetos extensos. A tabela 4.15 resume as informações e os parâmetros utilizados pelas funções de distribuição para representar os diversos tamanhos de objetos da categoria Acadêmico. 

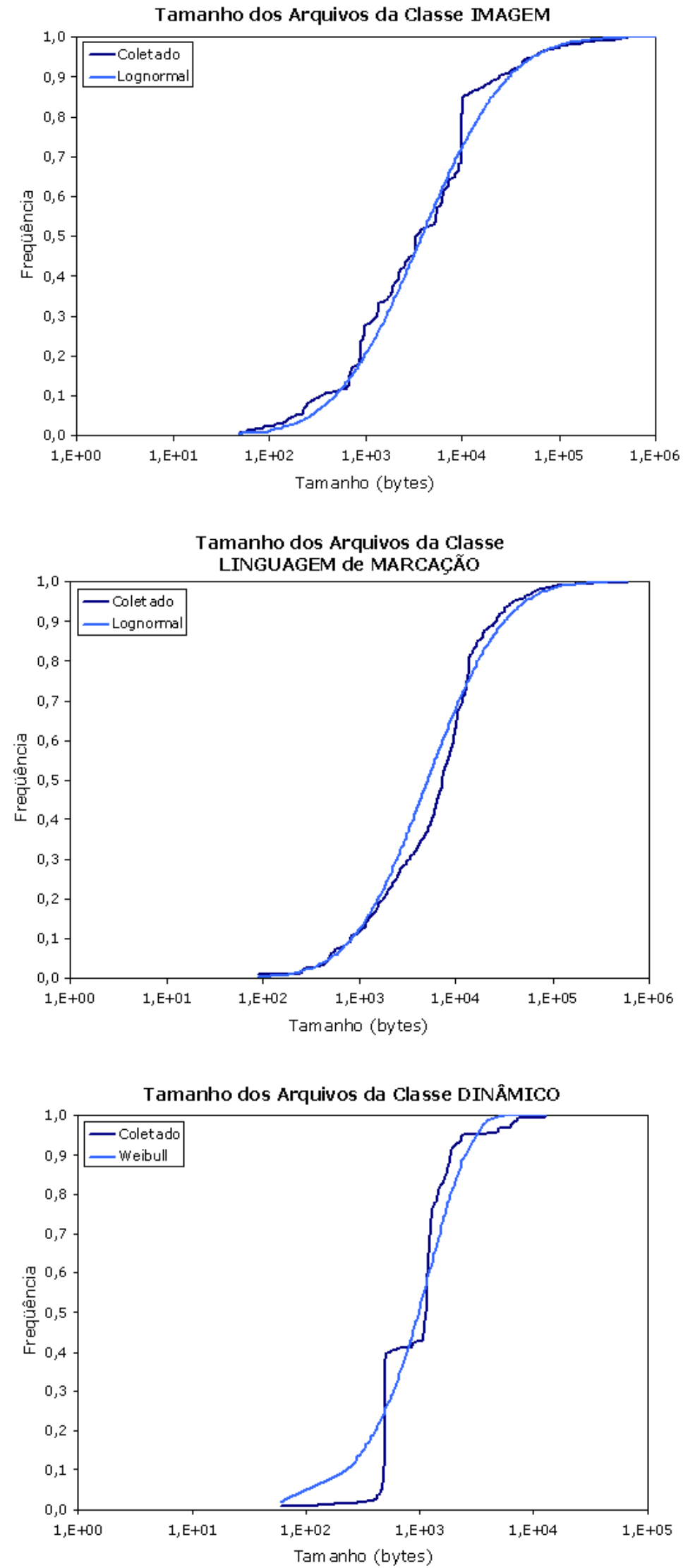

Figura 4.17: Tamanho dos objetos Imagem, Linguagem de marcação e Dinâmico da categoria Acadêmico. 

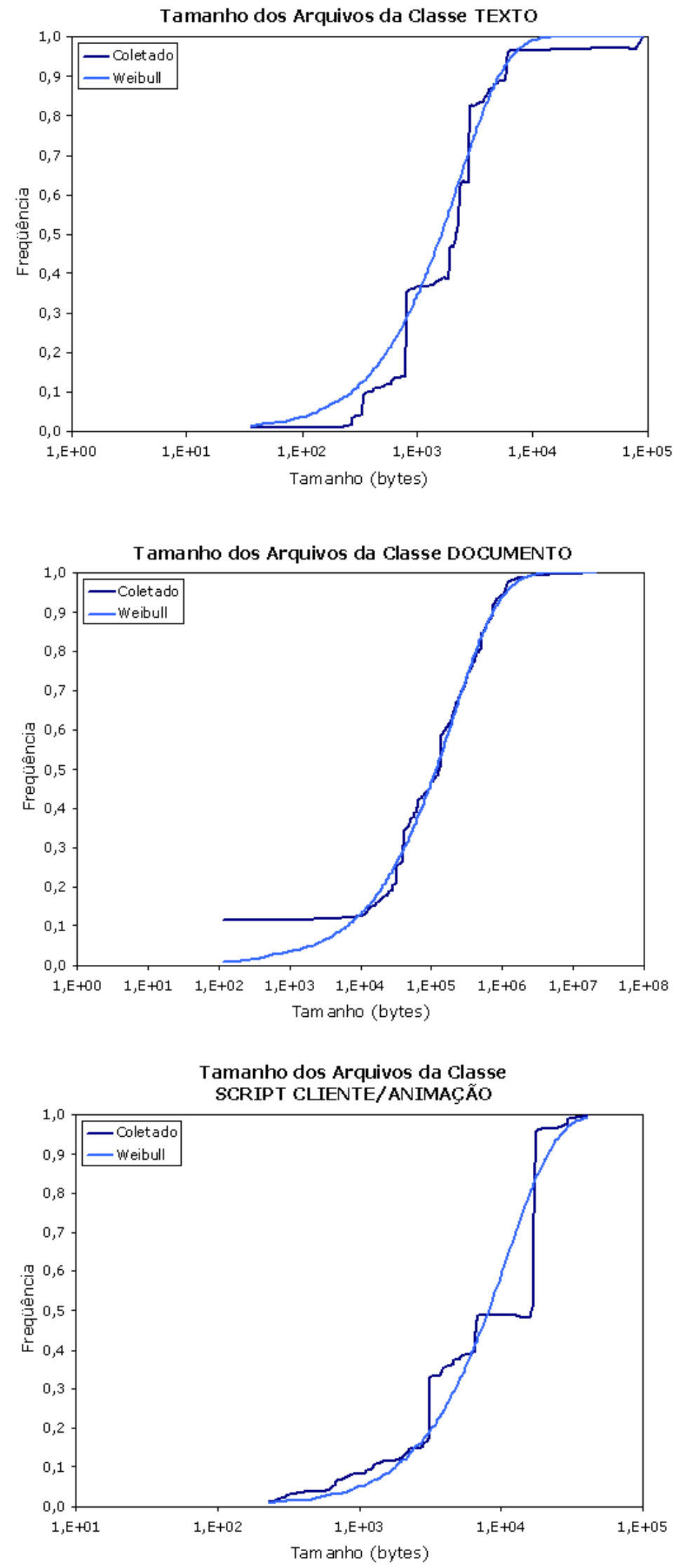

Figura 4.18: Tamanho dos objetos Texto, Documento e Script Cliente da categoria Acadêmico. 


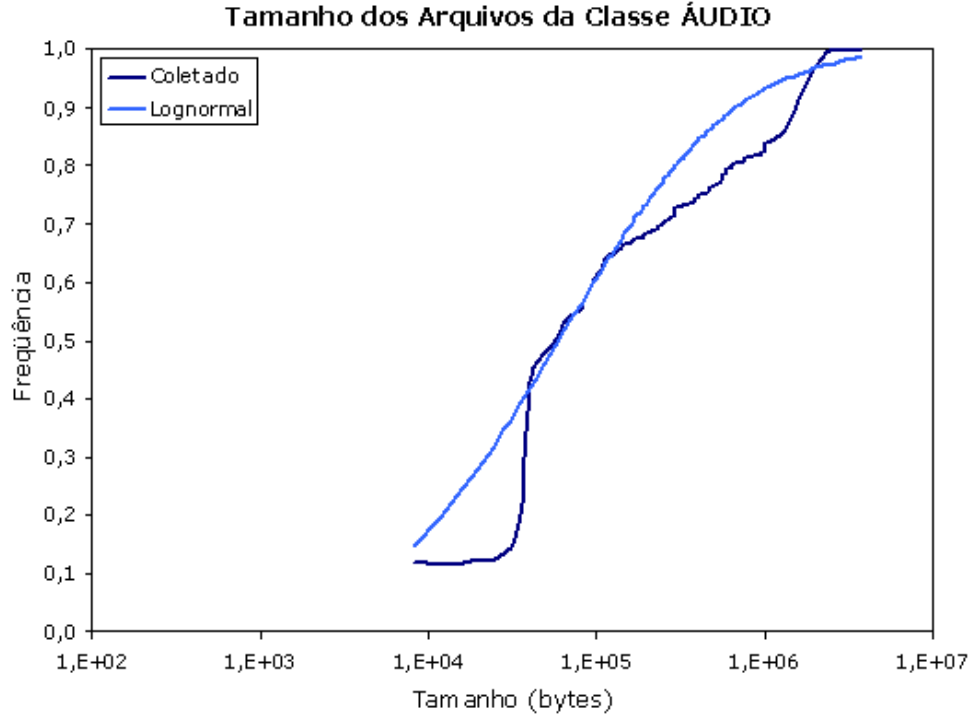

Tamanho dos Arquivos da

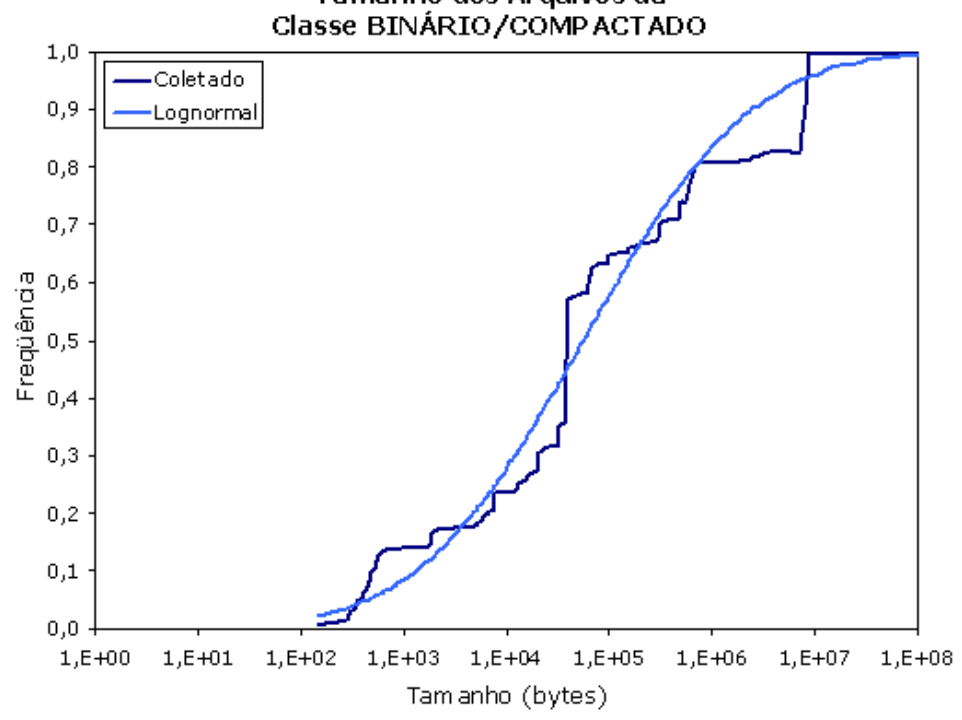

Tamanho dos Arquivos da Classe víDEO

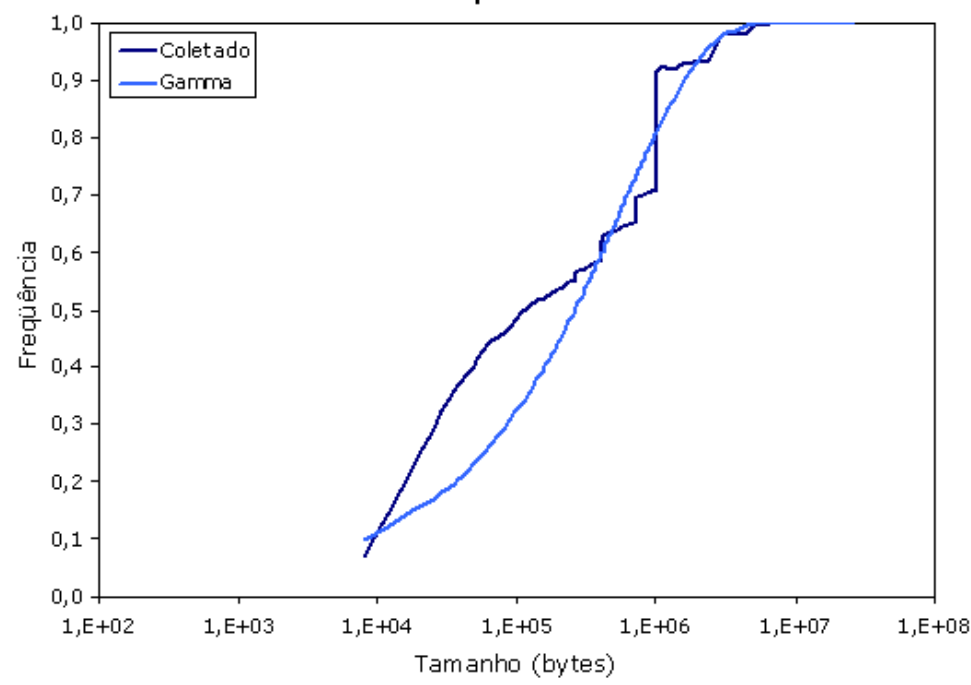

Figura 4.19: Tamanho dos objetos Áudio, Binário e Vídeo da categoria Acadêmico. 
Tabela 4.15: Modelos matemáticos para o tamanho dos objetos da categoria Acadêmico.

\begin{tabular}{|c|c|cc|c|c|}
\hline \hline $\begin{array}{c}\text { Classe } \\
\text { de Objeto }\end{array}$ & $\begin{array}{c}\text { Função de } \\
\text { Distribuição }\end{array}$ & \multicolumn{2}{|c|}{ Parâmetros } & Média & $\begin{array}{c}\text { Desvio } \\
\text { Padrão }\end{array}$ \\
\hline \hline Imagem & Lognormal & $\mu: 8,25$ & $\sigma: 1,62$ & 14.217 & 50.857 \\
\hline \hline $\begin{array}{c}\text { Linguagem } \\
\text { de Marcação }\end{array}$ & Lognormal & $\mu: 8,55$ & $\sigma: 1,42$ & 14.160 & 36133 \\
\hline \hline Dinâmico & Weibull & $\alpha: 1,29$ & $\beta: 1.296$ & 1.198 & 936 \\
\hline \hline Texto & Weibull & $\alpha: 1,04$ & $\beta: 2.295$ & 2.259 & 2.172 \\
\hline \hline Documento & Weibull & $\alpha: 0,65$ & $\beta: 206.413$ & 282.016 & 449.747 \\
\hline \hline $\begin{array}{c}\text { Script Cliente } \\
\text { e Animação }\end{array}$ & Weibull & $\alpha: 1,24$ & $\beta: 10.908$ & 10.178 & 8.256 \\
\hline \hline Áudio & Lognormal & $\mu: 11,00$ & $\sigma: 1,90$ & 364.033 & $2,18 E+06$ \\
\hline \hline $\begin{array}{c}\text { Binário e } \\
\text { Compactado }\end{array}$ & Lognormal & $\mu: 10,94$ & $\sigma: 2,93$ & $4,12 E+06$ & $3.02 E+08$ \\
\hline \hline Vídeo & Gamma & $\alpha: 0,49$ & $\theta: 1.208 .495$ & 592.162 & 845.946 \\
\hline \hline
\end{tabular}

\subsubsection{Categoria Notícia/Informativo}

Neste tópico discute-se os resultados alcançados com a análise da carga de trabalho de servidores Web com conteúdo de Notícia/Informativo, segundo o código de resposta, a classe de objeto, o intervalo de chegada e o tamanho dos objeto e ao final, sugere-se modelos matemáticos para representar o ambiente.

\section{Código de Resposta}

O primeiro passo analisa os código de resposta coletados dos servidores $W e b$ de Notícia/Informativo. A figura 4.20 mostra o gráfico dos resultados da média dos quatro logs analisados e a função de distribuição Geométrica, com parâmetro 0,65, para representar o comportamento das requisições.

As requisições bem sucedidas $(2 \mathrm{xx})$ também representam a maioria na categoria Informativo, com $65 \%$ do total. Já a classe 3xx obteve maior presença do que em Acadêmico. Os valores superaram a taxa de $31 \%$. Os códigos de resposta da classe 4xx não alcançaram valores expressivos, apenas 3\%, a menor de todas as categorias. Erros no servidor (5xx) não apresentam resultados significativos.

\section{Classe de Objeto}

Essa etapa discute a análise das classes de objetos. A figura 4.21(a) mostra o gráfico da média dos quatro logs de servidores $W e b$ com conteúdo Notícia/Informativo e a quantidade máxima de bytes transferidos. 


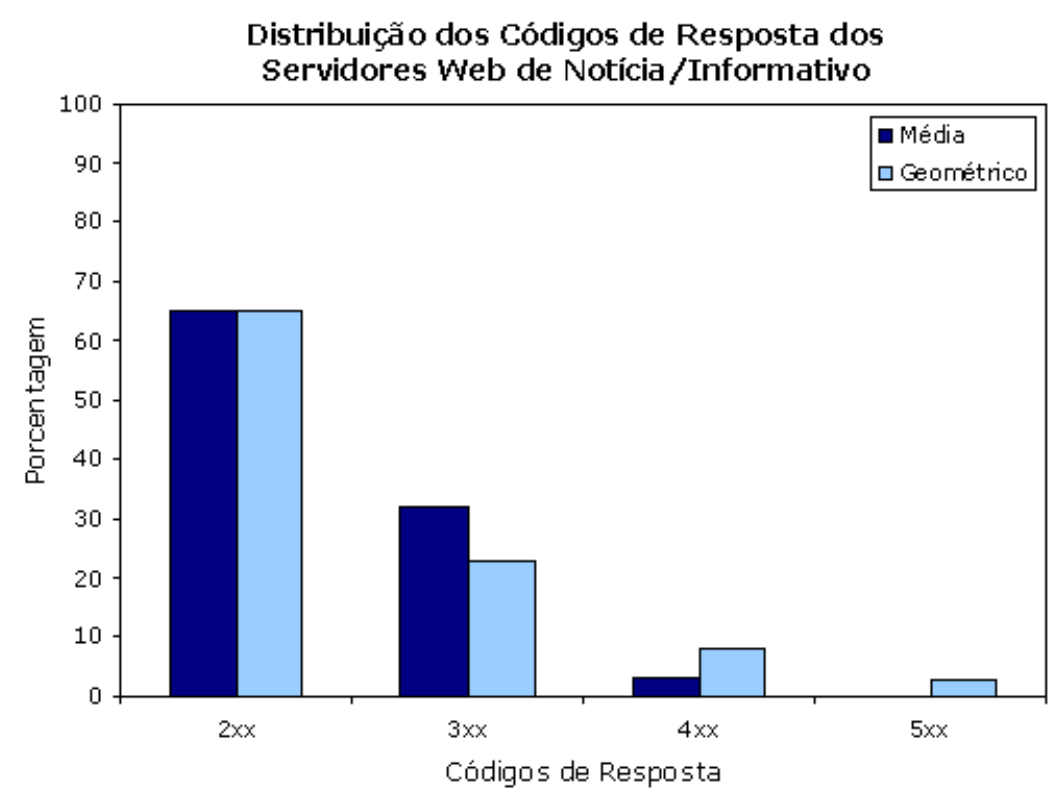

Figura 4.20: Análise dos códigos de respostas da categoria Notícia/Informativo.

O gráfico da figura 4.21(a) mostra que 48,75\% das requisições buscam por objetos da classe Imagem. Apesar de ser o mais referenciado, o volume de dados transferido é de apenas 25\%. A Linguagem de Marcação representa uma quantidade menor com, aproximadamente, $11 \%$. No entanto, essa pequena porcentagem corresponde a $29 \%$ dos bytes transferidos. O grande destaque está na classe Dinâmico, cujo número de requisições supera a marca de $30 \%$ e é responsável por mais de $25 \%$ do volume total de dados. Outra importante diferença está na classe Vídeo. Com menos de 0,01\% dos pedidos ao servidor $W e b$, ela foi capaz de gerar $4,75 \%$ dos bytes.

Os objetos Script Cliente/Animação são mais comum nessa categoria, correspondendo a 3,77\% das requisições e transferindo mais de $8 \%$ dos bytes. A classe Texto, entretanto, não apresenta diferenças em relação a categoria Acadêmico.

A partir das informações é possível propor um modelo matemático para representar o comportamento das classes de objetos dos Servidores Web de Notícia/Informativo. No outro gráfico 4.21(b) são apresentados a média dos quatro logs e a função Geométrica, com parâmetro 0,45 .

\section{Intervalo de Chegada}

Os gráficos de freqüência acumulada das figuras 4.22, 4.23 e 4.24 mostram os resultados coletados dos logs, baseado no intervalo de chegada das requisições. Além disso, eles também apresentam os modelos matemáticos utilizados para simular o ambiente da $W e b$ 


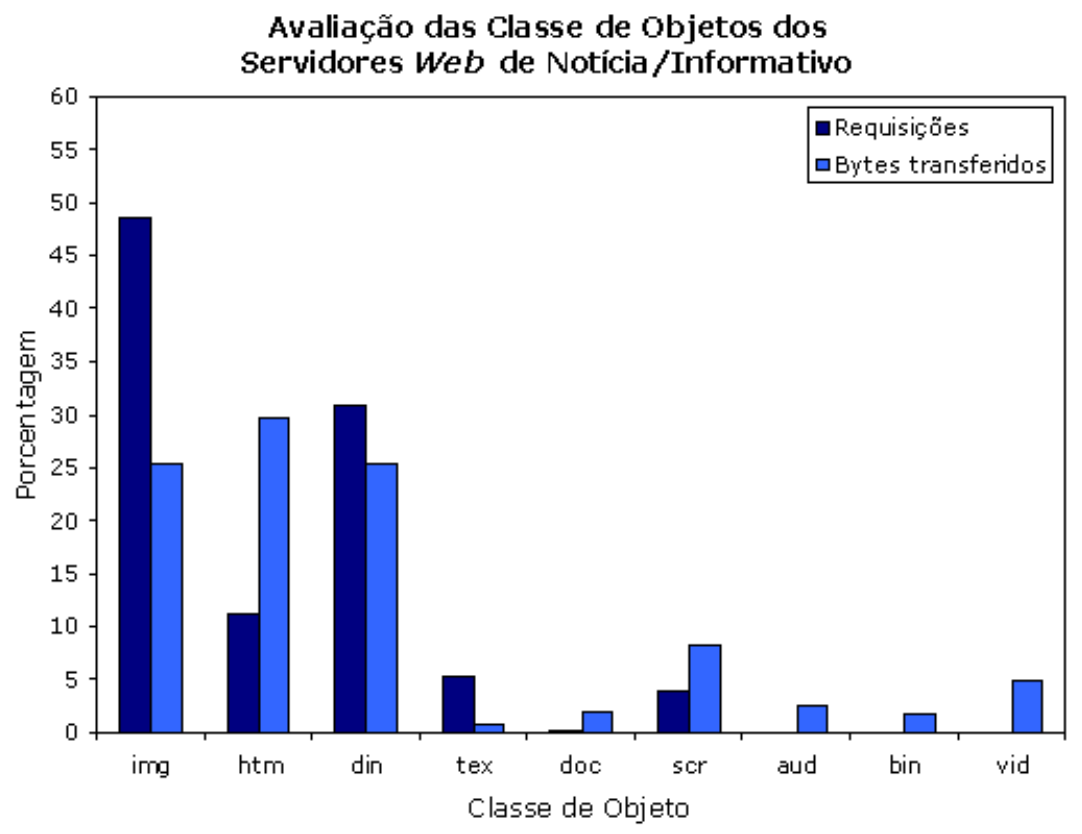

(a)

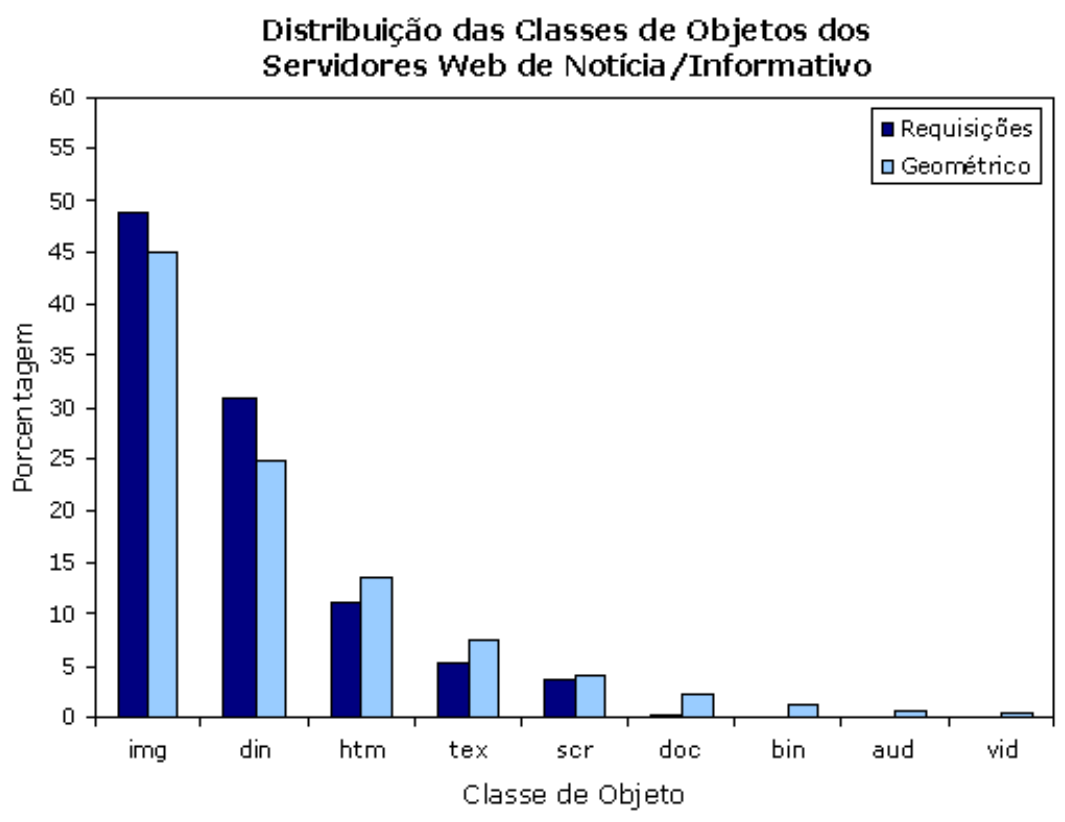

(b)

Figura 4.21: Análise das classes de objetos da categoria Notícia/Informativo.

de Notícia/informativo.

A classe Imagem possui a maior concentração entre os intervalos de zero e 1 segundo. Isso corresponde a mais de $80 \%$ das requisições. Intervalos máximos não superam os $10^{3}$ segundos. A Linguagem de Marcação, no entanto, possui uma concentração menor de requisições entre intervalos iguais a zero e 1 segundo, com apenas $22 \%$ dos pedidos. 

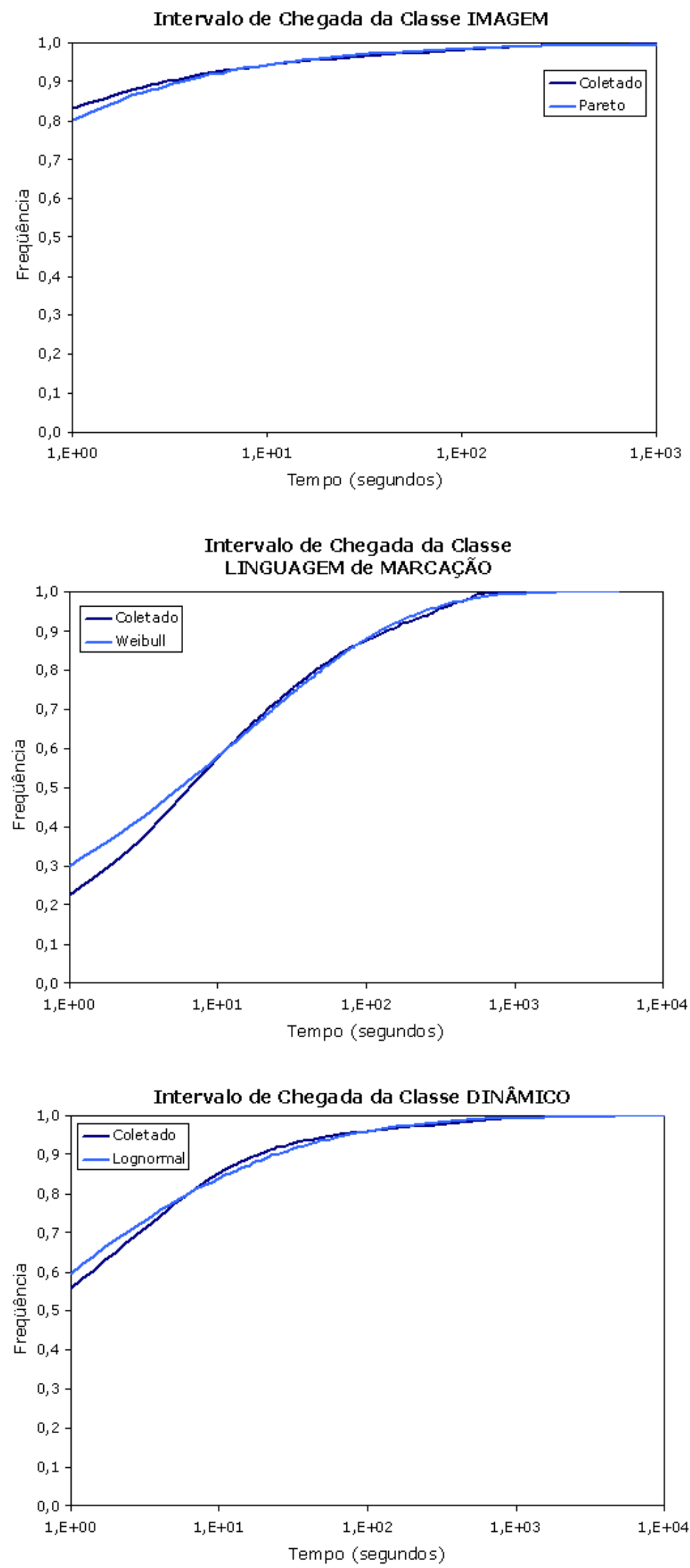

Figura 4.22: Intervalo de chegada dos objetos Imagem, Linguagem de marcação e Dinâmico da categoria Notícia/Informativo. 

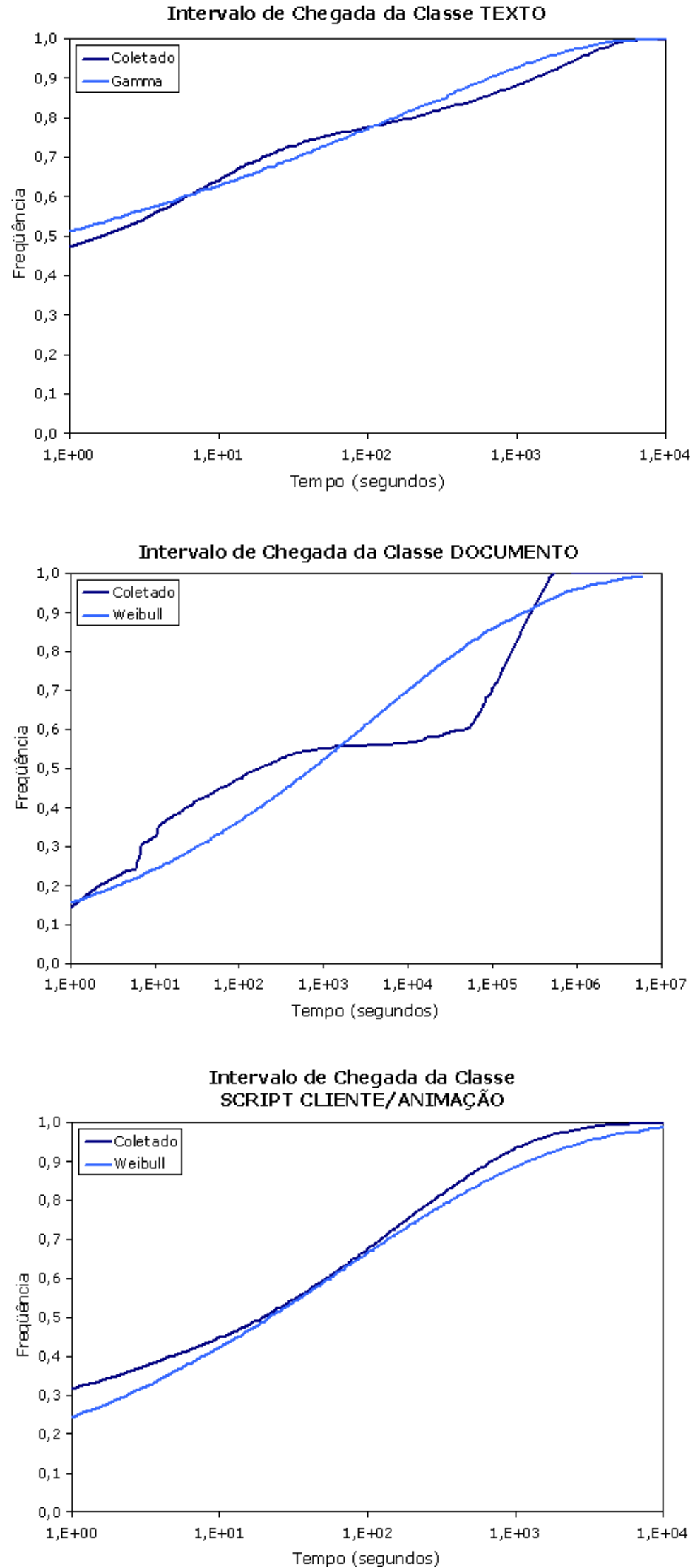

Figura 4.23: Intervalo de chegada dos objetos Texto, Documento e Script cliente da categoria Notícia/Informativo. 

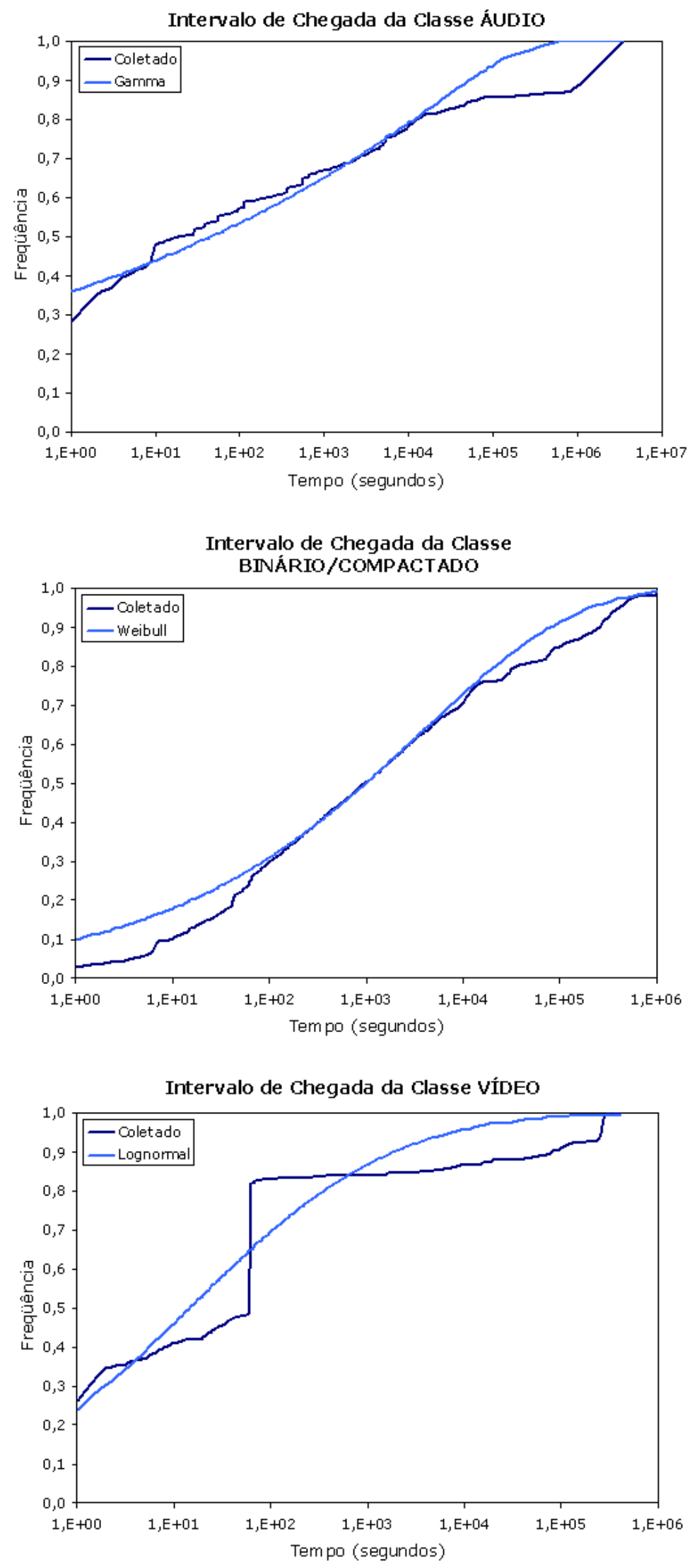

Figura 4.24: Intervalo de chegada dos objetos Áudio, Binário e Vídeo da categoria Notícia/Informativo. 
Os objetos Dinâmico, ao contrário do que se encontra na categoria Acadêmico, em Informativo possui, aproximadamente, $55 \%$ das requisições chegando em intervalos de zero e 1 segundo, mostrando exigir mais do servidor $W e b$, enquanto os objetos Binário/Compactado possui a menor concentração, com menos de $3 \%$ e tempos máximos que podem chegar a $10^{6}$ segundos. Já a classe Script Cliente/Animação, Texto e Áudio representam, respectivamente, $31 \%, 47 \%$ e $28 \%$ entre chegadas de no máximo 1 segundo e não excedem os $10^{4}$ segundos.

A tabela 4.16 resume as funções de distribuição de probabilidade e os parâmetros utilizados por ela para modelar o comportamento de chegada das requisições dos usuários ao servidor. Esses resultados estão todos implementados no W4Gen.

Tabela 4.16: Modelos matemáticos para o intervalo de chegada da categoria Notícia/Informativo.

\begin{tabular}{|c|c|cc|c|c|}
\hline \hline $\begin{array}{c}\text { Classe } \\
\text { de Objeto }\end{array}$ & $\begin{array}{c}\text { Função de } \\
\text { Distribuição }\end{array}$ & \multicolumn{2}{|c|}{ Parâmetros } & Média & $\begin{array}{c}\text { Desvio } \\
\text { Padrão }\end{array}$ \\
\hline \hline Imagem & Pareto & $\alpha: 0,05$ & $\beta: 0,54$ & 0 & 0 \\
\hline \hline $\begin{array}{c}\text { Linguagem } \\
\text { de Marcação }\end{array}$ & Weibull & $\alpha: 0,39$ & $\beta: 14,55$ & 51 & 170 \\
\hline \hline Dinâmico & Lognormal & $\mu:-0,75$ & $\sigma: 3,08$ & 54 & 6.225 \\
\hline \hline Texto & Gamma & $\alpha: 0,09$ & $\theta: 2.920$ & 262 & 876 \\
\hline \hline Documento & Weibull & $\alpha: 0,21$ & $\beta: 4.148$ & $3,33 E+05$ & $4,53 E+06$ \\
\hline \hline $\begin{array}{c}\text { Script Cliente } \\
\text { e Animação }\end{array}$ & Weibull & $\alpha: 0,30$ & $\beta: 75$ & 694 & 3.755 \\
\hline \hline Áudio & Gamma & $\alpha: 0,09$ & $\theta: 248.005$ & 22.320 & 74.401 \\
\hline \hline $\begin{array}{c}\text { Binário e } \\
\text { Compactado }\end{array}$ & Weibull & $\alpha: 0,27$ & $\beta: 3.818$ & 59.231 & 406.599 \\
\hline \hline Vídeo & Lognormal & $\mu: 2,68$ & $\sigma: 3,80$ & 19.930 & $2,72 E+07$ \\
\hline \hline
\end{tabular}

\section{Tamanho do Objeto}

As figuras 4.25, 4.26 e 4.27 mostram os gráficos, em freqüência acumulada, dos resultados coletados na análise dos quatro logs. Ele também apresenta os modelos matemáticos utilizados para simular o tamanho dos objetos de Web sites com conteúdo de Notícia/Informativo.

As Imagens possuem arquivos que variam de apenas 100 bytes a $10^{5}$ bytes, com $10 \%$ das requisições referenciando tamanhos menores que 100 bytes. Já a classe Dinâmico, ao contrário dos servidores Web Acadêmico, 40\% das requisições são para objetos maiores que $10^{4}$ bytes $(9,77$ Kbytes $)$, confirmando a alta taxa de transferência de dados obtidas na figura $4.21(\mathrm{a})$. 

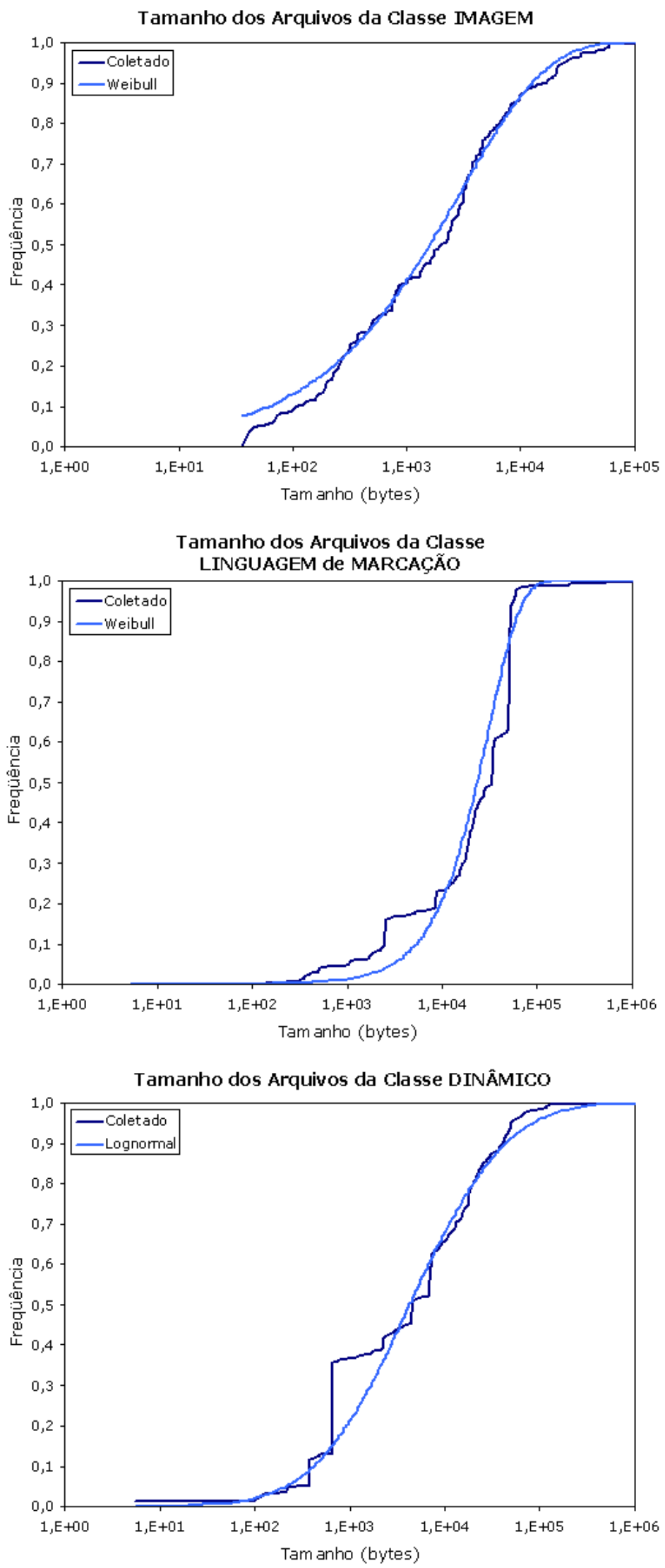

Figura 4.25: Tamanho dos objetos Imagem, Linguagem de marcação e Dinâmico da categoria Notícia/Informativo. 

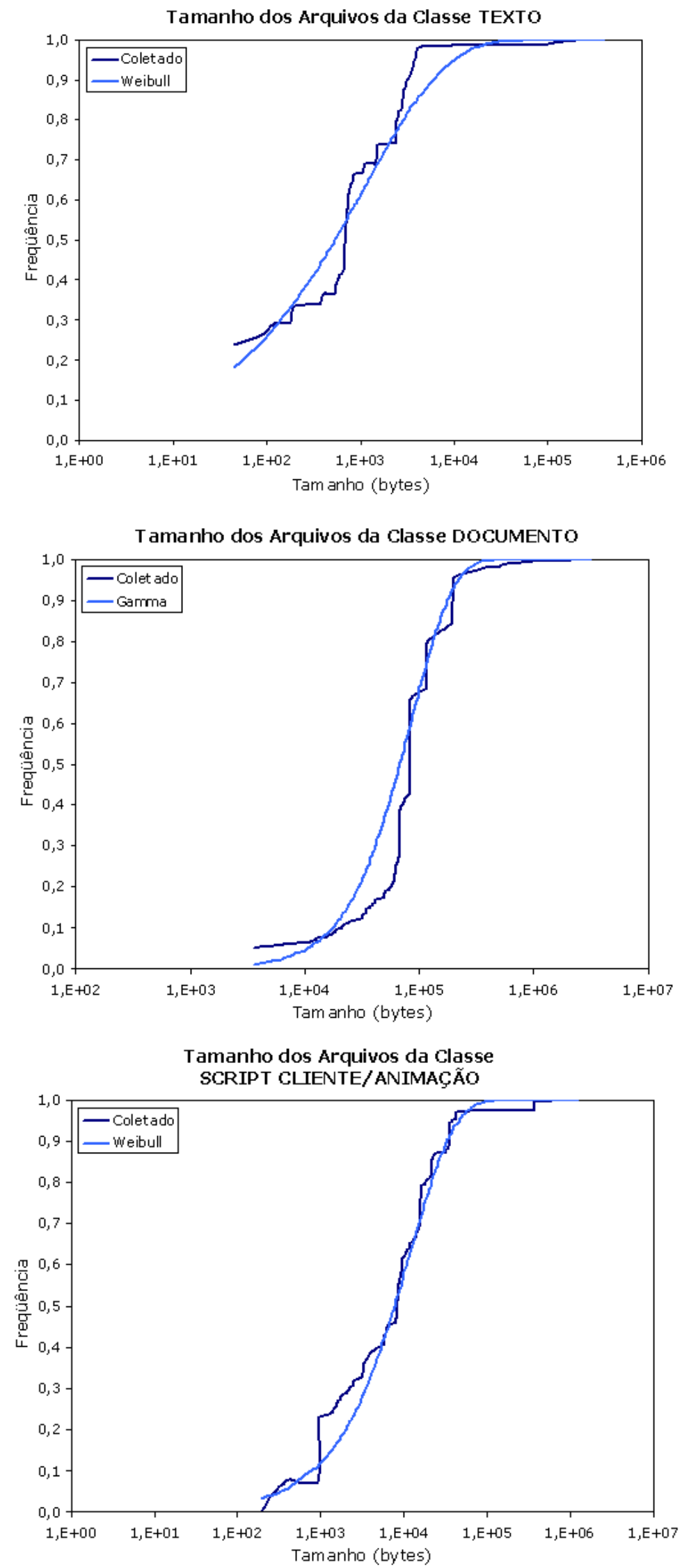

Figura 4.26: Tamanho dos objetos Texto, Documento e Script cliente da categoria Notícia/Informativo. 

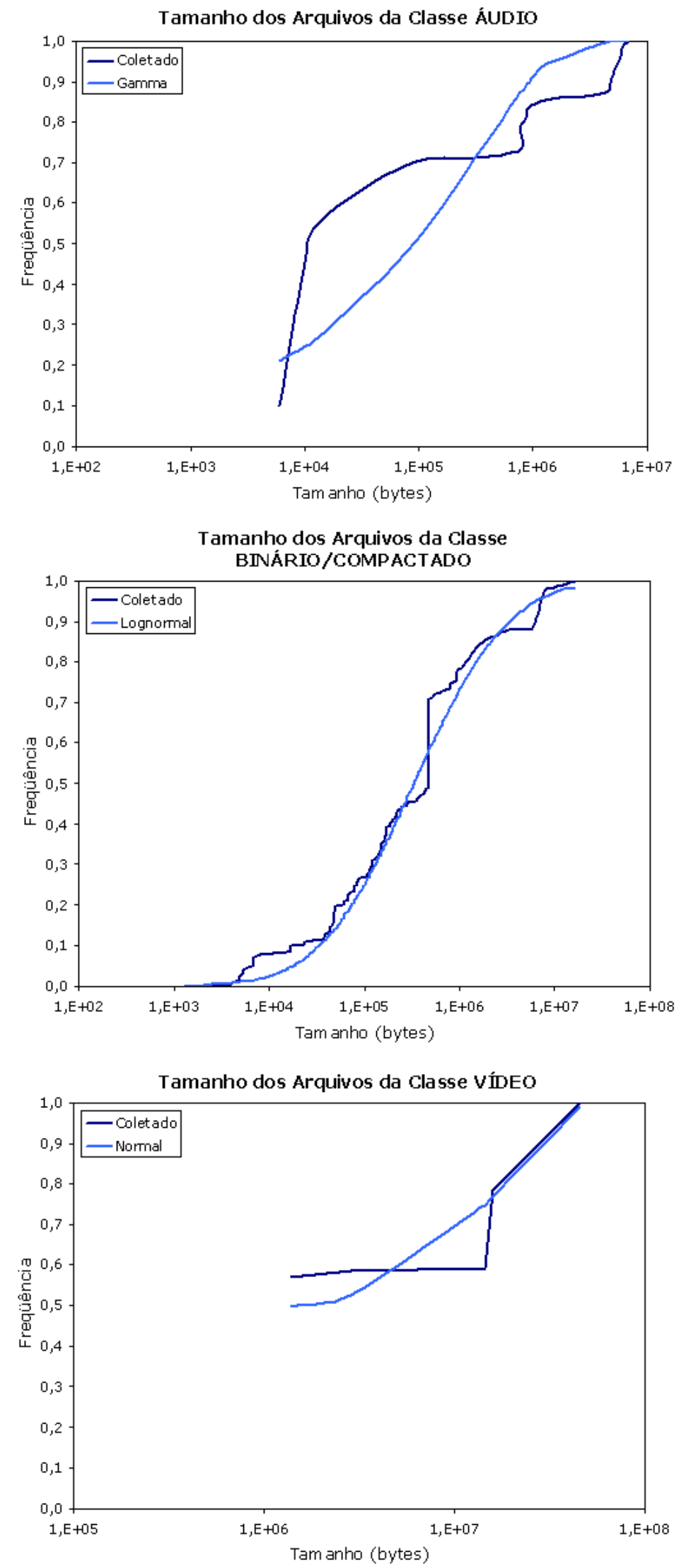

Figura 4.27: Tamanho dos objetos Áudio, Binário e Vídeo da categoria Notícia/Informativo. 
O objeto Texto é uma classe que contém arquivos pequenos. O seu gráfico mostra que $23 \%$ das requisições buscam, em servidores Web, objetos inferiores a 100 bytes e tamanhos máximos que chegam a 1 Kbyte. Em ambientes Acadêmicos, esse valor cai para, aproximadamente, 1\%. Documento, Binário/Compactado, Áudio e Vídeo possuem objetos extensos, como mostra as figuras 4.26 e 4.27. Observa-se que a quantidade de dados transferida em cada requisição do usuário pode ultrapassar com facilidade os $10^{7}$ bytes (aproximadamente 9,5 Mbytes) para a classe Vídeo e obter valores acima de $10^{6}$ para a classe Documento, Áudio e Binário/Compactado. Por fim, os Scripts Clientes/Animação possuem tamanhos que variam de 100 e $10^{5}$ bytes (98 Kbytes), com menos de $1 \%$ buscando objetos maiores que 98 Kbytes.

A tabela 4.17 apresenta os modelos matemáticos e os parâmetros utilizados para representar cada classe de objeto.

Tabela 4.17: Modelos matemáticos para o tamanho dos objetos da categoria Notícia/Informativo.

\begin{tabular}{|c|c|cc|c|c|}
\hline \hline $\begin{array}{c}\text { Classe } \\
\text { de Objeto }\end{array}$ & $\begin{array}{c}\text { Função de } \\
\text { Distribuição }\end{array}$ & \multicolumn{2}{|c|}{ Parâmetros } & Média & $\begin{array}{c}\text { Desvio } \\
\text { Padrão }\end{array}$ \\
\hline \hline Imagem & Weibull & $\alpha: 0,58$ & $\beta: 3.012$ & 4.743 & 8.702 \\
\hline \hline $\begin{array}{c}\text { Linguagem } \\
\text { de Marcação }\end{array}$ & Weibull & $\alpha: 1,28$ & $\beta: 31.257$ & 28.960 & 22.796 \\
\hline \hline Dinâmico & Lognormal & $\mu: 8,37$ & $\sigma: 1,82$ & 22.611 & 116.290 \\
\hline \hline Texto & Weibull & $\alpha: 0,50$ & $\beta: 1.107$ & 2.213 & 4.950 \\
\hline \hline Documento & Gamma & $\alpha: 1,54$ & $\theta: 55.871$ & 86.041 & 69.334 \\
\hline \hline $\begin{array}{c}\text { Script Cliente } \\
\text { e Animação }\end{array}$ & Weibull & $\alpha: 0,83$ & $\beta: 12.079$ & 13.343 & 16.168 \\
\hline \hline Áudio & Gamma & $\alpha: 0,33$ & $\theta: 969.377$ & 319.894 & 556.864 \\
\hline \hline $\begin{array}{c}\text { Binário e } \\
\text { Compactado }\end{array}$ & Lognormal & $\mu: 12,72$ & $\sigma: 1,79$ & $1,65 E+06$ & $8,07 E+06$ \\
\hline \hline Vídeo & Normal & $\mu: 1.517 .140$ & $\sigma: 19.442 .942$ & $1,52 E+06$ & $1,94 E+07$ \\
\hline \hline
\end{tabular}

\subsubsection{Categoria Tradicional}

Essa seção apresenta as características da carga de trabalho de servidores $W e b$ com conteúdo Tradicional, baseado nos quatro itens discutidos neste capítulo e, ao final, propõe modelos matemáticos. Os resultados são utilizados pelo W4Gen para gerar cargas de trabalhos sintéticas representativa de tal ambiente. 


\section{Código de Resposta}

A primeira etapa discute os códigos de resposta dos servidores Web de conteúdo Tradicional. A figura 4.28 mostra a média dos resultados dos dois logs utilizados para caracterizar essa categoria e o modelo Geométrico, com parâmetro 0,59, utilizado para simular o ambiente.

Como ocorre nas outras categorias, a classe 2xx representa a maior parte, com $59 \%$ dos pedidos. Já a classe 3xx apresenta, aproximadamente, 25\%. Observa-se que 5xx não assume valores, mostrando que erros no servidor não são comuns nesse grupo.

A classe 4xx alcança o maior valor das três categorias analisadas. Com uma média acima de $25 \%$, a Tradicional registra altas taxas de erros nas requisições dos clientes. O código de resposta 404 (Not found), responsável por esse alto índice da classe, indica a tentativa de acesso a uma região inexistente do Web site.

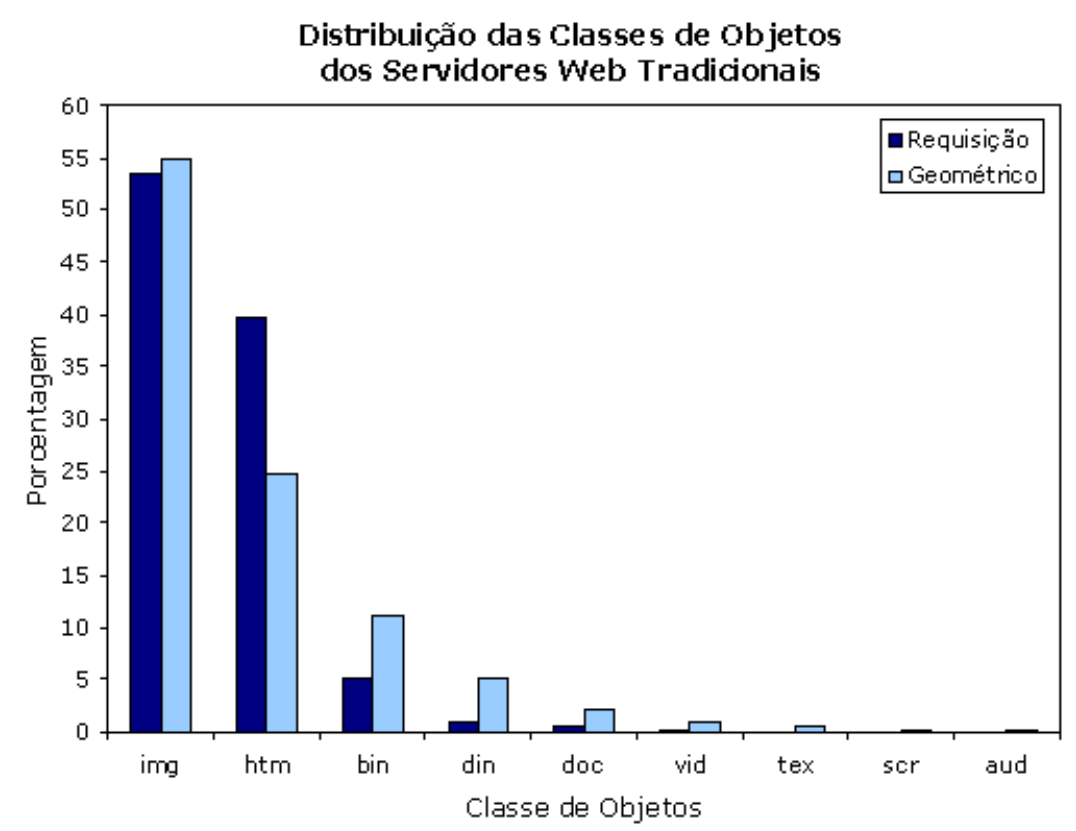

Figura 4.28: Análise dos códigos de respostas da categoria Tradicional.

\section{Classe de Objeto}

A avaliação por categoria de Web site analisou as classes de objetos, buscando identificar comportamentos específicos. A figura 4.29(a) apresenta o volume de dados transferidos por cada classe e a quantidade de requisições nos servidores Web Tradicionais.

Como na categoria Notícia/Informativo, a classe Imagem corresponde ao maior número de requisições, seguida pela Linguagem de Marcação, com 53,6\% e 39,7\% respectivamente. 
No entanto, a quantidade de bytes transferidos pela Imagem equivale a 48,3\%. Esse valor supera todas a outras classes, principalmente a Linguagem de Marcação (aproximadamente 39\% dos bytes), que apesar ser menos referenciada, não é capaz de gerar um volume maior de dados, como foi anteriormente apresentado.

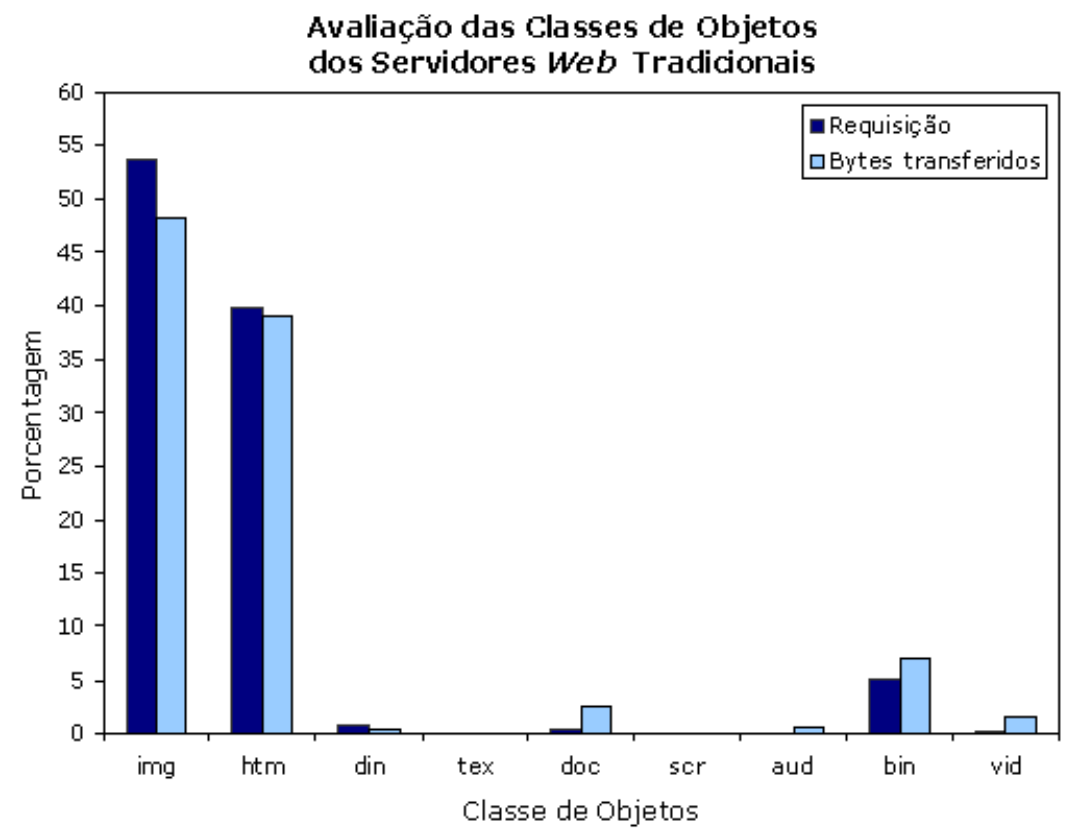

(a)

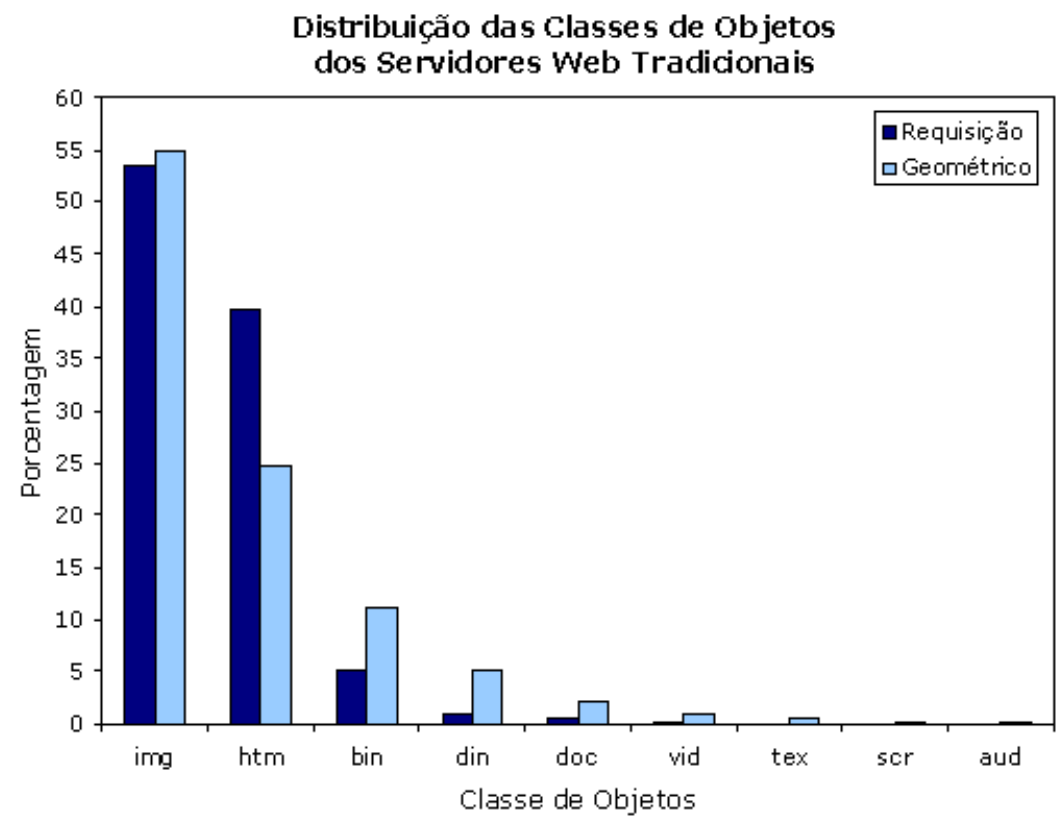

(b)

Figura 4.29: Análise das classes de objetos da categoria Tradicional.

A classe Texto e Script Cliente/Animação não obtiveram valores expressivos, menos de $0,1 \%$, provando ser pouco utilizada. Outro destaque são as requisições dinâmicas. 
Com menos de $1 \%$ e com um volume de dados menor que 0,5\%, a categoria Tradicional dificilmente requer um alto poder de processamento. A classe Binário/Compactado tem maior importância em relação às outras duas categorias. Com 5,15\% das requisições e representando mais de $7 \%$ do total de bytes transferidos, ela é o terceira classe mais conhecida.

Para representar o comportamento das classes de objetos requisitadas nos Servidores Web Tradicionais, a figura 4.29(b) apresenta o modelo Geométrico, com parâmetro 0,55, utilizado para simular o ambiente de requisições.

\section{Intervalo de Chegada}

As figuras 4.30, 4.31 e 4.32 mostra os resultados da análise de logs de servidores Web Tradicionais e apresenta funções de distribuição de probabilidade para simular o ambiente de chegada das requisições.

A classe Imagem, como nas outras categorias, possui a maior demanda entre intervalos iguais a zero e 1 segundo, com 44\%. Isso mostra que tais objetos são freqüentemente requisitados e adequados para a cache. A Linguagem de Marcação, diferente das Imagens, possui uma concentração menor, com apenas $14 \%$ dos pedidos, como mostra o seu gráfico da figura 4.30 e tempos máximos entre requisições que não ultrapassam os $10^{3}$ segundos. Esse comportamento é próximo as outras categorias.

A classe Dinâmico e Texto possuem comportamentos parecidos com a categoria Acadêmico, com $26 \%$ e $3 \%$ das requisições entre intervalos de zero e 1 e tempos máximos que chegam a $10^{5}$ e $10^{4}$ segundos, respectivamente. Já o gráfico da classe Binário/Compactado mostra que $42 \%$ das requisições estão entre os intervalo menores que 1 segundo, a segunda maior taxa de chegada e com $4 \%$ para valores acima $10^{5}$ segundos. Esse intervalo pequeno entre requisições, também comum na categoria Acadêmico, pode sobrecarregar o disco do servidor se arquivos forem muitos extensos, como o download de aplicativos. Como destaca a próxima seção, esse tamanho pode alcançar os 95 Mbytes, uma taxa de transferência alta para uma única requisição. A classe Vídeo não mostrou ser muito acessado, com menos de 10\% alcançando zero ou 1 segundo. O mesmo não ocorre na classe Notícia/Informativo, cujo valores atigem quase $30 \%$.

A tabela 4.18 resume as informações e os parâmetros usados para modelar os comportamento de chegada das requisições. Essa característica da carga de trabalho está implementada no W4Gen, permitindo simular o ambiente de usuários acessando Web sites com conteúdo tradicional. 

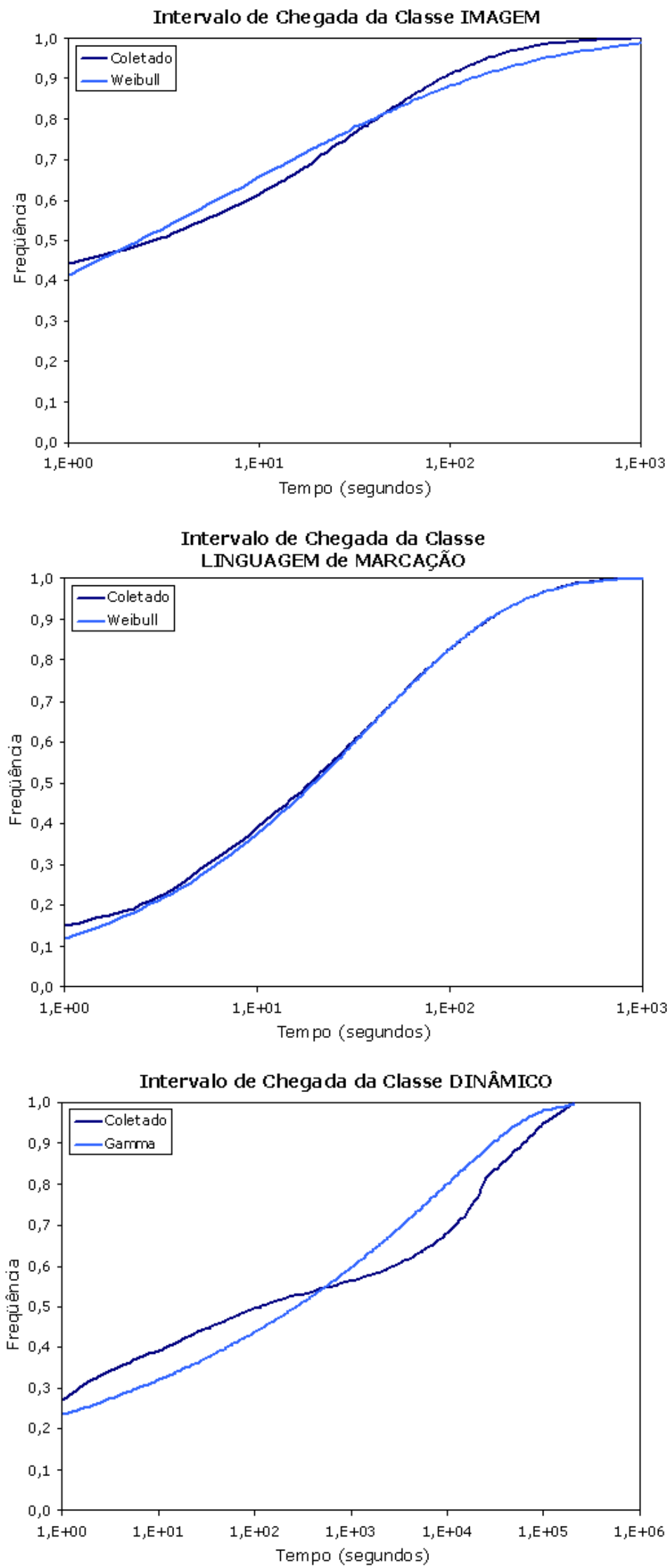

Figura 4.30: Intervalo de chegada dos objetos Imagem, Linguagem de marcação e Dinâmico da categoria Tradicional. 

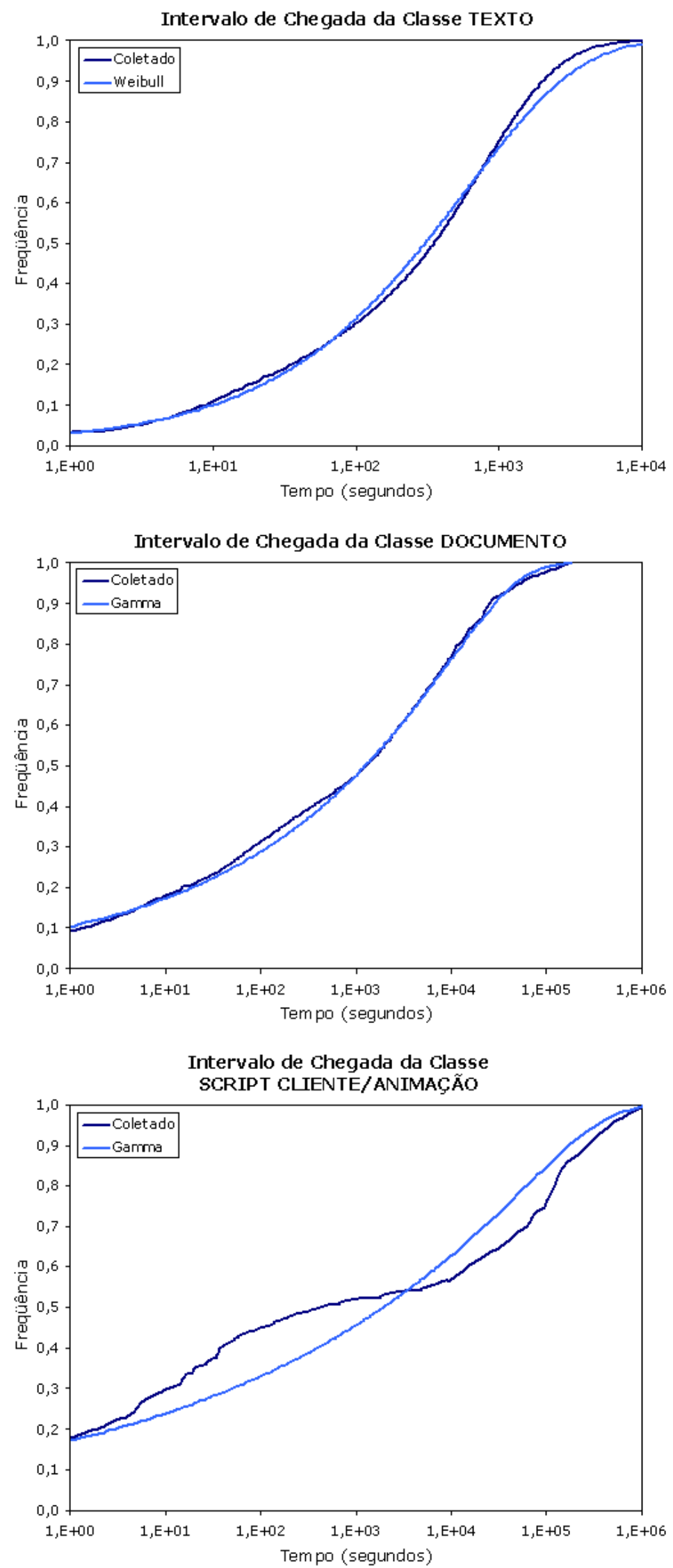

Figura 4.31: Intervalo de chegada dos objetos Texto, Documento e Script cliente da categoria Tradicional. 

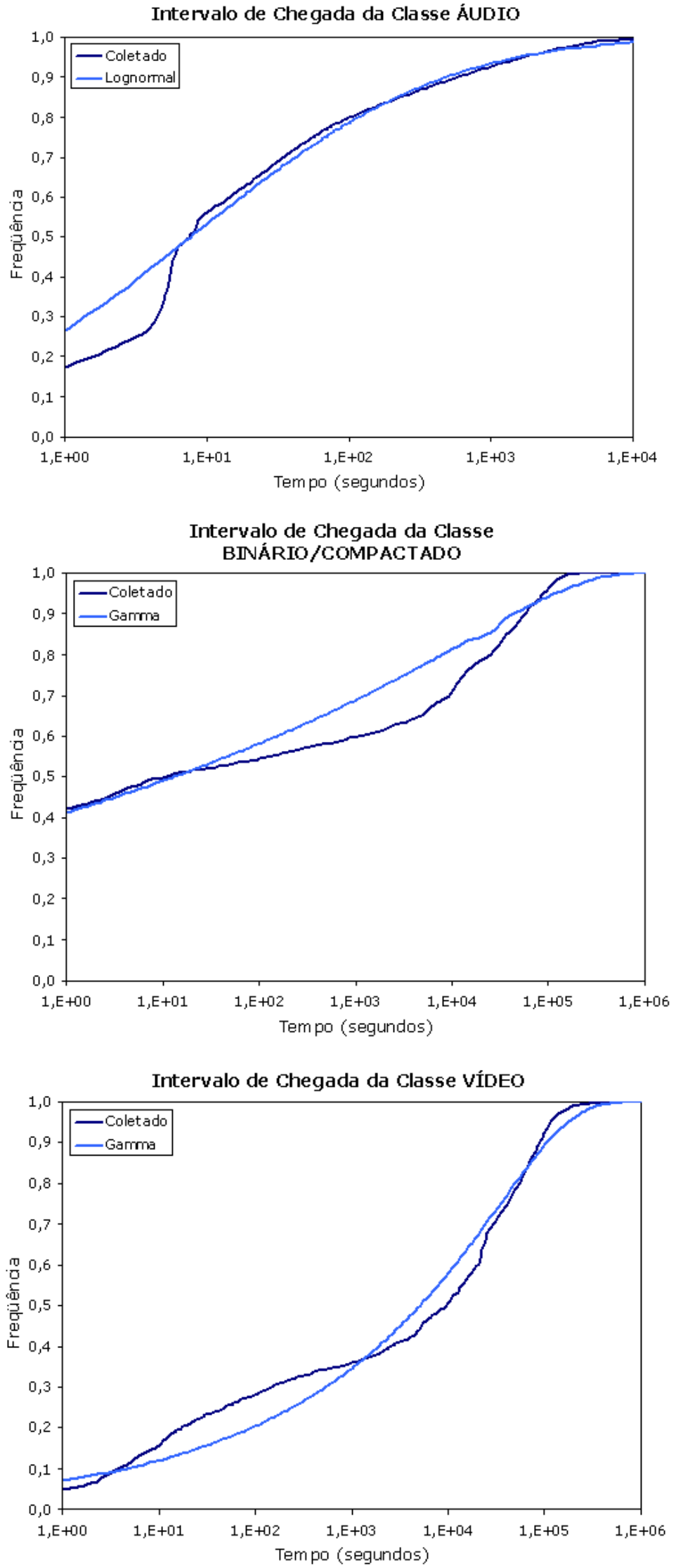

Figura 4.32: Intervalo de chegada dos objetos Áudio, Binário e Vídeo da categoria Tradicional. 
Tabela 4.18: Modelos matemáticos para o intervalo de chegada da categoria Tradicional.

\begin{tabular}{|c|c|cc|c|c|}
\hline \hline $\begin{array}{c}\text { Classe } \\
\text { de Objeto }\end{array}$ & $\begin{array}{c}\text { Função de } \\
\text { Distribuição }\end{array}$ & \multicolumn{2}{|c|}{ Parâmetros } & Média & $\begin{array}{c}\text { Desvio } \\
\text { Padrão }\end{array}$ \\
\hline \hline Imagem & Weibull & $\alpha: 0,30$ & $\beta: 7,99$ & 73 & 400 \\
\hline \hline $\begin{array}{c}\text { Linguagem } \\
\text { de Marcação }\end{array}$ & Weibull & $\alpha: 0,57$ & $\beta: 37,50$ & 60 & 113 \\
\hline \hline Dinâmico & Gamma & $\alpha: 0,14$ & $\theta: 74.988$ & 10.498 & 28.057 \\
\hline \hline Texto & Weibull & $\alpha: 0,55$ & $\beta: 600$ & 1.021 & 2.007 \\
\hline \hline Documento & Gamma & $\alpha: 0,22$ & $\theta: 43.377$ & 9.542 & 20.345 \\
\hline \hline $\begin{array}{c}\text { Script Cliente } \\
\text { e Animação }\end{array}$ & Gamma & $\alpha: 0,14$ & $\theta: 428.528$ & 59.993 & 160.340 \\
\hline \hline Áudio & Lognormal & $\mu: 2,03$ & $\sigma: 3,25$ & 1.497 & 294.338 \\
\hline \hline $\begin{array}{c}\text { Binário e } \\
\text { Compactado }\end{array}$ & Gamma & $\alpha: 0,07$ & $\theta: 268.705$ & 18.809 & 71.092 \\
\hline \hline Vídeo & Gamma & $\alpha: 0,23$ & $\theta: 154.645$ & 35.568 & 74.165 \\
\hline \hline
\end{tabular}

\section{Tamanho do Objeto}

As figuras 4.33, 4.34 e 4.35 mostram os resultados coletados e as propostas de modelos matemáticos para simular o ambiente Tradicional.

A classe Imagem possui o maior número de requisições e de dados transferidos. Os tamanhos variam de apenas 10 bytes a $10^{5}$ bytes (98 Kbytes), com mais de $50 \%$ das requisições transferindo arquivos acima de 1 Kbyte.

A segunda maior classe, Linguagem de Marcação, possui um comportamento semelhante a Imagem, com arquivos dentro do mesmo limite. Nota-se que $2 \%$ dos arquivos transferidos são menores que 10 bytes, o que não ocorre nas categorias Acadêmico e Notícia/Informativo.

A classe Binário/Compactado possui tamanho de arquivos entre $10^{4}$ a $10^{7}$ bytes, com aproximadamente 3\% atingindo valores acima dos 9,5 Mbytes. Ao contrário das outras categorias, mais de 10\% dos arquivos são menores que 100 bytes. Já a classe Documento varia de $10^{3}$ a $10^{6}$ bytes e arquivos menores que 100 bytes representam $20 \%$.

A tabela 4.19 resume os parâmetros e modelos matemáticos utilizados para representar os tamanhos de arquivos da $W e b$ tradicional. Essas distribuições também estão implementadas no W4Gen. 


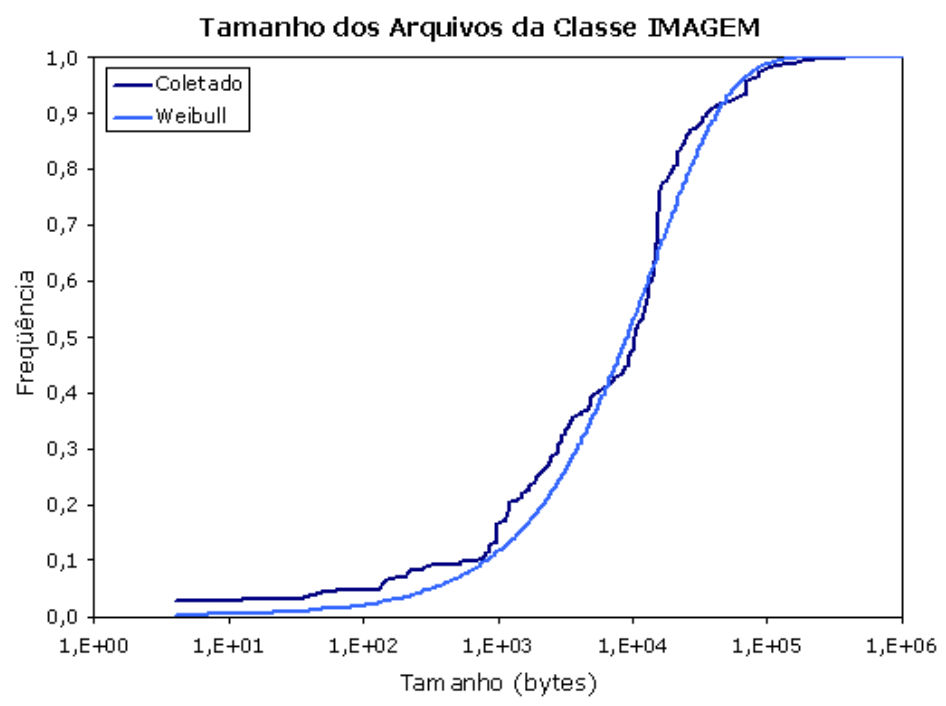

Tamanho dos Arquivos da
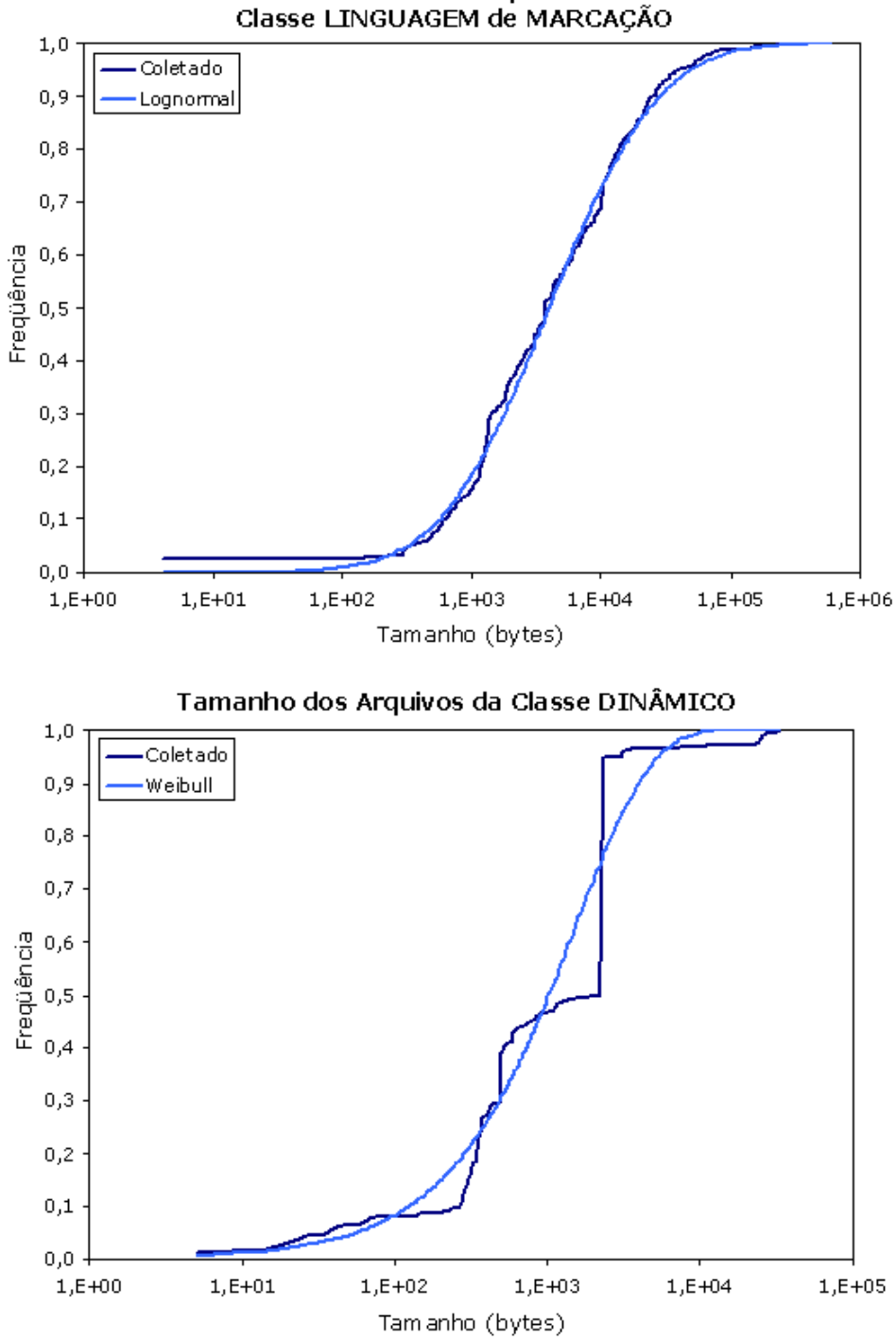

Figura 4.33: Tamanho dos objetos Imagem, Linguagem de marcação e Dinâmico da categoria Tradicional. 

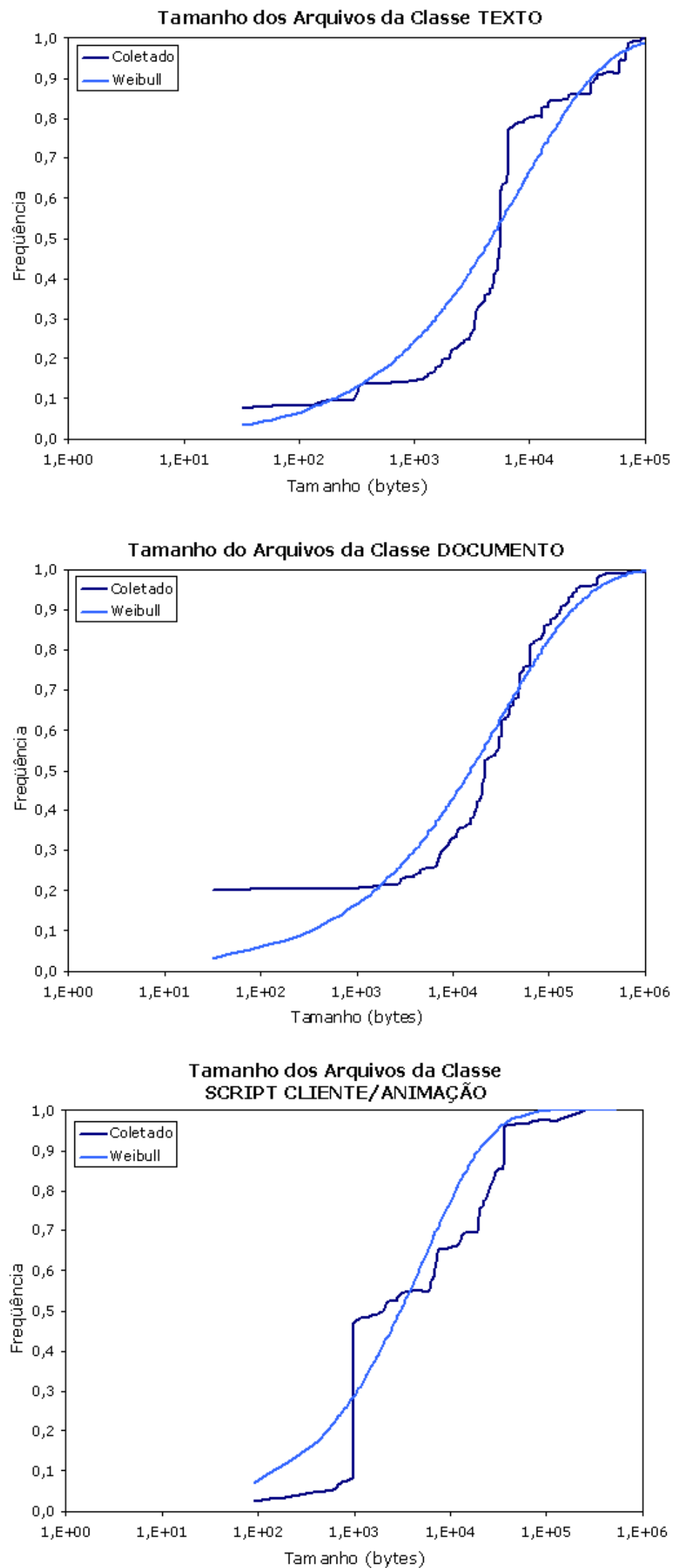

Figura 4.34: Tamanho dos objetos Texto, Documento e Script cliente da categoria Tradicional. 


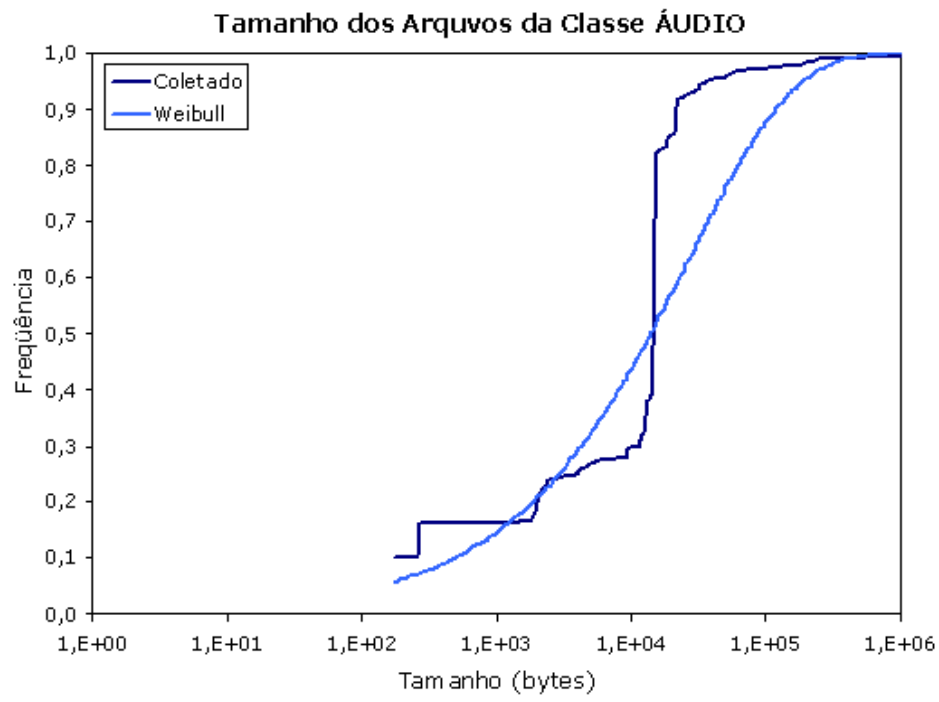

Tamanho dos Arquivos da Classe
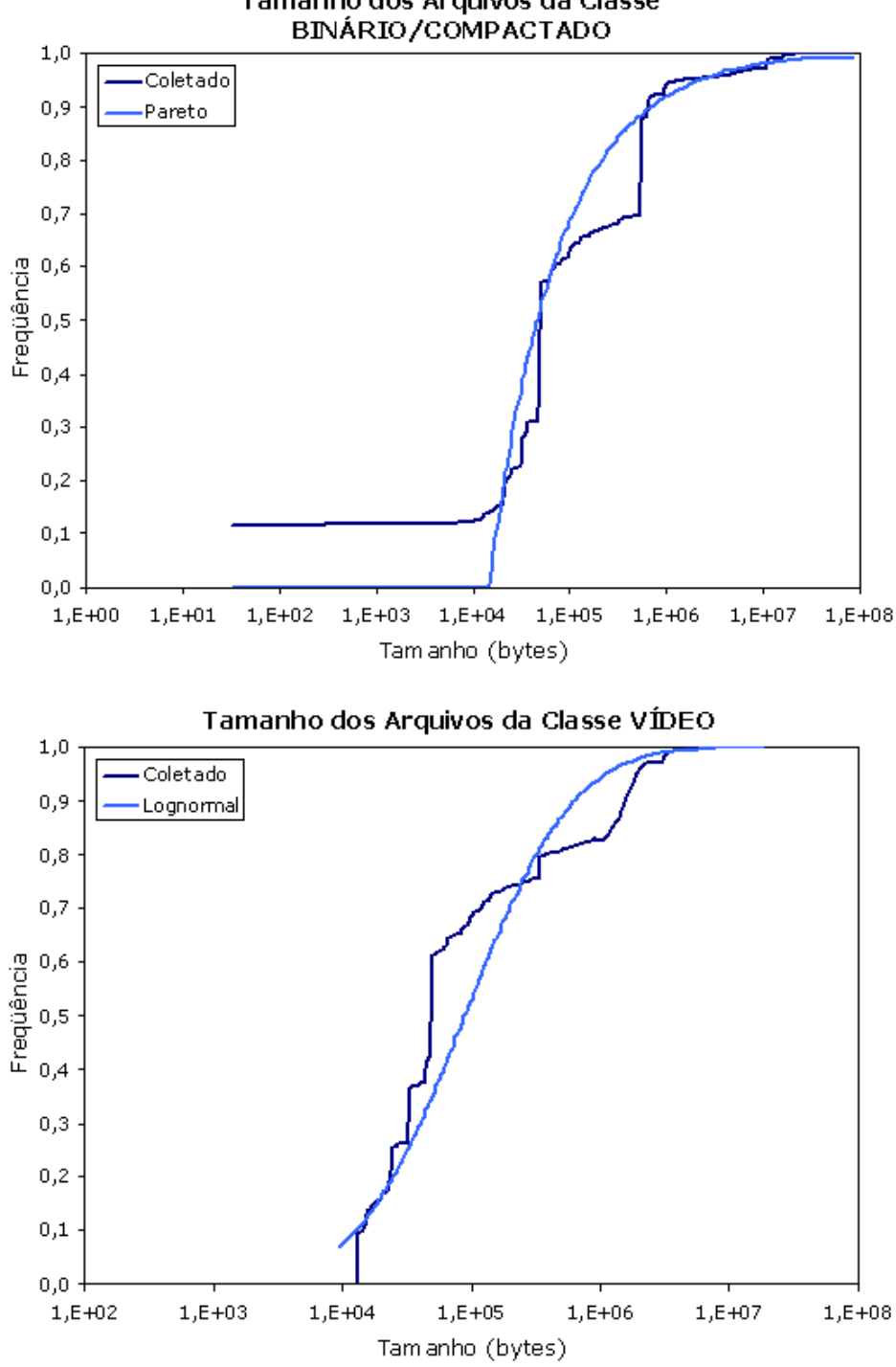

Figura 4.35: Tamanho dos objetos Áudio, Binário e Vídeo da categoria Tradicional. 
Tabela 4.19: Modelos matemáticos para o tamanho dos objetos da categoria Tradicional.

\begin{tabular}{|c|c|cc|c|c|}
\hline \hline $\begin{array}{c}\text { Classe } \\
\text { de Objeto }\end{array}$ & $\begin{array}{c}\text { Função de } \\
\text { Distribuição }\end{array}$ & \multicolumn{2}{|c|}{ Parâmetros } & Média & $\begin{array}{c}\text { Desvio } \\
\text { Padrão }\end{array}$ \\
\hline \hline Imagem & Weibull & $\alpha: 0,78$ & $\beta: 14.570$ & 16.818 & 21.790 \\
\hline \hline $\begin{array}{c}\text { Linguagem } \\
\text { de Marcação }\end{array}$ & Lognormal & $\mu: 8,30$ & $\sigma: 1,53$ & 12.970 & 39.747 \\
\hline \hline Dinâmico & Weibull & $\alpha: 0,89$ & $\beta: 1.543$ & 1.633 & 1.839 \\
\hline \hline Texto & Weibull & $\alpha: 0,60$ & $\beta: 8.498$ & 12.785 & 22.478 \\
\hline \hline Documento & Weibull & $\alpha: 0,49$ & $\beta: 32.395$ & 67.298 & 154.833 \\
\hline $\begin{array}{c}\text { Script Cliente } \\
\text { e Animação }\end{array}$ & Weibull & $\alpha: 0,64$ & $\beta: 5.326$ & 7.405 & 12.030 \\
\hline \hline Áudio & Weibull & $\alpha: 0,56$ & $\beta: 26.920$ & 44.594 & 85.590 \\
\hline \hline $\begin{array}{c}\text { Binário e } \\
\text { Compactado }\end{array}$ & Pareto & $\alpha: 14.500$ & $\beta: 0,60$ & 21.750 & 23.731 \\
\hline \hline Vídeo & Lognormal & $\mu: 11,40$ & $\sigma: 1,52$ & 283.565 & 854.397 \\
\hline \hline
\end{tabular}

\subsubsection{Comparativo entre as Categorias}

Esta seção realiza um comparativo entre as três categorias de carga de trabalho apresentadas. Com relação ao código de resposta, a categoria Acadêmico alcançou o maior índice para classe 2xx, representando $69 \%$ das requisições, enquanto que a categoria Tradicional obteve apenas 59\%. Para a classe de código de resposta 3xx, esses valores variaram de $25 \%$ a $32 \%$ para as categorias Acadêmico e Notícia/Informativo, respectivamente. Já a classe $4 \mathrm{xx}$ variou de apenas $3 \%$ para a categoria Noticia/Informativo a $16 \%$ para a categoria Tradicional. Requisições do tipo 5xx obtiveram 0,01\% para todas as categorias. Ao analisar os resultados, observa-se um padrão entre as categorias do ponto de vista dos códigos de resposta com algumas oscilações, conseqüência da variabilidade encontrada na Web. A invariante 1 e 2 da tabela 4.20 apresenta o resumo das informações sobre o código de resposta.

Com relação as classes de objetos, a grande proporção das requisições está concentrada na classe Imagem. Com exceção da categoria Acadêmico, cujo número de requisições para a Linguagem de Marcação foi superior, para as outras duas categorias a classe Imagem atingiu proporções muito superiores a qualquer outro tipo de objeto, confirmando a sua popularidade na Web. Para a classe Linguagem de Marcação, observa-se que tais objetos são requisitados com maior freqüência nas categorias Acadêmico e Tradicional, com 44\% e $40 \%$ respectivamente. Na categoria Notícia/Informativo esse valor atingiu apenas 11\%, sendo compensado pelo objeto Dinâmico, cujo valor ultrapassou os $30 \%$. Portanto, quanto maior é o número de referências a objetos do tipo Linguagem de Marcação, menor será o 
número de requisições Dinâmicas.

Do ponto de vista dos outros objetos analisados, na categoria Acadêmicos observa-se uma presença maior de requisições para objetos do tipo Documento, representando quase $5 \%$ do total. Para as outras duas categorias, este valor não ultrapassa 0,5\%. A categoria Notícia/Informativo destaca-se pela presença maior de requisições para objetos do tipo Script Cliente/Animação, o que não ocorre nas outras duas categorias. Além disso, observa uma quantidade maior de requisições para a classe Texto. Por fim, na categoria Tradicional observa-se uma concentração elevada de requisições para objetos do tipo Binário/Compactado, com valores que atinge 5,14\% do total. Para as outras categorias, esse valor não supera 0,2\%. Outro destaque está na classe Vídeo que alcançou 0,8\%. Apesar de ser um valor pequeno, nas outras duas categorias este valor atinge somente 0,04\% para a categoria Acadêmico e menos de $0,01 \%$ para a categoria Notícia/Informativo. Em Tradicional também observa a presença muito pequena de objetos do tipo Texto.

Para o intervalo de chegada das requisições, observa-se que em todas as categorias analisadas, a classe Imagem obteve a maior concentração entre os 10 primeiros segundos, enquanto que a classe Linguagem de Marcação assume valores próximos em todas as categorias, representado pelo mesmo modelo matemático. Para a categoria Acadêmico, o intervalo das requisições do tipo Documento apresentou os menores intervalos entre as requisições, com $30 \%$ entre zero e 1 segundo. Já a categoria Notícia/Informativo, o intervalo de chegada dos objetos do tipo Dinâmico e Texto apresentaram as maiores taxas entre tempos de no máximo 1 segundo, com de 55\% e 47\% respectivamente. Por fim, a categoria Tradicional destaca-se pela concentração de requisições do tipo Binário/Compactado, com mais de $40 \%$ entre no máximo 1 segundo.

O tamanho dos objetos também apresentam algumas relações. Todas as categorias analisadas concentraram a maior parte das requisições para os objetos Imagem e Texto entre $10^{2}$ e $10^{5}$ bytes, enquanto que a classe Linguagem de Marcação, estes valores alcançaram os $10^{6}$ bytes. Para a categoria Acadêmico, o destaque está no tamanho dos objetos do tipo Documento, que podem atingir proporções que chegam a $10^{7}$ bytes. Já a categoria Notícia/informativo destaca-se pela ausência de requisições de Vídeo menores que $10^{6}$ bytes e de requisições Dinâmicas que podem ser maiores que $10^{5}$ bytes. Na classe Tradicional observa-se que objetos do tipo Áudio possui o menores tamanhos, com valores que não ultrapassam os $10^{6}$ bytes.

A tabela 4.20 apresenta as invariantes observada na análise das categoria. Este estudo também pode ser estendido para outros tipos de categorias, tal como, e-commerce. 
Tabela 4.20: As invariantes das categorias de Web sites.

\begin{tabular}{|c|l|}
\hline \hline Invariante & Descrição \\
\hline \hline 1 & Taxa de sucesso de requisições ao servidor encontra-se entre 59\% a 69\%. \\
\hline \hline 2 & $\begin{array}{l}\text { O número de requisições para objetos do tipo Linguagem de Marcação é } \\
\text { inverso o número de requisições Dinâmicas }\end{array}$ \\
\hline \hline 3 & $\begin{array}{l}\text { A classe Imagem possui a maior concentração das referências entre inter- } \\
\text { valos de no máximo 10 segundos para as três categorias. }\end{array}$ \\
\hline \hline 4 & $\begin{array}{l}\text { O intervalo de chegada da classe Linguagem de Marcação possui valores } \\
\text { próximos nas três categorias, representado pela mesma distribuição. }\end{array}$ \\
\hline \hline 5 & $\begin{array}{l}\text { O tamanhos dos arquivos da classe Imagem está entre } 10^{2} \text { e } 10^{5} \text { bytes para } \\
\text { as três categorias. }\end{array}$ \\
\hline \hline
\end{tabular}

\subsection{Considerações Finais}

O crescimento contínuo da $W e b$ tem motivado inúmeras pesquisas que visam melhorar o seu desempenho. Para isso, é preciso compreender o seu comportamento para propor novas soluções. Portanto, este capítulo apresentou-se alguns trabalhos da literatura sobre caracterização de carga de trabalho da $W e b$ e a sua evolução ao longo dos últimos anos. Em seguida discutiu-se a coleção dos dados, apresentando o formato do Common Log Format do Apache utilizado para extrair as informações da Web, algumas informações gerais sobre os dados utilizados e o processo de redução aplicado aos logs para eliminar requisições com erros.

Neste capítulo também foi apresentado um estudo da caracterização da carga de trabalho da $W e b$, coletada de nove logs de diferentes magnitudes, variando de poucas semanas a anos de atividade. Nessa análise, discutiram-se algumas características gerais, como a versões do protocolo HTTP e os métodos usados para requisitar as páginas. Além disso, o intervalo de chegada, as classes de objetos, o código de resposta retornado pelo servidor e o tamanho dos objetos também foram estudados. Ao final modelos matemáticos foram propostos para simular o comportamento dos usuários da Web. Por fim, a seção 4.5 apresentou a mesma análise baseado nas quatro características da seção anterior. Entretanto, devido a diversidade de logs, foi possível classificá-los em categorias, com base no conteúdo do Web site e tratá-los, separadamente, afim de quantificar ambientes específicos da WWW.

Para compreender a evolução da $W e b$, os gráficos da figura 4.36 apresentam os resultados acrescentando a análise da carga de trabalho de 2005. Observa-se que no gráfico 4.36(a), o número de requisições retornadas com o código de resposta 2xx manteve-se próximo ao valor observado em 2003, não apresentando uma queda conforme foi visto nos 
outros anos. Já a classe 3xx (redirecionamento) reduziu de 31,6\%, em 2003, para 25,8\%, em 2005, não seguindo o crescimento observado nos últimos anos. O grande destaque, no entanto, está no código de resposta 4xx que ultrapassou 9\% em 2005. Isso mostra a presença excessiva de requisições com erros, com destaque para a presença de requisições do tipo 404 (Not Found), ou seja, o usuário tenta acessar um objeto (região) que não existe no servidor. Para a classe 5xx não foi observado nenhum crescimento de 2003 para 2005.

Na figura 4.36(b) é apresentado a evolução no comportamento dos objetos mais requisitados nos servidores Web. Observa-se que a Linguagem de Marcação (HTML) representam 28\% de todas as requisições. Esse crescimento de 2003 para 2005 deve-se, principalmente, pela presença de categorias de Web sites, tais como, Tradicional que ainda utilizam muito esse tipo objeto. Já classe Imagem obteve a menor média durante os últimos anos, com apenas $48 \%$ das requisições. Devido a diversidade de logs analisados, essa classe diminuiu influenciada pela tendências das categorias de Web site Acadêmico e Notícia/Informativo.

Ao contrário das outras classes, os objetos Dinâmicos obtiveram um comportamento que se repete durante a última década, ou seja, ele vem crescendo nos últimos anos e, atualmente, representa $15 \%$ das requisições. Esse aumento é uma das conseqüências da facilidade atual de desenvolver páginas dinâmicas e da popularização das linguagens de programação, tais como, PHP, ASP e JSP. A classe Outros, que incluem arquivos multimídia e animações, manteve-se próxima aos valores observados em 2003, não havendo nenhum queda substancial.

Os resultados apresentados neste capítulo são usados para implementar o gerador de cargas de trabalho sintéticas, o W4Gen, baseado no comportamento atual da Internet, para avaliar o desempenho de modelos de servidores Web e de novos algoritmos de escalonamento.

O próximo capítulo desta dissertação apresenta o $W 4 G e n$, descrevendo suas principais características e como é possível modificar sua estrutura de implementação para incorporar novas informações da carga de trabalho para avaliação de desempenho de modelos de servidores $W e b$. 


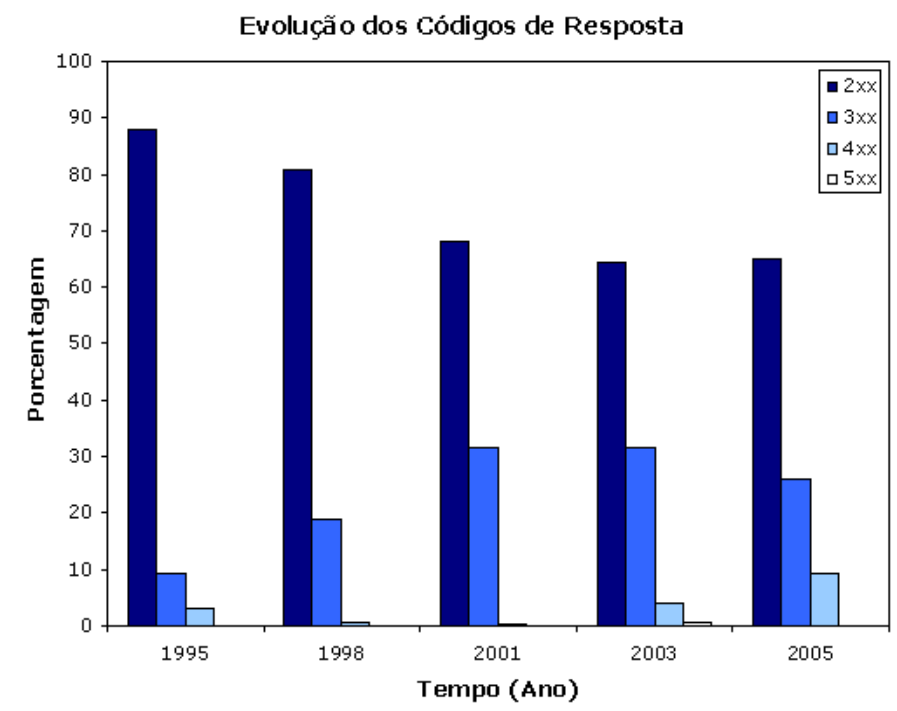

(a)

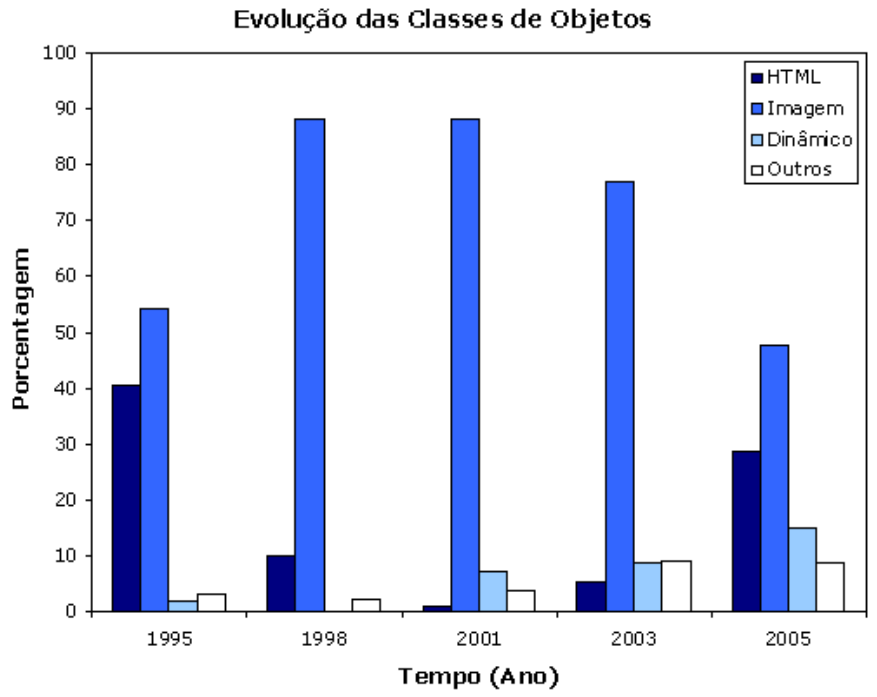

(b)

Figura 4.36: Evolução da carga de trabalho com base nos resultados atuais. 


\section{W4Gen}

\subsection{Considerações Iniciais}

Como foi discutido anteriormente, o crescimento da Web tem motivado várias pesquisas que buscam quantificar seu tráfego, analisando e compreendendo as características da carga de trabalho. Com base nessa ideia, neste capítulo será apresentado o $W_{4} G e n$ (World Wide Web Workload Generator), um gerador de cargas de trabalho sintéticas, capaz de reproduzir ambientes da $W e b$ para a simulação.

Baseado em informações coletadas de diversos traces de servidores Apache, todos os modelos de carga são gerados por meio de funções de distribuição de probabilidade, apresentadas no capítulo anterior. Além disso, W4Gen também possui uma interface gráfica amigável, fornecendo um ambiente para o usuário reproduzir alguns cenários, tais como, sites de notícia, sites acadêmico, entre outros. O W4Gen também permite modificar as características da carga de trabalho, adequando-o para o perfil desejado.

Neste capítulo, portanto, será apresentado o W4Gen, discutindo o ambiente de geração da carga de trabalho sintética e a sua estrutura de implementação para inserir novos tipos de características. Para isso, a seção 5.2 mostra alguns dos trabalho relacionados a essa área de avaliação de desempenho. Na seção 5.3 são discutidos os componentes da carga de trabalho e a biblioteca de funções de distribuição. Na seção 5.4 é apresentado o diagrama de classe, explicando como é possível acrescentar novos elementos a carga de trabalho. Por fim, na seção 5.5 é apresentada a interface gráfica do W4Gen.

\subsection{Trabalhos Relacionados}

Apesar da grande necessidade de se avaliar os servidores $W e b$, visando oferecer aos usuários um melhor serviço, poucos trabalhos foram encontrados na literatura descrevendo geradores de carga para servidores $W e b$. Esses poucos trabalhos encontrados apresentam 
benchmarks que, apesar de bastante útil para avaliar o desempenho, possuem um propósito diferente do pretendido nesta dissertação. Como a maioria dos benchmarks apresenta a geração de uma carga para avaliar servidores $W e b$, eles serão discutidos nesta seção.

\section{WebStone}

O WebStone é um dos benchmarking mais conhecidos para avaliar o desempenho de servidores Web. Ele envia uma série de requisições HTTP/1.0 do tipo GET para documentos específicos no servidor.

A carga de trabalho é gerada através da simulação de múltiplos clientes executando em um computador ou em vários ao mesmo tempo. As características, tais como, a freqüência de acesso e tamanho dos arquivos foram derivados de padrões de acesso a Web sites populares. Disponível no site do novo fabricante para download, a Midicraft (WEBSTONE, 2002), ele testa o servidor $W e b$ usando requisições do tipo estática e dinâmica.

Os principais resultados produzidos são o throughput e a latência. O throughput representa o número de bytes por segundo retornados pelo servidor Web. Já a latência é dividida em dois tipos: latência da conexão e latência da requisição (WEBSTONE, 2002). O primeiro atraso reflete o tempo para estabelecer uma conexão com o servidor, enquanto o segundo determina o tempo para a conclusão da transferência dos dados após a conexão ser estabelecida.

\section{SPECWeb}

Desenvolvido pela SPEC, o SPECWeb é um benchmarking cujo objetivo é medir o desempenho de servidores $W e b$ segundo o número de requisições simultâneas suportadas (sobrecarga), em plataformas Windows NT e UNIX. Ele consiste de um servidor Web e um conjunto de clientes que geram a carga de trabalho. O objetivo é aumentar a intensidade de requisições feitas pelos clientes a fim de levar o servidor ao seu limite extremo, onde ele começa a degradar de forma significativa. Essa quantidade de pedidos entre clientes e servidores representam o número real de conexões simultâneas suportadas e, portanto, esta é a métrica utilizada (SPECWEB2005, 2005).

A carga de trabalho do SPECWeb é baseada em estudos de logs de vários servidores populares da Internet e alguns Web sites menores. Isto inclui páginas estáticas e dinâmicas, uso de sessões, além de teste com conexões persistente encontrada no protocolo HTTP/1.1 (SPECWEB2005, 2005). Ele também mistura quatro classes de arquivos de 
acordo com o tamanho do arquivo e a porcentagem de acesso. Dentro de cada classe, as distribuições mostram de fato que certos arquivos são acessados com maior freqüência. Esses acessos são distribuídos segundo a lei de Zipf (ZIPF, 1972).

\section{Surge}

Barford \& Crovella (1998) propôs uma outra forma para gerar cargas de trabalho para servidores Web. O SURGE (Scalable URL Reference Generator), como é chamado, reproduz a carga por meio de funções de distribuição de probabilidade, com base na análise de traces específicos de servidores $W e b$ reais.

Ele utiliza o conceito de User Equivalent ${ }^{1}$, medindo o desempenho através do comportamento de uma população de usuários. Com isso, o benchmarking obtém uma aproximação mais realista do ambiente da Internet. Além disso, outras características, tais como, tamanho e popularidade dos arquivos, tamanho das requisições, referências embutidas $^{2}$ e localidade temporal são também agregadas a carga de trabalho.

\section{Httperf}

O Httperf, desenvolvido por Mosberger \& Jin (1998), é um outra alternativa disponível capaz de reproduzir basicamente dois tipos de carga de trabalho, uma carga híbrida e uma carga baseada em traces. Ambos os métodos permitem a simulação de uma carga orientada a sessão, contendo tanto requisições estáticas quanto dinâmicas.

No formato híbrido, o benchmarking possibilita especificar uma única ou múltiplas URLs junto com o tempo de pensar (think time) para representar as sessões. Já na geração baseada em traces, as sessões de usuários são definidas com base nas informações coletadas dos traces. HTTPerf permite o uso dos protocolos HTTP/1.0 e 1.1, incluindo cookies e a inserção de requisições com suporte a SSL. Ele também permite especificar algumas características do browser, tais como, o uso de conexões múltiplas simultâneas.

\section{Geist}

Uma outra alternativa é o Geist (KANT et al., 2001), um benchmarking desenvolvido em 2001, capaz de gerar uma carga de trabalho real para exercitar servidores Web com

\footnotetext{
${ }^{1}$ Um processo em laço infinito que alterna entre realizar a requisição ao servidor e aguardar um tempo para, então, refazer um novo pedido. Esse característica imita o comportamento de um usuário da Web.

${ }^{2}$ Refere-se a requisições executadas automaticamente pelo browser quando um usuário acessa uma página da $W e b$.
} 
conteúdo de e-commerce. Ele fornece um grande número de parâmetros permitindo caracterizar desde simples chamadas a páginas estáticas a complexas transações, comuns em sites comerciais.

Diferentemente de outros geradores, o Geist concentra seus esforços na característica do tráfego agregado que chega ao servidor, permitindo o melhor controle de suas propriedades. O tráfego agregado, ao invés de emular o comportamento de usuários individuais, como ocorre com outras abordagens, ele tenta simular as propriedades importantes do ponto de vista do servidor, criando diversos threads que irão gerar as requisições no tempo correto.

Todos esses trabalho geram requisições para servidores Web reais. Este trabalho, no entanto, reproduz uma carga para ser utilizada na simulação de modelos de servidores Web, como será explicado na próxima seção.

\subsection{Sobre o W4Gen}

A WWW possui características especiais que a tornam um sistema exclusivo. Atualmente, ela é composta de milhares de instituições de pesquisa, órgãos do governo e, principalmente, empresas privadas. Devido a grande variedade de sites $^{3}$ e a dificuldade atual de obter cargas de trabalho reais condizente com a realidade, o W4Gen foi desenvolvido como parte desse trabalho, cujo objetivo é gerar alguns tipos de cargas de trabalho sintética para avaliação de desempenho de modelos de servidores Web. Com ele é possível imitar o ambiente da $W e b$ e facilitar a validação de novos modelos e de algoritmos de escalonamento que visam aumentar o desempenho como um todo.

Nesta seção será iniciada a discussão sobre a biblioteca de classes PSOL utilizada pelo W4Gen. Depois serão apresentadas as principais características e, ao final, o formato da carga de trabalho, identificando os campos que a compõem.

\subsubsection{Biblioteca de Modelos Matemáticos}

A PSOL (Probability/Statistics Object Library) (SIEGRIST, 2005) é uma biblioteca de classes, desenvolvida em linguagem Java, cujo objetivo é ajudar professores e estudantes a ilustrar os conceitos e técnicas da probabilidade e estatística de uma maneira interativa.

\footnotetext{
${ }^{3}$ Cada site possui características específicas e exige demandas diferenciadas nos servidores Web. Por exemplo, há requisições com consumo maior de disco (binário) e requisições com consumo maior de CPU (dinâmica).
} 
Licenciada pela Creative Commons License que permite copiar, distribuir, exibir e executar a obra, ela foi projetada pela Universidade do Alabama, em Huntsville. Composta de applets com interfaces e objetos matemáticos, ela é facilmente extensível permitindo a adição de novos modelos matemáticos.

Como parte dos requisitos para geração de carga de trabalho para $W e b$, a PSOL foi utilizada para reproduzir as características das requisições. Além das distribuições básicas, o W4Gen também utiliza a Pareto Geral, com a adição de um parâmetro de escala. Esse modelo não está implementado na biblioteca PSOL e, portanto, precisou ser acrescentada ao conjunto de classes do gerador. A equação da densidade da Pareto Geral é apresentada em 5.1.

$$
f(x)=\frac{(\alpha \beta)^{\beta}}{x^{\beta+1}} \quad(\alpha>0, \beta>0)
$$

A função Geométrica precisou ser adaptada para reproduzir as características do objeto e do código de resposta. Ao invés de simplesmente gerar números aleatórios, a nova distribuição agora é capaz de gerar o domínio de valores apresentado na tabela 5.1, representando melhor as características da requisição.

\subsubsection{Características Gerais}

Desenvolvido em Linguagem Java, o W4Gen é um gerador de cargas para avaliação de desempenho de modelos de servidores $W e b$. Suas principais características são:

- Gerar cargas de trabalhos sintéticas para modelos de servidores $W e b$.

- Gerar cargas de trabalhos de ambientes pré-definidos, tais como, sites acadêmicos, notícia, entre outros.

- Possibilitar a modificação de determinadas características da carga de trabalho, permitindo uma configuração específica de um ambiente da Web.

- Selecionar dentre inúmeras funções de distribuição de probabilidade a mais apropriada para reproduzir uma característica da carga de trabalho.

- Permitir ao usuário selecionar modelos pré-definidos ou criar seu próprio modelo de carga, por meio de uma Interface gráfica amigável. 
O objetivo é atender os usuários (alunos e professores) que necessitem de cargas de trabalho para avaliar seus modelos de servidores $W e b$, algoritmos de escalonamento, entre outros. O intuito, portanto, é eliminar a etapa de selecionar novas cargas de trabalho para os diversos tipos de ambientes da Web.

Composto de uma interface gráfica simples, o W4Gen permite modificar todas as características da carga e reproduzir várias situações. O usuário, no entanto, deve ter um controle sobre as modificações realizadas, pois a escolha de uma nova distribuição pode não representar fielmente o comportamento usual da $W e b$. Os padrões pré-definidos no W4Gen são baseados nos estudos apresentados no capitulo anterior.

\subsubsection{Modelo de Carga de Trabalho}

O W4Gen é capaz de gerar cargas de trabalho sintéticas segundo quatro características: o intervalo de chegada das requisições, a classe de objeto, o código de resposta retornado pelo servidor $W e b$ e o tamanho do objeto.

A figura 5.1 apresenta os componentes da carga de trabalho. A primeira característica determina o timestamp da requisição, ou seja, o instante em que ela chegou ao servidor Web. Também é importante ressaltar que todos os valores produzidos estão organizados em ordem crescente, sempre iniciando em zero.

O segundo campo identifica o tipo de objeto requisitado no servidor Web. Neste caso, esse campo pode assumir nove valores, representando as nove classes ${ }^{4}$ criadas para agrupar as variações de objetos. A classificação foi apresentada no capítulo anterior, na seção 4.4.3.

\begin{tabular}{||l|l|l|l|}
\hline Timestamp & Objeto & $\begin{array}{c}\text { Código de } \\
\text { resposta }\end{array}$ & $\begin{array}{l}\text { Tamanho } \\
\text { do objeto }\end{array}$ \\
\hline
\end{tabular}

Figura 5.1: Formato da requisição do $W_{4} G e n$.

O próximo elemento da carga de trabalho representa o código de resposta retornado pelo servidor $W e b$. De grande importância, essa informação determina se a requisição gerada pelo usuário foi aceita e processada, alocando recursos do sistema, ou se ela foi rejeitada por falta de informações ou por estar inválida. Portanto, quatro valores representam os quatro tipos de código de resposta. Esses valores estão discriminados na tabela 5.1 .

\footnotetext{
${ }^{4}$ Essas classes são baseadas na extensão do arquivo requisitado.
} 
Por fim, o tamanho do objeto determina a quantidade de dados transferido, em bytes. Nesse instante, somente as requisições cujo código de resposta é equivalente a 200 ou 2xx assumem valores maiores que zero. Para todas as outras classes, os tamanhos são iguais a zero.

A figura 5.2 mostra um exemplo de um arquivo reproduzido pelo W4Gen, contendo os quatro campos anteriormente mencionados. No exemplo, todas as requisições chegaram no mesmo instante, ou seja, no tempo zero. Observa-se também a presença de diversos tipos de objetos, tais como, imagem (image), vídeo (video), entre outros e dois grupos de código de resposta, a 2xx (Successful) e a 3xx (redirecionamento).

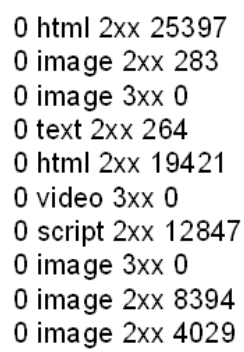

Figura 5.2: Exemplo de um arquivo texto reproduzido pelo $W_{4} G e n$.

A tabela 5.1 resume o domínio de valores que os elementos da carga de trabalho podem assumir. Para o timestamp e o tamanho do objeto, os valores compreendem um número inteiro positivo. No elemento objeto, nove valores representam as novas classes de objeto, enquanto que no campo código de resposta, quatro valores determinam as quatro possíveis classes de retornos. A próxima seção apresenta a modelagem do W4Gen.

Tabela 5.1: O domínio de valores para os campos da requisição.

\begin{tabular}{|c|c|}
\hline \hline Campos & Domínio de valores \\
\hline \hline Timestamp & {$[0,+\infty)$} \\
\hline \hline Objeto & $\begin{array}{r}\text { image, html, dynamic, text, document, } \\
\text { script, audio, binary, video }]\end{array}$ \\
\hline \hline $\begin{array}{c}\text { Código de } \\
\text { resposta }\end{array}$ & {$[2 \mathrm{xx}, 3 \mathrm{xx}, 4 \mathrm{xx}, 5 \mathrm{xx}]$} \\
\hline \hline $\begin{array}{c}\text { Tamanho } \\
\text { do Objeto }\end{array}$ & {$[0,+\infty)$} \\
\hline \hline
\end{tabular}

\subsection{Modelagem do W4Gen}

A modelagem é uma parte importante das atividades que conduzem ao desenvolvimento de um bom software. Ela também é uma simplificação da realidade que facilita a 
compreensão do comportamento do sistema, delimitando o problema (FOWLER; SCOTT, 2000).

Com o intuito de definir melhor a estrutura do W4Gen e também facilitar a continuação do seu desenvolvimento optou-se por usar a UML (Unified Modeling Language). Algumas das vantagens da UML são as disseminações do padrão entre os vários desenvolvedores e a facilidade de comunicação. É importante ressaltar que não foram utilizados todos os recursos disponíveis pela linguagem, pois não é esse o foco principal do trabalho. O objetivo é esclarecer como foi implementado e auxiliar futuros desenvolvedores, agregando outras características a carga de trabalho ou, adaptá-lo para alguma outra situação. A próxima seção descreve o diagrama de classes do W4Gen.

\subsubsection{Diagrama de Classe}

O diagrama de classes representa as classes, interfaces, pacotes e colaborações que farão parte do sistema e o relacionamento entre elas. Além disso, ele também mostra os atributos e operações de uma classe e as restrições à maneira como elas são conectadas (FOWLER; SCOTT, 2000).

Para facilitar a compreensão, o diagrama de classe do W4Gen foi subdividido e será apresentada a estrutura de cada pacote com alguns métodos e atributos não relevantes excluídos. A figura 5.3 mostra o principal diagrama de classe, o pacote componente. A superclasse abstrata ComponenteCargaTrabalho tem como objetivo permitir a inserção de novos componentes ao sistema. As suas subclasses representam os componentes que fazem parte da carga de trabalho reproduzida pelo W4Gen, cada qual com seus atributos e métodos. Outro destaque importante é a classe CargaTrabalho, responsável por criar os modelos de carga, conforme os parâmetros alterados pelos usuários na interface gráfica.

Para adicionar novos componentes à carga de trabalho (por exemplo, tempo de chegada das sessões) basta criar uma nova classe que herda o ComponenteCargaTrabalho e implementar o método abstrato gerarElementos(). Para que a nova característica seja acrescentada ao log sintético, a classe CargaTrabalho também deverá ser alterada para suportar esse novo elemento. Os métodos gerarCargaTrabalhoDisco() e gerarCargaTrabalhoDiscoPorTempo() deverão ser sobrecarregados.

A figura 5.4 mostra o diagrama de classe do pacote layoutsistema do W4Gen. Essas classes são responsáveis por instanciar os componentes ${ }^{5}$ da interface gráfica de cada um

\footnotetext{
${ }^{5}$ Esses componentes referem-se as classes do pacote swing do Java.
} 
dos elementos que compõem a carga de trabalho. A principal classe, o Gerador, faz a conexão entre os painéis que permitem aos usuários alterar as configurações padrões e a classe CargaTrabalho, responsável por gerar as requisições.

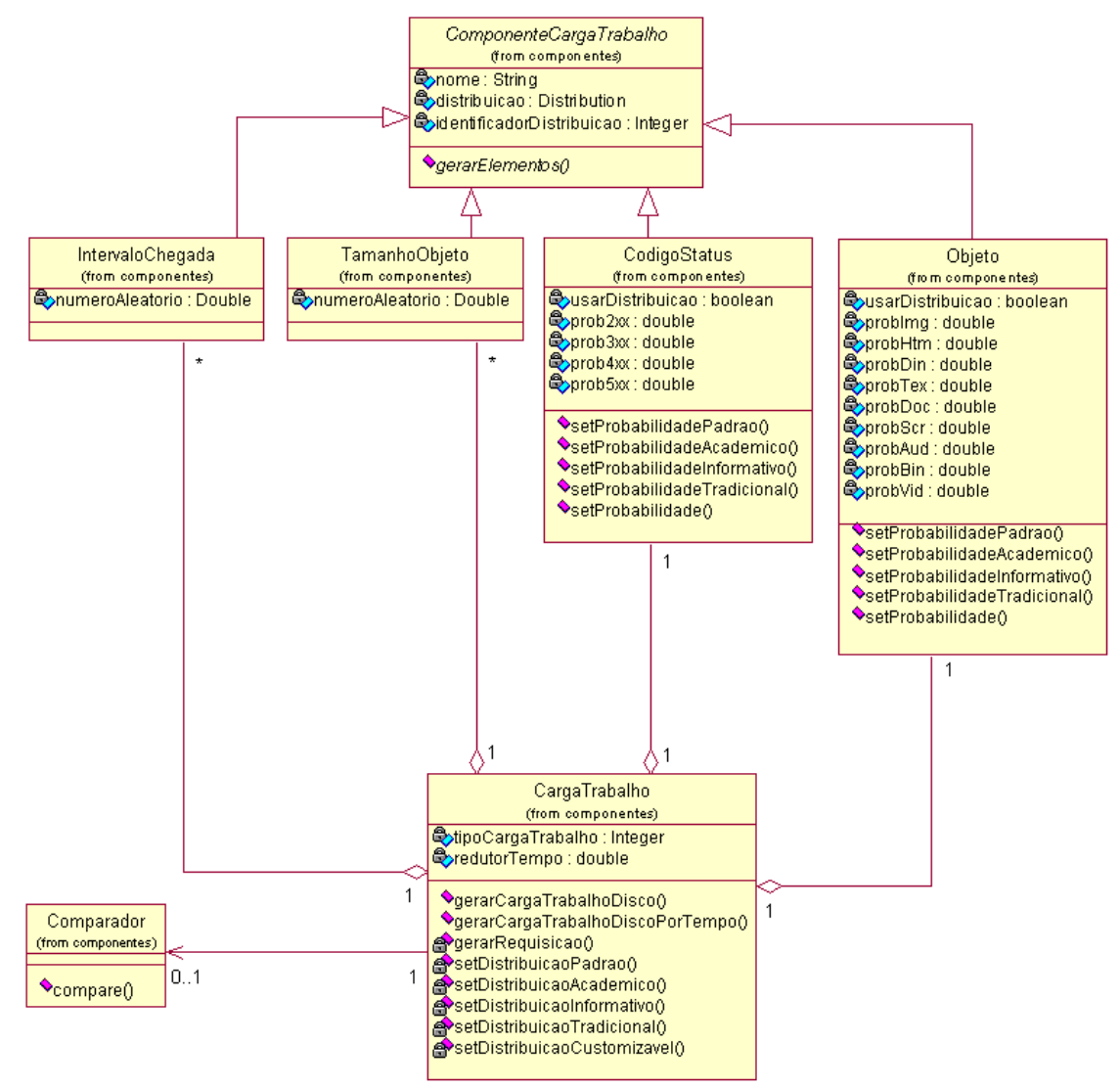

Figura 5.3: Diagrama de classe do pacote componente.

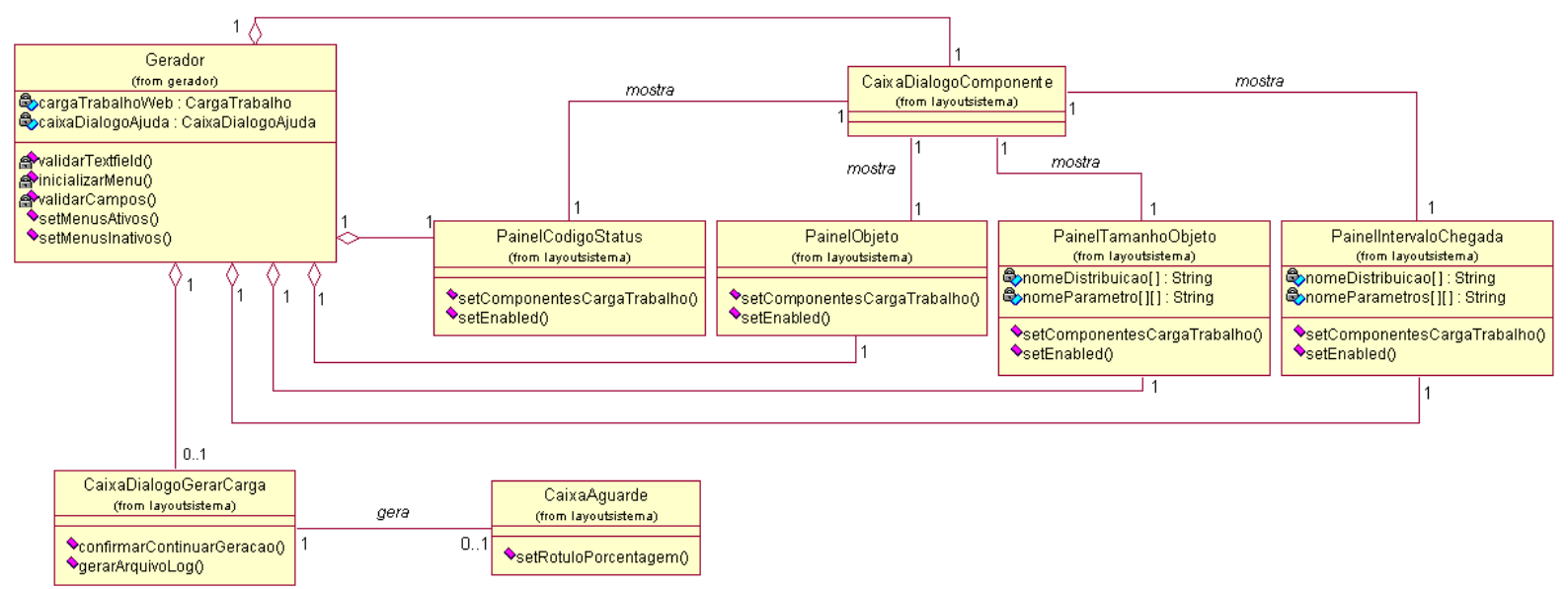

Figura 5.4: Diagrama de classe do pacote layoutsistema.

A figura 5.5 apresenta o diagrama de classe das novas distribuições implementadas e adaptadas para o W4Gen. Essas classes seguem a estruturada da biblioteca de classes PSOL, ou seja, elas herdam os métodos e atributos de suas respectivas superclasses. A 
GeneralParetoDistribution é uma subclasse de Distribution (pacote PSOL), enquanto a outras duas são subclasses da GeometricDistribution (pacote PSOL).

\begin{tabular}{|l|}
\hline $\begin{array}{c}\text { GeneralParet oDistribution } \\
\text { (from distribuicoes) }\end{array}$ \\
\hline \&scale : double \\
\&shape : double \\
\hline getCDF0 \\
$\nabla_{\text {getDensity0 }}$ \\
getMean0 \\
getMedian0 \\
getQuantile0 \\
getSD0 \\
\hline getVariance0
\end{tabular}
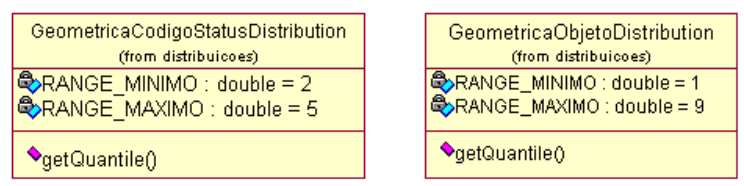

Figura 5.5: Diagrama de classe do pacote distribuicoes.

\subsection{Interface Gráfica}

O W4Gen é composto de uma interface gráfica amigável que permite ao usuário reproduzir cargas de trabalho de alguns dos ambientes da Web ou, simplesmente, modificar seus parâmetros, adaptando as características da carga as necessidades da avaliação de desempenho. Sua finalidade é facilitar o uso para gerar novos tipos de carga de trabalho. As próximas seções discutem as interfaces de cada um dos quatro componentes e quais modificações são permitidas pela ferramenta.

\subsubsection{Código de Resposta}

A figura 5.6 mostra a interface gráfica que permite ao usuário configurar o código de resposta retornado pelos servidores Web. O W4Gen possui três técnicas diferentes para gerar o código de resposta. São elas:

- Usar somente requisição 200. Ativando esse caixa de checagem, o W4Gen não utilizará nenhuma distribuição ou qualquer informação para gerar os códigos de respostas. Ele, simplesmente, acrescentará o código 200 a todas as requisições.

- Usar segundo uma distribuição. No caso do primeiro item não estar selecionado, o W4Gen permite ao usuário gerar os códigos de resposta segundo a distribuição Geométrica apresentada no capítulo anterior. Nesse caso é preciso definir o valor do parâmetro que configura a função de distribuição. A barra de rolagem da figura 5.6(a) permite essa modificação.

- Usar segundo valores de porcentagem. No caso dos itens anteriores não estarem selecionados, o W4Gen permite gerar os códigos de resposta segundo os valores 
de porcentagem. Para isso é obrigatório configurar cada um dos quatro tipos diferentes de código de resposta retornado pelo servidor Web: 2xx, 3xx, 4xx e 5xx. Esses valores são modificados através da barra de rolagem, como mostra a figura 5.6(b). Ao invés de usar alguma função de distribuição, o W4Gen utiliza uma função de números aleatórios.

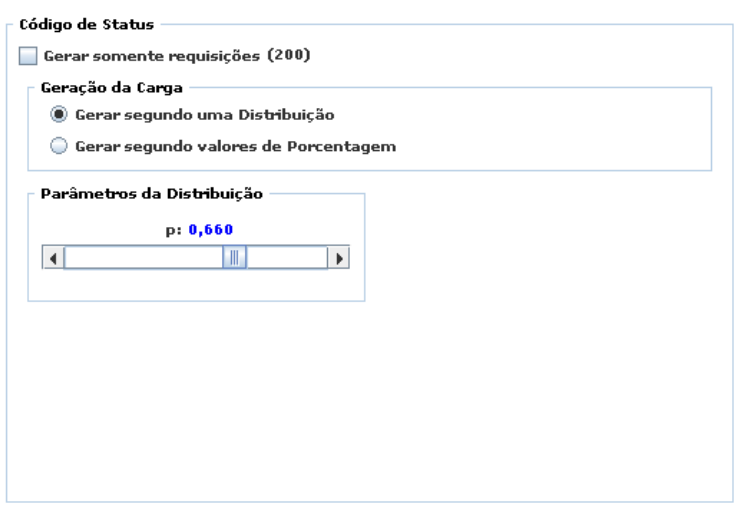

(a)

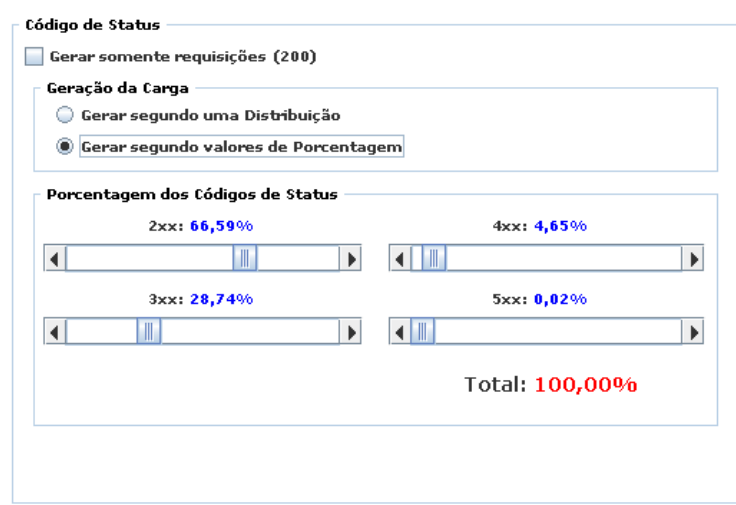

(b)

Figura 5.6: Interface do W4Gen para manipular o código de resposta.

\subsubsection{Classe de Objeto}

O objeto é uma característica importante da carga de trabalho da Web. A figura 5.7 apresenta a interface gráfica que permite configurar as classes de objetos de acordo com as necessidades de cada usuário. O W4Gen possui duas técnicas diferentes para gerar os nove tipos de objetos. São elas:

- Usar segundo uma distribuição. O W4Gen permite gerar as classes de objetos segundo a distribuição Geométrica apresentada no capítulo anterior. Para isso, é preciso definir o valor do parâmetro que configura a função de distribuição. A barra de rolagem que aparece na figura 5.7(a) permite modificar esse parâmetro.

- Usar segundo valores de porcentagem. O W4Gen permite gerar as classes de objetos segundo os valores de porcentagem. Para isso, o usuário deve configurar a porcentagem de cada um dos nove tipos diferentes de objeto: Imagem, HTML (Linguagem de marcação), Dinâmico, Texto, Documento, Script Cliente/Animação, Áudio, Binário/Compactado e Vídeo. Esses valores são modificados através da barra de rolagem, como mostra a figura 5.7(b). A seqüência de requisições segue o comportamento de uma função de números aleatórios. 


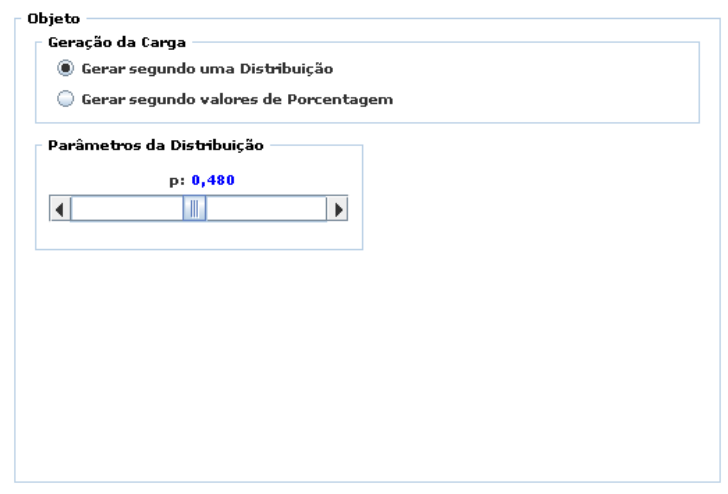

(a)

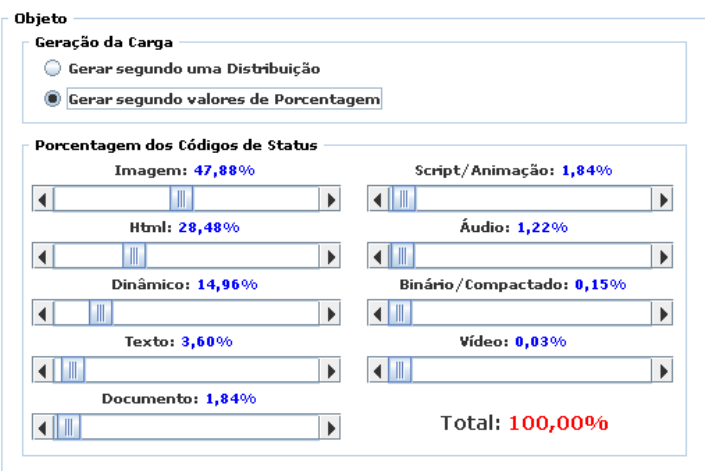

(b)

Figura 5.7: Interface do W4Gen para manipular o objetos.

\subsubsection{Intervalo de Chegada}

O W4Gen fornece uma única forma de reproduzir essa caracteristica, ao contrário do que ocorre nos componentes anteriormente apresentados. Baseado somente em função de distribuição para cada classe de objeto, o usuário pode definir o tipo de distribuição que melhor se adapta as características do comportamento de chegada dos diferentes tipos de requisições, permitindo sobrecarregar o servidor da maneira desejada.

Doze tipos de distribuições, cada qual com seus respectivos parâmetros, podem ser utilizadas para determinar o intervalo de tempo entre a chegada das requisições da mesma classe. A figura 5.8 apresenta a interface com o usuário na qual ele pode configurar as distribuições e os seus parâmetros. Para cada objeto há um campo que determina a distribuição que pode ser utilizada.

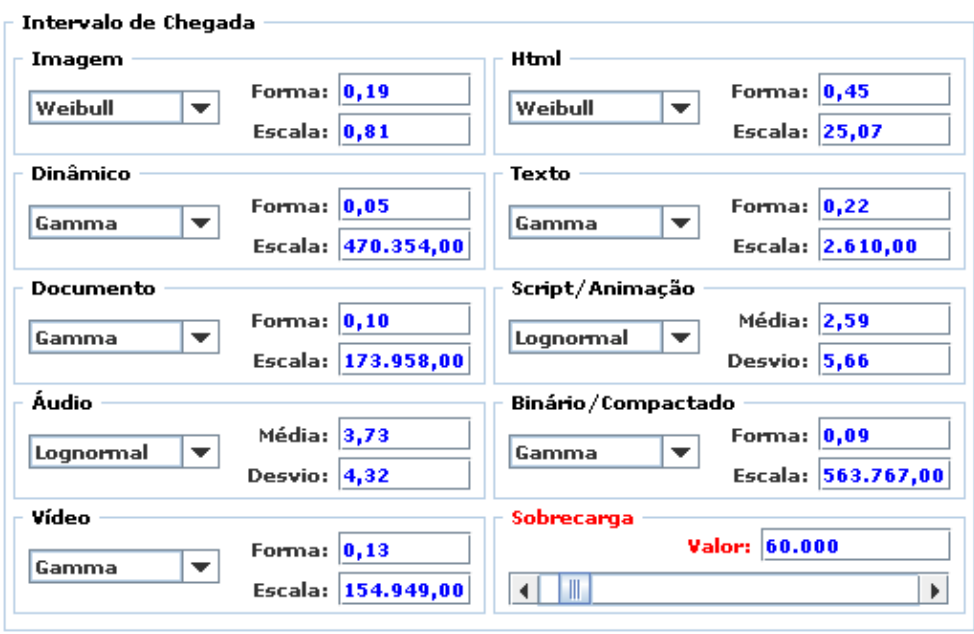

Figura 5.8: Interface do W4Gen para manipular o intervalo de chegada.

A presença de um campo sobrecarga no canto inferior direito da figura 5.8 permite o 
usuário comprimir o tempo de chegada entre as requisições, impondo um carga de trabalho pesada visando saturar o servidor $W e b$. Esse valor divide o tempo pela constante digitada no campo valor. Nas avaliações do modelo de SWDS apresentada no próximo capítulo, esse campo foi utilizado para sobrecarregar um modelo sistema de quatro servidores.

\subsubsection{Tamanho do Objeto}

O tamanho dos objetos é também essencial para a avaliação de desempenho. Através de uma interface gráfica amigável, o W4Gen é capaz de fornecer ao usuário um ambiente para modificar essa característica. De maneira simples, é possível escolher entre diferentes funções de distribuição aquela que o usuário achar mais adequada ou, simplesmente, manter as configurações padrões, baseado no estudo do comportamento dos traces, apresentado no capitulo anterior.

Para cada classe de objeto o usuário pode escolher uma distribuição. A figura 5.9 apresenta a interface com o usuário, muito semelhante ao intervalo de chegada anteriormente discutido. Além de escolher as funções é preciso definir os valores de seus parâmetros. A mudança desses valores pode distorcer a realidade da $W e b$ e reproduzir um comportamento diferente, gerando conclusões falsas na análise, já que a carga de trabalho influencia diretamente no desempenho global do sistema (MENASCé; ALMEIDA, 2003).

\begin{tabular}{|c|c|c|c|c|c|c|c|}
\hline \multicolumn{4}{|l|}{ Imagem } & \multicolumn{4}{|l|}{ Htoml } \\
\hline Lognormal & $\nabla$ & \multirow{2}{*}{$\begin{array}{l}\text { Média: } \\
\text { Desvio: }\end{array}$} & 8,12 & Weibull & $\boldsymbol{\nabla}$ & \multirow{2}{*}{$\begin{array}{l}\text { Forma: } \\
\text { Escala: }\end{array}$} & \multirow{2}{*}{$\begin{array}{l}0,74 \\
17.998,00\end{array}$} \\
\hline & & & 1,65 & & & & \\
\hline \multicolumn{4}{|l|}{ Dinâmico } & \multicolumn{2}{|l|}{ Texto } & \multirow{3}{*}{$\begin{array}{l}\text { Forma: } \\
\text { Escala: }\end{array}$} & \\
\hline Lognormal & $\boldsymbol{\nabla}$ & \multirow{2}{*}{$\begin{array}{l}\text { Média: } \\
\text { Desvio: }\end{array}$} & 6,92 & \multirow{2}{*}{ Weibull } & \multirow{2}{*}{$\nabla$} & & 0,80 \\
\hline & & & 2,28 & & & & $2.481,00$ \\
\hline \multicolumn{4}{|l|}{ Documento } & \multicolumn{2}{|c|}{ Script/Animação } & & \\
\hline Lognormal & $\nabla$ & \multirow{2}{*}{$\begin{array}{l}\text { Média: } \\
\text { Desvio: }\end{array}$} & 10,32 & Weibull & $\nabla$ & \multirow{2}{*}{$\begin{array}{l}\text { Forma: } \\
\text { Escala: }\end{array}$} & 0,73 \\
\hline & & & 2,17 & & & & $10.551,00$ \\
\hline \multicolumn{4}{|l|}{ Áudio } & \multicolumn{4}{|c|}{ Binário/Compactado } \\
\hline Gamma & $\nabla$ & \multirow{2}{*}{$\begin{array}{l}\text { Forma: } \\
\text { Escala: }\end{array}$} & \multirow{2}{*}{$\begin{array}{l}0,25 \\
619.778,00\end{array}$} & Lognormal & $\nabla$ & \multirow{2}{*}{$\begin{array}{l}\text { Média: } \\
\text { Desvio: }\end{array}$} & 11,60 \\
\hline & & & & Gamma & $\triangle$ & & 2,61 \\
\hline \multicolumn{2}{|l|}{ Vídeo } & \multirow{3}{*}{$\begin{array}{l}\text { Média: } \\
\text { Desvio: }\end{array}$} & & Logistica & -1 & & \\
\hline lononormal & $\nabla$ & & 12,14 & Lognormal & $\equiv$ & & \\
\hline & 急 & & 2,13 & $\begin{array}{l}\text { Normal } \\
\text { Pareto }\end{array}$ & $\nabla$ & & \\
\hline
\end{tabular}

Figura 5.9: Interface do W4Gen para manipular o tamanho dos objetos.

\subsection{Considerações Finais}

Esse capítulo apresentou a especificação do W4Gen (World Wide Web Workload Generator), um protótipo de um gerador de cargas para avaliação de desempenho de modelos 
de servidores Web. Para alcançar esses objetivos discutiram-se alguns trabalhos relacionados na área, tais como, WebStone, SPECWeb, Surge, HTTPerf e Geist, apresentando suas características para avaliar um servidor $W e b$.

A seção 5.3 discutiu os detalhes do gerador, comentando o modelo de carga de trabalho, a biblioteca de classes PSOL utilizada para reproduzir as características do Intervalo de Chegada, Objeto, Código de Resposta, Tamanho de Objeto e os recursos disponíveis pelo protótipo. O capítulo também apresentou o diagrama de classes do W4Gen e como é possível estendê-lo para agregar novas características ao modelo de carga de trabalho. Ao final, apresentou-se à interface gráfica e quais formas de simular a carga de trabalho estão disponíveis.

O próxima capítulo dessa dissertação apresenta os testes realizados com as cargas de trabalho sintéticas e compara os resultados com um trace real coletado do site da copa do mundo de 1998. 


\section{Simulações com a Carga de Trabalho do W4Gen}

\subsection{Considerações Iniciais}

No capítulo anterior foi discutido o W4Gen, um protótipo capaz de gerar cargas de trabalho sintéticas para avaliação de desempenho de modelos de servidores $W e b$, segundo quatro características: o intervalo de chegada das requisições, a classe de objeto, o código de resposta e o tamanho do objeto. Entretanto, a proposta de reproduzir cargas de trabalho sintéticas precisa ser validada, verificando sua adequação para a avaliação de desempenho. Diante disso, neste capítulo serão apresentados os cenários e os testes realizados com o SWDS (Servidor Web com diferenciação de Serviços), definindo os mecanismos de diferenciação e as carga de trabalho adotados nas simulações. Para isso, na seção 6.2 será apresentado o simulador usado para executar os testes e a parametrização das simulações. Já na seção 6.3 serão discutido os testes e os resultados obtidos.

\subsection{Características Gerais da Simulação}

Nesta seção será discutido algumas informações gerais sobre o simulador usado para validar as novas cargas de trabalho e do modelo de servidor Web com diferenciação de serviços, além dos parâmetros adotados na simulação para determinar, por exemplo, latência do disco e a capacidade de processamento dos elementos que a compõem. A próxima etapa inicia uma breve introdução do Simpack.

\subsubsection{Simpack}

A técnica de análise de desempenho utilizada em Teixeira (2004) e Barbato et al. (2005) foi a simulação, por trata-se de uma abordagem flexível, onde os resultados podem ser obtidos de forma mais rápida, ao contrário dos testes com experimentos reais usando 
bechmarkings, tais como, HTTperf, WebStone, entre outros.

O simulador Simpack (CUBERT; FISHWICK, 1995), disponível pela GPL (GNU public License), é um diretório de ferramentas com suporte a simulação de eventos discretos. O Simpack possui bibliotecas escritas em $\mathrm{C}++$ e Java, composta de uma ampla gama de métodos voltados à simulação de redes filas. A escolha pelo Simpack deve-se à experiência na utilização em trabalhos anteriores no LaSDPC e da implementação do SWDS, permitindo validar a carga de trabalho gerada pelo W4Gen e avaliar o desempenho.

\subsubsection{Parametrização}

Seguindo o metodologia utilizada em Teixeira et al. (2005), Barbato et al. (2005), o foco dos experimentos é o desempenho do servidor SWDS e sua capacidade de fornecer diferenciação de serviços, afim de testar os algoritmos implementados. Os detalhes de rede e a interconexão entre os servidores não são modelados. Portanto, assume-se que a mídia física não representa um gargalo do sistema, com capacidade de transferência suficiente na rede. Todos os nós do cluster são modelados com CPU, disco e interface de rede própria. O modelo utilizado foi descrito no capítulo 3.3.

A tabela 6.1 apresenta a parametrização adotada no modelo SWDS. O classificador e o controle de admissão possuem uma capacidade de processamento de 8.000 e 4.000 requisições por segundos, respectivamente. Os discos dos servidores são definidos com uma taxa de transferência de $37 \mathrm{MBps}$ e uma latência de 8,5 ms, utilizando como base um disco IBM Deskstar 75GXP (IBM, 2003). Esses valores são usados para o cálculo do tempo de serviço das requisições estáticas. Já o tempo das requisições dinâmicas está definido como $10 \mathrm{~ms}$.

Tabela 6.1: Parâmetros do modelo SWDS (TEIXEIRA, 2004).

\begin{tabular}{|l|c|}
\hline \hline Parâmetro & Valor \\
\hline \hline Capacidade do Classificador & $8.000 \mathrm{req} / \mathrm{seg}$ \\
\hline \hline Capacidade do Controle de Admissão & $4.000 \mathrm{req} / \mathrm{seg}$ \\
\hline \hline Taxa de transferência do disco & $37 \mathrm{MBps}$ \\
\hline \hline Latência do disco & $8,5 \mathrm{~ms}$ \\
\hline \hline Capacidade da interface de rede & $80 \mathrm{Mbps}$ \\
\hline \hline Tempo de serviço das requisições dinâmicas & $10 \mathrm{~ms}$ \\
\hline \hline
\end{tabular}

Na próxima seção serão apresentados os testes realizados com alguns modelos de carga de trabalho, modificando suas características e verificando o comportamento do servidor SWDS diante delas. 


\subsection{Avaliação de Desempenho do SWDS}

Nesta seção serão apresentados os cenários usados nas simulações e os resultados obtidos para validar a carga de trabalho do W4Gen. Para as duas simulações apresentadas são definidas novos modelos de carga de trabalho, todos eles utilizando a mesma configuração do mecanismo de diferenciação de serviços do controle de admissão, a fim de comparar os resultados tanto com o trace da copa do mundo de 1998 quanto com outros tipos de carga. O modelo consiste de clusters de servidores Homogêneos.

A tabela 6.2 informa as configurações do modelo SWDS adotados em todas as simulações desta seção. O primeiro item define o tamanho máximo da fila como mecanismo de diferenciação para restringir a sobrecarga do sistema. Já o algoritmo de escalonamento usado para aplicar a qualidade de serviço no SWDS é o RSVAdap, descrito em Barbato et al. (2005). Ele exige como parâmetro o nível de diferenciação aplicado as classes de serviços cujo valor é de 10\%. A chegada de requisições ao servidor da classe alta e baixa equivale a $50 \%$.

Tabela 6.2: Configurações gerais do modelo SWDS.

\begin{tabular}{|l|c|}
\hline \hline Parâmetro & Valor \\
\hline \hline Mecanismos de diferenciação & Tamanho da fila (1024) \\
\hline \hline Algoritmo de diferenciação & RSVAdap \\
\hline \hline Nível de diferenciação & $10 \%$ \\
\hline \hline Requisições de alta prioridade & $50 \%$ \\
\hline \hline Requisições de baixa prioridade & $50 \%$ \\
\hline \hline
\end{tabular}

\subsubsection{Simulação com as Características da Copa de 1998}

Esta simulação testa o modelo de SWDS utilizando uma carga de trabalho que representa as mesmas características usadas nas simulações de Teixeira (2004) e Barbato et al. (2005), ou seja, ela imita o comportamento do log da copa do mundo de 1998, comparando os resultados obtidos.

\section{Características da Carga de Trabalho}

A tabela 6.3 apresenta um resumo das informações da carga de trabalho reproduzida pelo W4Gen. O tempo máximo de simulação é de aproximadamente 30 minutos e a constante K, que representa o número definido pelo usuário do W4Gen para comprimir o 
tempo entre as chegadas das requisições no sistema, é 8. Já a quantidade de requisições é de, aproximadamente, 685 mil, com uma taxa de chegada de 380 requisições por segundo.

Neste caso, utilizou-se uma distribuição Normal, com média 0 e desvio padrão 3, para representar o intervalo de chegada das requisições. As outras características, como a porcentagem dos códigos de respostas e a porcentagem dos tipos de objetos requisitados são idênticos aos valores resumidos na tabela 4.2 e 4.3 do capítulo 4 .

Tabela 6.3: Informações sobre a carga de trabalho representativa do log da Copa.

\begin{tabular}{|l|c|}
\hline \hline Parâmetro & Valor \\
\hline \hline Tempo de simulação & $1.800 \mathrm{seg}$ \\
\hline \hline redutor $(\mathrm{K})$ & 8 \\
\hline \hline Total de chegada & $684.941 \mathrm{req}$ \\
\hline \hline Taxa de chegada & $380 \mathrm{req} / \mathrm{seg}$ \\
\hline \hline Intervalo de Chegada & Normal $(\mu=0, \sigma=3)$ \\
\hline \hline Tamanho dos objetos & Lognormal $(\mu=10,13, \sigma=2,19)$ \\
\hline \hline
\end{tabular}

\section{Resultados Experimentais}

O experimento considerou o uso do controle de admissão limitando o tamanho da fila, utilizando o algoritmo RSVAdap com as configurações definidas anteriormente.

Os resultados da tabela 6.4 e 6.5 mostram o comportamento do servidor SWDS diante dos testes com a carga do W4Gen e utilizando o Log da copa de 1998, respectivamente. As simulações foram executadas trinta vezes com um intervalo de confiança de $95 \%$.

Observa-se que, na média, 98\% dos recursos do sistema foram utilizados. Para a simulação com o log da copa do mundo de 1998 esse valor atingiu os 99\%. Como essa utilização é calculada pela relação entre o tempo de serviço e o tempo observado (tempo da simulação até o momento), percebe-se que os recursos ficaram ocupados por quase toda a simulação. Já o tempo de resposta médio também se manteve próximo nos dois casos, com 6,22 segundos para a simulação com o modelo de carga do W4Gen e 6,47 para o $\log$ da copa do mundo.

A quantidade de requisições admitidas das classes de baixa e alta prioridade também foi bem próximo nas duas simulações, como pode ser observado nas tabelas 6.4 e 6.5. Para as classes de alta prioridade essa diferença não supera 1\%. Já para as admissões das requisições de baixa prioridade a diferença foi um pouco maior, admitindo $87 \%$ das requisições na simulação com a carga do W4Gen e 93\%, usando o log da copa. Por fim, o tempo de resposta médio para cada uma das classes mostra a proximidade da carga 
reproduzida pelo W4Gen, validando o gerador de cargas de trabalho. Para ambas as classes os valores se mantiveram próximos nas duas simulações, com pequenas variações que não excedem 0,5 segundo.

Tabela 6.4: Estatísticas da simulação usando a carga do W4Gen.

\begin{tabular}{|l|c|c|}
\hline \hline Parâmetros & \multicolumn{2}{|c|}{ Todas as requisições } \\
\hline \hline Utilização dos recursos (\%) & \multicolumn{2}{|c|}{$98,08 \pm 0,15$} \\
Tempo médio de resposta (seg) & \multicolumn{2}{|c|}{$6,22 \pm 0,13$} \\
\hline \hline & Classe Baixa & Classe Alta \\
\hline \hline Admissões (\%) & $86,84 \pm 0,54$ & $99,01 \pm 0,30$ \\
Términos (\%) & $99,77 \pm 0,02$ & $99,91 \pm 0,02$ \\
Tempo médio de resposta (seg) & $7,25 \pm 0,19$ & $5,32 \pm 0,09$ \\
\hline \hline
\end{tabular}

Tabela 6.5: Estatísticas da simulação usando o log da Copa de 1998.

\begin{tabular}{|l|c|c|}
\hline \hline Parâmetros & \multicolumn{2}{|c|}{ Todas as requisições } \\
\hline \hline Utilização dos recursos (\%) & \multicolumn{2}{|c|}{$99,84 \pm 0,03$} \\
Tempo médio de resposta (seg) & \multicolumn{2}{|c|}{$6,47 \pm 0,05$} \\
\hline \hline & Classe Baixa & Classe Alta \\
\hline \hline Admissões (\%) & $92,87 \pm 0,10$ & $99,97 \pm 0,01$ \\
Términos (\%) & $99,61 \pm 0,06$ & $99,69 \pm 0,05$ \\
Tempo médio de resposta (seg) & $7,31 \pm 0,08$ & $5,56 \pm 0,10$ \\
\hline \hline
\end{tabular}

\subsubsection{Simulação com uma Carga Padrão}

Esta última simulação testa o modelo de Servidor Web com Diferenciação de Serviço com duas cargas de trabalho com características do comportamento padrão, que representa a média de todos os logs analisados. As características e os modelos matemáticos dessa carga foram discutidos na seção 4.4.

\section{Características das Cargas de Trabalho}

As tabelas 6.6 e 6.7 apresentam as características gerais da cargas de trabalho utilizadas nas simulações. Neste caso, o ambiente padrão foi selecionado com uma carga cujo tempo máximo de simulação é de, aproximadamente, 30 minutos. Já a constante K, que comprime o tempo de chegada das requisições, foi modificada em ambas as cargas, assumindo o valor de $1,0 \times 10^{7}$, para a carga 01 e o valor $2,0 \times 10^{7}$ para a carga 02 . Essa variação no valor de $\mathrm{K}$ determina o aumento ou redução no número de requisições que chega ao sistema. Para a carga de trabalho 02 , o aumento de duas vezes no valor de $\mathrm{K}$ ocasionou no aumento de pouco mais duas vezes o número de requisições que chega ao sistema, conforme pode ser visto na linha total de chegada das tabelas 6.6 e 6.7 . 
Tabela 6.6: Informações gerais sobre a carga de trabalho Padrão 01.

\begin{tabular}{|l|c|}
\hline \hline Parâmetro & Valor \\
\hline \hline Ambiente & Padrão \\
\hline \hline Tempo de simulação & $1.722 \mathrm{seg}$ \\
\hline \hline redutor $(\mathrm{K})$ & $1,0 \times 10^{7}$ \\
\hline \hline Total de chegada & $422.197 \mathrm{req}$ \\
\hline \hline Taxa de chegada & $245 \mathrm{req} / \mathrm{seg}$ \\
\hline \hline
\end{tabular}

Tabela 6.7: Informações gerais sobre a carga de trabalho Padrão 02.

\begin{tabular}{|l|c|}
\hline \hline Parâmetro & Valor \\
\hline \hline Ambiente & Padrão \\
\hline \hline Tempo de simulação & $1.794 \mathrm{seg}$ \\
\hline \hline redutor $(\mathrm{K})$ & $2,0 \times 10^{7}$ \\
\hline \hline Total de chegada & $955.196 \mathrm{req}$ \\
\hline \hline Taxa de chegada & $532 \mathrm{req} / \mathrm{seg}$ \\
\hline \hline
\end{tabular}

\section{Resultados Experimentais}

Os resultados da tabela 6.8 apresenta o comportamento do servidor SWDS diante da carga de trabalho padrão 01. Já os resultados da tabela 6.9 apresenta as estatísticas com a mesma configuração do SWDS, porém utilizando a carga de trabalho padrão 02, com um número maior requisições. As simulações foram executadas trinta vezes com um intervalo de confiança de $95 \%$.

Tabela 6.8: Estatísticas da simulação usando uma carga Padrão 1.

\begin{tabular}{|l|c|c|}
\hline \hline Parâmetros & \multicolumn{2}{|c|}{ Todas as requisições } \\
\hline \hline Utilização dos recursos (\%) & \multicolumn{2}{|c|}{$17,84 \pm 0,11$} \\
Tempo médio de resposta (seg) & \multicolumn{2}{|c|}{$5,87 \pm 0,15$} \\
\hline \hline & Classe Baixa & Classe Alta \\
\hline \hline Admissões (\%) & $20,32 \pm 0,50$ & $42,45 \pm 0,28$ \\
Términos (\%) & $97,08 \pm 0,09$ & $98,94 \pm 0,04$ \\
Tempo médio de resposta (seg) & $5,59 \pm 0,54$ & $5,99 \pm 0,33$ \\
\hline \hline
\end{tabular}

A partir desses resultados, observa-se que na simulação da carga 01 menos de $18 \%$ dos recursos do sistema foram utilizados, característica comum devido a presença de rajadas. Já o tempo médio de resposta alcançou 5,87 segundos. Ao contrário do que se observa na simulação com a carga de trabalho 02, a utilização média do sistema é de quase $28 \%$ e com um tempo de resposta de 5,56 segundos. O aumento da utilização do sistema foi conseqüência do grande número de requisições encontradas na carga de trabalho 02, que mantém por mais tempo o sistema ocupado. 
A quantidade de requisições admitidas em ambas as classes da simulação com carga de trabalho 01 foi de, aproximadamente, $20 \%$ e $42 \%$ para as classes baixa e alta prioridade, respectivamente. Esses valores são superiores a simulação utilizando a carga 02 cujos valores são de, aproximadamente, $13 \%$ e $32 \%$ para as classes baixa e alta prioridade, respectivamente. Essa concentração maior de requisições dentro de um mesmo intervalo de tempo força o servidor $W e b$ a rejeitar mais requisições tanto de baixa como de alta prioridade. Portanto, o aumento do K e, conseqüentemente, o aumento da taxa de chegada (requisições por segundo) tende a reduzir o número de requisições admitidas no sistema.

Tabela 6.9: Estatísticas da simulação usando a carga Padrão 2.

\begin{tabular}{|l|c|c|}
\hline \hline Parâmetros & \multicolumn{2}{|c|}{ Todas as requisições } \\
\hline \hline Utilização dos recursos (\%) & \multicolumn{2}{|c|}{$27,86 \pm 0,05$} \\
Tempo médio de resposta (seg) & \multicolumn{2}{|c|}{$5,56 \pm 0,09$} \\
\hline \hline & Classe Baixa & Classe Alta \\
\hline \hline Admissões (\%) & $13,20 \pm 0,14$ & $32,39 \pm 0,16$ \\
Términos (\%) & $98,35 \pm 0,08$ & $98,01 \pm 0,02$ \\
Tempo médio de resposta (seg) & $5,55 \pm 0,12$ & $5,56 \pm 0,16$ \\
\hline
\end{tabular}

\subsection{Considerações Finais}

O objetivo do presente capítulo foi apresentar os resultados da avaliação de desempenho do modelo de Servidor Web com diferenciação de serviços, proposto em Teixeira (2004), e do algoritmo RSVAdap, proposto em Barbato et al. (2005), analisando o seu comportamento diante das novas cargas de trabalho. Essa análise constitui a validação das cargas de trabalho para a avaliação do desempenho. Para isso, utilizou-se o W4Gen para representar as características da carga de trabalho da copa do mundo de 1998, cujo resultados já foram anteriormente discutidos e comparados com a simulação usando o trace real da copa. Também foi discutido a avaliação de desempenho utilizando uma carga de trabalho padrão, composta da média de todos os logs analisados. Os resultados foram comparados alterando o valor da constante $\mathrm{K}$, responsável por comprimir as requisições e mantê-las dentro de intervalo de tempo menor a fim de sobrecarregar o servidor.

No próximo capítulo serão apresentadas as conclusões obtidas com o desenvolvimento deste trabalho, as contribuições e as propostas de trabalhos futuros relacionados à avaliação de desempenho. 


\section{Conclusão}

\subsection{Considerações Finais}

A Web é um sistema em crescimento que passou de um simples meio de publicação para disseminar informações, por meio do uso de páginas estáticas, para uma infraestrutura com suporte a processamento de transações, com uso de páginas dinâmicas com acesso regular a banco de dados. Com essa evolução, muitos esforços já foram e serão gastos para melhorar o tempo de resposta das requisições dos usuários.

Dentre os diversos estudos, pode-se destacar o modelo de servidor Web com diferenciação de serviço (SWDS), cujo objetivo é oferecer uma arquitetura para o fornecimento de serviços diferenciados, integrando os princípios de QoS aplicados na camada de rede.

No entanto, a validação do modelo SWDS, executada por meio de simulações usando o trace da copa do mundo de 1998, não demonstrou sua viabilidade com base nas características atuais, constituindo um comportamento antigo de uma época na qual a $W e b$ pouco conhecia o protocolo HTTP/1.1, aplicações dinâmicas, entre diversos outros recursos. Ao longo desses últimos anos, muitas tecnologias mudaram, provocando uma mudança na demanda dos servidores $W e b$.

Com base nessa idéia, a finalidade deste trabalho é desenvolver um gerador de cargas de trabalho sintéticas para a avaliação de desempenho de modelos de servidores Web, permitindo ao usuário, por meio de uma interface gráfica simples, modificar as características essenciais da carga de trabalho ou utilizar modelos de carga de trabalho já implementados. Assim, ele permite adequar melhor ao ambiente da Web e prever com uma maior exatidão se propostas de modelos de servidores, novos algoritmos de escalonamento de requisições, entre outros, serão capazes de atender as expectativas do novos usuários e dos novos tipos de Web sites.

Os resultados, discutidos no capítulo 4, demonstraram o comportamento da $W e b$ atual segundo quatro perspectivas: o intervalo de chegada das requisições dos objetos, os tipos 
de objetos mais requisitados, o código de resposta e por fim o tamanho do objeto e quais modelos matemáticos podem ser usados para representar essas características. No capítulo também é apresentado a análise das três categorias (Acadêmico, Notícia/Informativo e Tradicional) identificadas no conjunto de logs estudados, determinando o comportamento específico de acesso a cada um dos Web site.

Outro grande destaque é a presença de um estudo comparativo entre os tipos de categorias, observando a presença de cinco invariantes. Por exemplo, a taxa de sucesso atual dos servidores Web está entre $59 \%$ e 69\%. Também foi observado que o número de requisições para objetos do tipo Linguagem de Marcação é inverso o número de requisições Dinâmicas. Do ponto de vista do intervalo de chegada das requisições, observa-se que a classe Imagem possui a maior concentração das referências entre intervalos de, no máximo, 10 segundos para as três categorias e o intervalo de chegada da classe Linguagem de Marcação possui valores parecidos nas três categorias, representado pela mesma distribuição. Por fim, identificou-se que os tamanhos dos arquivos da classe Imagem concentra-se entre $10^{2}$ e $10^{5}$ bytes para as todas as categorias.

Os testes apresentados no capítulo 6 demonstraram a validade dos dados (carga de trabalho) reproduzidos pelo W4Gen, testando a potencialidade do protótipo para gerar cargas de trabalho. Isso foi observado através de simulação com uma carga semelhante ao log da copa do mundo de 1998.

\subsection{Trabalhos Relacionados}

O grupo de pesquisa em Sistemas Distribuídos e Programação Concorrente do Instituto de Ciências Matemáticas e de Computação da Universidade de São Paulo (ICMCUSP) tem direcionado diversos esforços na linha de pesquisa que visa a avaliação de desempenho de servidores $W e b$. Esse trabalho de mestrado é parte integrante de diversos projetos em andamento, com alguns deles já concluídos. A seguir, estão relacionados outros trabalhos:

- O trabalho de iniciação científica de Traldi et al. (2004) consistiu em transportar o algoritmo Weighted Fair Queuing (WFQ), projetado para o nível de rede, para o nível de aplicação, sendo incluído,assim, no modelo de Servidor Web com Diferenciação de Serviços (SWDS).

- O trabalho de iniciação científica de Barbato et al. (2005), utilizado nas confi- 
gurações dos ambientes testados nesse mestrado, consistiu em implementar o algoritmo RSVAdap, cujo objetivo é particionar dinamicamente o cluster de servidores $W e b$, de acordo com a carga de trabalho vigente no sistema, a fim de melhorar o atendimento dos clientes de mais alta prioridade.

- O trabalho de mestrado de Estrella (2006) estudou a validação de mecanismos de negociação no módulo de controle de admissão do modelo SWDS, verificando uma melhoria no atendimento aos clientes pertencentes a uma determinada classe de serviço para que esses tivessem uma qualidade de serviço garantida.

- O trabalho de mestrado de Mourão (2005) tem como objetivo introduzir a capacidade de reconhecimento de sessões HTTP no modelo do servidor SWDS, característica atualmente não contemplada.

- O trabalho de mestrado de Messias (2006) será conduzido com o objetivo de implementar um protótipo de servidor $W e b$ com diferenciação de serviços e compará-lo com um servidor Web tradicional para avaliar os possíveis ganhos em ambiente real.

- Outros projetos em andamento dentro do grupo também poderão utilizar o W4Gen, a fim de facilitar a validação mediante a testes com uma carga de trabalho mais atual.

\subsection{Contribuições}

As principais contribuições desse trabalho estão divididas em dois grupos:

- Caracterização da carga de trabalho da $W e b$.

- Desenvolvimento de um protótipo para a geração de cargas de trabalho sintéticas para modelos de servidores $W e b$.

Como primeira contribuição, este trabalho realizou-se um estudo de caracterizarão da carga de trabalho de servidores Web atuais, segundo quatro perspectivas: o intervalo de chegada das requisições; as classes de objetos; o código de resposta retornado pelo servidor; e o tamanho do objetos, propondo alguns modelos matemáticos para simular cada uma dessas características. Com este estudo de logs mais recentes, este trabalho também contribuiu para compreender melhor o tráfego da $W e b$, atualizando as informações que foram inicialmente levantadas por Arlitt \& Williamson (1996). Os resultados obtidos por 
este estudo também serve de base para ser utilizado em outros trabalhos que buscam informações sobre o comportamento de acesso as páginas da Web.

Além disso, foi realizado uma classificação dos traces de servidores Web em categorias, com base no conteúdo do site. Com essa classificação, três categorias foram identificadas e analisadas isoladamente, obtendo o comportamento em cada uma delas. Isso permitiu identificar as características das cargas de trabalho específicas para alguns dos ambientes da WWW, permitindo compreender o comportamento dos usuários da Web em ocasiões específicas, como o acesso a sites de instituições de ensino (Acadêmico). Este trabalho também realizou um estudo comparativo entre as três categorias analisadas e apontou cinco invariantes nas cargas de trabalho, ou seja, características que são comuns em todas as categorias analisadas.

Como outra contribuição, esse projeto de mestrado desenvolveu um protótipo de um gerador de cargas de trabalho sintéticas, o W4Gen, cujo objetivo é facilitar diversos estudos em andamento, principalmente, no grupo de Sistemas Distribuídos e Programação Concorrente (LaSDPC) para avaliar o desempenho da $W e b$, eliminando a etapa de selecionar novas cargas de trabalho. Com o diagrama de classe apresentado no capítulo 5 e pela forma como foi estruturado do gerador de cargas também é possível a inserção de novas características a carga de trabalho da $W e b$, através da criação das novas classes que irão representar as novas informações.

Com o gerador, o usuário pode alterar parâmetros da carga de trabalho e reproduzir diversos tipos de carga, como também utilizar as categorias pré-definidas e implementadas no W4Gen, tais como, a carga de trabalho Padrão (composto da média de todos os traces analisados), de site Acadêmico, site de Web-publishing e de site Tradicional e reproduzir o comportamento da WWW. Os resultados também podem ser atualizados facilmente pelo usuário para acompanhar as mudanças da carga de trabalho da Web.

Este trabalho também apresenta a validação do gerador com testes usando sua carga de trabalho no modelo de servidor Web com Diferenciação de Serviços (SWDS), além de um teste simulando a carga de trabalho da copa do mundo de 1998.

\subsection{Sugestões para Trabalhos Futuros}

A caracterização e modelagem da carga de trabalho da $W e b$ abordados neste projeto de mestrado consistem num estudo inicial, podendo portanto serem ampliados visando oferecer ao usuário um número maior de recursos. Por isso, são apresentadas, a seguir, as 
sugestões para trabalhos futuros:

- Realizar um estudo do comportamento de chegada das sessões de usuários ao servidor Web, definindo uma distribuição de probabilidade que represente esse comportamento. Essa nova característica deverá se integrar a carga de trabalho do W4Gen. Para isso, é preciso anexar componentes a interface gráfica do W4Gen, permitindo ao usuário modificar as configurações e escolher entre a geração de cargas individuais ou em sessões.

- Realizar novos estudos de caracterização da carga de trabalho de outros ambientes da WWW, tais como, sites de e-commerce e implementá-los no W4Gen.

- Quantificar outros dados relevantes para a avaliação de desempenho, tais como, o tempo de processamento de requisições dinâmicas e estáticas e o tempo gasto no disco para transferir arquivos do tipo html, imagens e binários, acrescentando a carga de trabalho do W4Gen, com resultados que sejam independente da tecnologia de hardware e software utilizada.

- Adaptar o W4Gen para gerar cargas de trabalho para testar o desempenho de servidores $W e b$ reais.

- Acrescentar outros recursos ao W4Gen, como permitir ao usuários abrir e salvar as configurações da carga de trabalho.

- Testar as cargas de trabalho do W4Gen com outras configurações do modelo SWDS, por exemplo, usando o algoritmo de negociação implementado em Estrella (2006). 


\section{Referências}

ANDREOLINI, M.; CASALICCHIO, E.; COLAJANNI, M.; MAMBELLI, M. A Cluster-based Web System Providing Differentiated and Guaranteed Services. Cluster Computing, Kluwer Academic Publishers, v. 7, n. 1, p. 7-19, 2004.

APACHE. Log Files. Desenvolvido por Apache Software Foudation. 2005. Disponível em: http://httpd.apache.org/docs/1.3/logs.html. Acesso em: 21/06/2005.

ARLITT, M. F.; JIN, T. Workload Characterization of the 1998 World Cup Web Site. Palo Alto, Set 1999. 90 p.

ARLITT, M. F.; JIN, T. A Workload Characterization Study of the 1998 World Cup Web Site. IEEE Network Magazine, v. 14, n. 3, p. 30-37, Mai 2000.

ARLITT, M. F.; WILLIAMSON, C. L. Web Server Workload Characterization: the Search for Invariants. In: Proceedings of the 1996 ACM SIGMETRICS International Conference on Measurement and Modeling of Computer Systems. Nova York, NY, EUA: ACM Press, 1996. p. 126-137.

ARLITT, M. F.; WILLIAMSON, C. L. Internet Web Servers: Workload Characterization and Performance Implications. IEEE/ACM Transactions on Networking, v. 5, n. 5, p. 631-645, Out 1997.

BARBATO, A. K.; SANTANA, R. H. C.; TRALDI, O. A.; SANTANA, M. J.; TEIXEIRA, M. A. M. Avaliação de Desempenho: Modelagem e Simulação - Servidor Web com Serviços Diferenciados e Algoritmo de Reserva Adaptativa de Recursos (RSVAdap). In: 12a. Jornada Nacional de Iniciação Cientifica. Fortaleza, CE, Brasil: SBC, 2005. 57a. Reunião Anual da SBPC.

BARFORD, P.; CROVELLA, M. Generating Representative Web Workloads for Network and Server Performance Evaluation. In: Proceedings of the 1998 ACM SIGMETRICS Joint International Conference on Measurement and Modeling of Computer Systems. Boston, MA, EUA: ACM Press, 1998. p. 151-160.

BENT, L.; RABINOVICH, M.; VOELKER, G. M.; XIAO, Z. Characterization of a Large Web Site Population with Implications for Content Delivery. In: Proceedings of the 13th International Conference on World Wide Web. Nova York, NY, EUA: ACM Press, 2004. p. 522-533.

BLAKE, S.; BLACK, D.; CARLSON, M.; DAVIES, E.; WANG, Z.; WEISS, W. An Architecture for Differentiated Services. Dez 1998. RFC 2475, IETF.

BRADEN, R.; CLARK, D.; SHENKER, S. Integrated Services in the Internet Architecture. Jun 1994. RFC 1633, IETF. 
BRADEN, R.; ZHANG, L.; BERSON, S.; HERZOG, S.; JAMIN, S. Resource ReSerVation Protocol (RSVP) - Version 1 Functional Specification. Set 1997. RFC 2205, IETF.

CALZAROSSA, M.; SERAZZI, G. Workload Characterization: A Survey. IEEE Computer Society, v. 81, n. 8, p. 1136-1150, Ago 1993.

CDMIL. 2005. Disponível em: http://www.cdmil.com.br/logs/access_log. Acesso em: 20/04/2005.

CHEN, X.; MOHAPATRA, P. Performance Evaluation of Service Differentiating Internet Servers. IEEE Transactions Computers, IEEE Computer Society, v. 51, n. 11, p. 1368-1375, 2002.

CHOI, H. K.; LIMB, J. O. A Behavioral Model of Web Traffic. In: Proceedings of the Seventh International Conference on Network Protocols. Atlanta, GA, EUA: IEEE Computer Society, 1999. p. 327-334.

COMER, D. E. Internetworking with TCP/IP: Principles, Protocols and Architecture. 4. ed. Nova Jersey, EUA: Prentice Hall, 2000. 750 p.

COMER, D. E.; DROMS, R. Computer Network and Internets: with Internet Applications. 3. ed. Nova Jersey, EUA: Prentice Hall, 2003. 768 p.

CONNECTMED. 2005. Disponível em: http://www.sertaoggi.com.br/portal/ connectmed.com.br/logs/. Acesso em: 17/04/2005.

COPI. 2005. Disponível em: http://www.888999copi.com/.admin/access_log. Acesso em: $15 / 04 / 2005$.

COUlOuRIS, G.; DOLlimORE, J.; KINDBERG, T. Distributed Systems: Concepts and Design. 3. ed. Nova Jersey, EUA: Addison-Wesley, 2001. 672 p.

CUBERT, R. M.; FISHWICK, P. Simpack Toolkit. Jul 1995. Disponível em: http://www.cise.ufl.edu/ fishwick/simpack/simpack.html. Acesso em: $14 / 03 / 2006$.

DOVROLIS, C.; RAMANATHAN, P. A Case for Relative Differentiated Services and the Proportional Differentiation Model. IEEE Network, IEEE Computer Society, Set 1999.

ESTRELlA, J. C. Mecanismos de Negociação no Módulo de Controle de Admissão da Arquitetura de Servidor Web com Diferenciação de Serviços (SWDS). Dissertação (Mestrado) — USP/ICMC, São Carlos, SP, Abr 2006.

FINLAYSON, R.; MANN, T.; MOGUL, J.; THEIMER, M. Reverse Address Resolution Protocol. Jun 1984. RFC 903, IETF.

FOWLER, M.; SCOTT, K. UML Essencial: Um breve guia para a linguagem-padrão de modelagem de objetos. 2. ed. Porto Alegre, RS: Bookman, 2000. 169 p.

HUNT, C. TCP/IP Network Administration. 3. ed. Sebastopol, CA, EUA: O'Reilly, 2002. 746 p. 
IBM. IBM Hard Disk Drives. 2003. Disponível em: http://www.storage.ibm.com. Acesso em: 11/04/2006.

KANT, K.; TEWARI, V.; IYER, R. Geist: A generator for e-commerce \& internet server traffic. In: Proceedings of the International Symposium on Performance Analysis of Systems and Software. Tucson, Arizona: IEEE, 2001. p. 49-56.

KUROSE, J. F.; ROSS, K. W. Redes de Computadores e a Internet : Uma abordagem top-down. 3. ed. São Paulo, SP: Addison Wesley, 2006. 634 p.

MAHONEN, P.; RIIHIJARVI, J.; PETROVA, M.; SHELBY, Z. Hop-by-Hop toward Future Mobile Broadband IP. IEEE Communications Magazine, v. 42, p. 138-146, Mar 2004.

MEIRA, W. J.; MURTA, C. D.; CAMPOS, S. V. A.; NETO, D. O. G. Sistemas de Comércio Eletrônico: Projeto e Desenvolvimento. 1. ed. Rio de Janeiro, RJ: Campus, 2002. 371 p.

MENASCé, D. A.; ALMEIDA, V. A. F. Planejamento de Capacidade para Serviços na Web. 1. ed. Rio de Janeiro, RJ: Campus, 2003. 472 p.

MESSIAS, V. R. Implementação de um Protótipo de Servidor Web com Diferenciação de Serviços. Monografia (Exame de Qualificação) — Universidade de São Paulo, São Carlos, SP, Mar 2006.

MOdeStO, M.; JR. Álvaro R. P.; ZIVIANi, N.; CASTILlO, C.; BAEZA-YATES, R. Um Novo Retrato da Web Brasileira. In: XXXII Seminário Integrado de Software e Hardware. São Leopoldo, RS: SBC, 2005. p. 2005-2017.

MOSBERGER, D.; JIN, T. Httperf - A Tool for Measuring Web Server Performance. SIGMETRICS Performance Evaluation Review, ACM Press, Nova York, NY, EUA, v. 26 , n. 3 , p. 31-37, 1998.

MOURãO, H. C. B. Reconhecimento de Sessões HTTP em um Modelo para Servidor Web com Diferenciação de Serviços. Monografia (Exame de Qualificação) — Universidade de São Paulo, São Carlos, SP, Mar 2005.

NETCRAFT. March 2006 Web Server Survey. 2006. Disponível em: http: //news.netcraft.com/. Acesso em: 10/03/2006.

NEWMAN, M. E. J. The Structure and Function of Complex Networks. [S.1.], 2003. v. 45, n. $2,167-256$ p.

ORFALI, R.; HARKEY, D.; EDWARDS, J. Client/Server Survival Guide. 3. ed. Nova York: John Wiley, 1999. 800 p.

PINHEIRO, J. C. Avaliação de Políticas de Substituição de Objetos em Caches na Web. Dissertação (Mestrado) — USP/ICMC, São Carlos, SP, Dez 2001.

PLUMMER, D. C. An Ethernet Address Resolution Protocol. Nov 1982. RFC 826, IETF.

POSTEL, J. User Datagram Protocol. Ago 1980. RFC 768, IETF. 
POSTEL, J. Internet Control Message Protocol. Set 1981. RFC 792, IETF.

POSTEL, J. Internet Protocol. Set 1981. RFC 791, IETF.

POSTEL, J. Transmission Control Protocol. Set 1981. RFC 793, IETF.

SIEGRIST, K. Probability/Statistics Object Library. 2005. Disponível em: http: //www.math.uah.edu/stat/objects/index.xhtml. Acesso em: 19/10/2005.

SPECWEB2005. Standard Performance Evaluation Corporation. 2005. Disponível em: http://www.spec.org. Acesso em: 31/03/2006.

STANFORD. 2005. Disponível em: http://waas.stanford.edu/ $\sim_{\text {wwu/logs/ }}$ access_log. Acesso em: 16/04/2005.

STARDUST. White Paper - The Need for QoS. 1999. Disponível em: http: //www.qosforum.com. Acesso em: 12 de Jan. 2006.

STEVENS, W. R. UNIX Network Programming. 2. ed. Nova Jersey, EUA: Prentice Hall, 1997. 1240 p.

TANENBAUM, A. S. Computer Networks. 4. ed. Nova Jersey, EUA: Prentice Hall, 2002. $892 \mathrm{p}$.

TANEnBAUM, A. S. Sistemas Operacionais Modernos. 2. ed. São Paulo, SP: Pearson do Brasil, 2003. 707 p.

TEIXEIRA, M. A. M. Suporte a Serviços Diferenciados em Servidores Web: Modelos e Algoritmos. Tese (Doutorado) — ICMC-USP, São Carlos, SP, 2004.

TEIXEIRA, M. A. M.; SANTANA, M. J.; SAnTAnA, R. H. C. Analysis of Task Scheduling Algorithms in Distributed Web-server Systems. In: Proceedings of the International Sysmposium on Performance Evaluation of Computer and Telecommunication Systems. Montreal, Canadá: SPECTS 2003, 2003. p. 655-663.

TEIXEIRA, M. A. M.; SANTANA, M. J.; SANTANA, R. H. C. Using Adaptive Priority Controls for Service Differentiation in QoS-enabled Web Servers. In: Proceedings of the International Conference on Computational Science. Cracóvia: Lecture Notes on Computer Science, 2004. v. 3039, p. 537-540.

TEIXEIRA, M. A. M.; SANTANA, M. J.; SANTANA, R. H. C. Servidor Web com Diferenciação de Serviços: Fornecendo QoS para serviços da Internet. In: XXIII Simpósio Brasileiro de Redes de Computadores. Fortaleza, CE: SBC, 2005. v. 15, n. 5, p. 745-770.

TRALDI, O. A.; SANTANA, M. J.; BARBATO, A. K.; SANTANA, R. H. C.; TEIXEIRA, M. A. M. Avaliação de Desempenho: Modelagem e Simulação - Servidor Web com Serviços Diferenciados e Algoritmo Weighted Fair Queuing (WFQ). In: 12o. Simpósio Internacional de Iniciação Científica da Universidade de São Paulo. São Paulo, SP: [s.n.], 2004.

TUM. 2005. Disponível em: http://www4.in.tum.de/ isabelle/logs/access_log. Acesso em: 17/04/2005. 
VEENET. 2005. Disponível em: http://veenet.value.net/logs/access_log. Acesso em: 16/04/2005.

WANG, Q.; MAKAROFF, D. J.; EDWARDS, H. K. Characterizing Customer Groups for an E-commerce Web Site. In: Proceedings of the 5th ACM Conference on Electronic Commerce. Nova York, NY, EUA: ACM Press, 2004. p. 218-227.

WANG, Q.; MAKAROFF, D. J.; EDWARDS, H. K.; THOMPSON, R. Workload Characterization for an E-commerce Web Site. In: Proceedings of the 2003 Conference of the Centre for Advanced Studies on Collaborative research. Toronto, Ontario, Canada: IBM Press, 2003. p. 313-327.

WEBER, S.; HARIHARAN, R. A New Synthetic Web Server Trace Generation Methodology. In: IEEE International Symposium on Performance Analysis of Systems and Software. Austin, Texas: IEEE, 2003. p. 80-90.

WEBSTONE: The benchmark for web servers. 2002. Disponível em: http: //www.mindcraft.com/webstone/. Acesso em: 30/03/2006.

XIAO, X.; NI, L. M. Internet QoS: a Big Picture. IEEE Network, Mar 1999.

YEAGER, N. J.; MCGRATH, R. E. Web Server Technology: the Advanced Guide for World Wide Web Information Providers. 1. ed. São Fransisco, CA, EUA: Morgan Kaufmann, 1996. 407 p.

ZHANG, J.; HAMALANEN, T.; JOUTSENSALO, J. A New Mechanism for Supporting Differentiated Services in Cluster-based Network Servers. In: Proceedings of the 10th IEEE Symposium on Modeling, Analysis, and Simulation of Computer and Telecommunications Systems. Fort Worth, Texas, EUA: IEEE Computer Society, 2002. p. $427-432$.

ZHAO, W.; OLSHEFSKI, D.; SCHULZRINNE, H. Internet Quality of Service: an Overview. IEEE Network, Set 1999.

ZIPF, G. K. Human Behavior and the Principle of Least-Effort. New York, NY: Addison-Wesley, 1972. 


\section{APÊNDICE A - Funções de Distribuição de Probabilidade}

Na estatistica, as variáveis aleatórias são divididas em dois grandes conjuntos: qualitativa; e quatitativa. Uma variável é definida como qualitativa quando os seus valores representam atributos e/ou quantidades, ou seja, possuem uma característica não numérica. Já as variáveis quantitativas, ou seja, de natureza numérica representam quantidades e, portanto, valores associados a ela. Neste contexto, uma função discreta de probabilidade atribui a cada valor da variável aleatória qualitativa uma probabilidade. Essa probabilidade é definida por meio de uma função matemática. Assim, a função de probabilidade deve satisfazer o seguinte contexto, apresentado em A.1.

$$
\left(0 \leq p_{i} \leq 1\right) e \sum_{i} p_{i}=1
$$

A tabela A.1 define a função discreta de probabilidade utilizada neste trabalho para representar as variáveis qualitativas da carga de trabalho.

Tabela A.1: Definições das funções de distribuição de probabilidade.

\begin{tabular}{|c|c|c|c|}
\hline \hline $\begin{array}{c}\text { Nome da } \\
\text { Distribuição }\end{array}$ & Parâmetro & Função & $\begin{array}{c}\text { Domínio } \\
\text { variável }\end{array}$ \\
\hline \hline Geométrica & $\rho$ & $\rho(1-\rho)^{k}$ & $0 \leq \rho \leq 1 e k=1,2,3, \ldots$ \\
\hline \hline
\end{tabular}

Para as variáveis aleatórias contínuas, diz que uma função $f(x)$ é uma função contínua de probabilidade, ou seja, uma função densidade de probabilidade se as duas condições em A.2 e A.3 forem satisfeitas.

i) $f(x) \geq 0$, para todo $x \in(-\infty, \infty)$;

ii) A área definida por $f(x)$ é igual a 1 ; 
A tabela A.2 define as funções de densidade de probabilidade utilizada neste trabalho para representar as variáveis quantitativas da carga de trabalho.

Tabela A.2: Definições das funções densidade de probabilidade.

\begin{tabular}{|c|c|c|c|c|}
\hline \hline $\begin{array}{c}\text { Nome da } \\
\text { Distribuição }\end{array}$ & Parâmetros & $\begin{array}{c}\text { Função } \\
\text { densidade }\end{array}$ & $\begin{array}{c}\text { Função } \\
\text { acumulada }\end{array}$ & Domínio \\
\hline \hline Gamma & $\alpha>0, \theta>0$ & $f(x)=\frac{1}{\theta \Gamma(\alpha)}\left(\frac{x}{\theta}\right)^{\alpha-1} e^{\frac{-x}{\theta}}$ & $F(x)=\frac{\Gamma\left(\frac{x}{\theta}\right)(\alpha)}{\Gamma(\alpha)}$ & $0<x<+\infty$ \\
\hline \hline Lognormal & $\mu, \sigma>0$ & $f(x)=\frac{1}{x \sqrt{2 \pi \sigma}} e^{-\frac{1}{2}\left[\frac{\ln x-\mu}{\sigma}\right]^{2}}$ & $F(x)=\phi\left(\frac{\ln x-\mu}{\sigma}\right)$ & $0 \leq x \leq+\infty$ \\
\hline \hline Pareto & $\alpha>0, \beta>0$ & $f(x)=\frac{(\alpha \beta)^{\beta}}{x^{\beta+1}}$ & $F(x)=1-\left(\frac{\alpha}{x}\right)^{\beta}$ & $x \geq \alpha$ \\
\hline \hline Weibull & $\alpha>0, \beta>0$ & $f(x)=\frac{\alpha x^{\alpha-1}}{\beta^{\alpha}} e^{-\left(\frac{x}{\beta}\right)^{\alpha}}$ & $F(x)=1-e^{-\left(\frac{x}{\beta}\right)^{\alpha}}$ & $0 \leq x<+\infty$ \\
\hline \hline
\end{tabular}

Na tabela A.2, $\phi$ representa a função erro para a função de distribuição acumulada da Lognormal, $\Gamma$ a função Gamma e $\Gamma(x)$ a função Gamma incompleta para a função de distribuição Gamma. 